\title{
Final Report on ITER Task Agreement 81-08
}

Richard L. Moore

March 2008

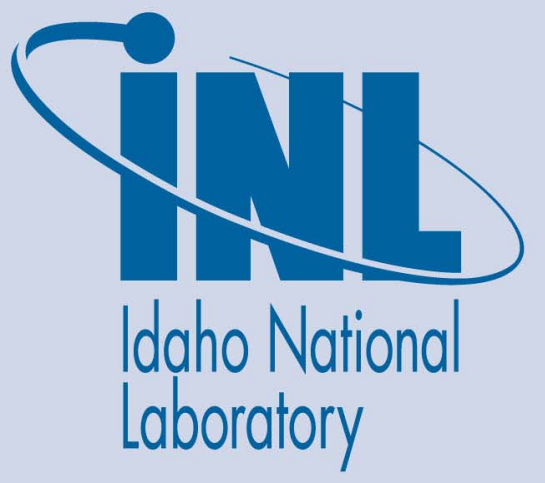

The INL is a U.S. Department of Energy National Laboratory operated by Battelle Energy Alliance 


\title{
Final Report on ITER Task Agreement 81-08
}

\author{
Richard L. Moore
}

March 2008

Idaho National Laboratory

Idaho Falls, Idaho 83415

http://www.inl.gov

Prepared for the

U.S. Department of Energy

Office of Science

Under DOE Idaho Operations Office

Contract DE-AC07-05ID14517 


\title{
Final Report on ITER Task Agreement 81-08
}

\author{
INL/EXT-08-13894
}

March 2008

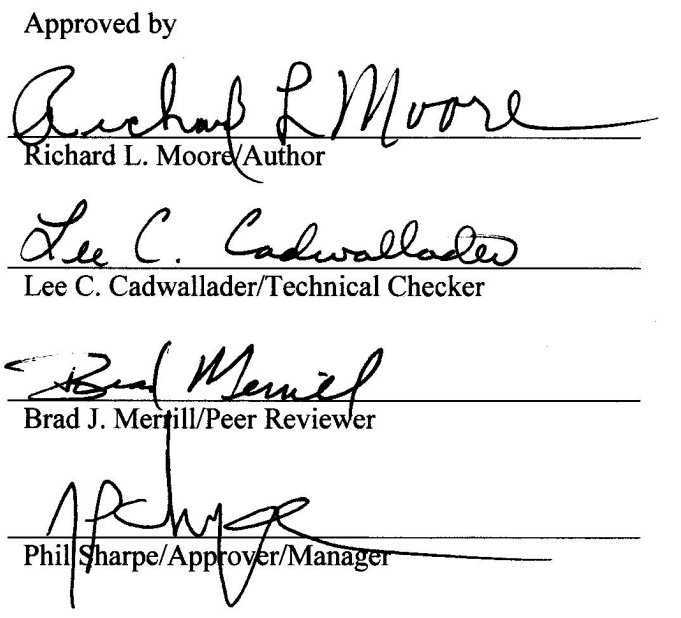

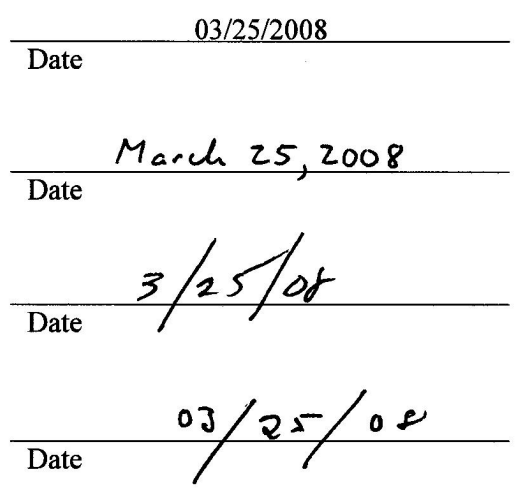




\section{ABSTRACT}

As part of an ITER Implementing Task Agreement (ITA) between the ITER US Participant Team (PT) and the ITER International Team (IT), the INL Fusion Safety Program was tasked to provide the ITER IT with upgrades to the fusion version of the MELCOR 1.8.5 code including a beryllium dust oxidation model. The purpose of this model is to allow the ITER IT to investigate hydrogen production from beryllium dust layers on hot surfaces inside the ITER vacuum vessel (VV) during in-vessel loss-ofcooling accidents (LOCAs). Also included in the ITER ITA was a task to construct a RELAP5/ATHENA model of the ITER divertor cooling loop to model the draining of the loop during a large ex-vessel pipe break followed by an in-vessel divertor break and compare the results to a simular MELCOR model developed by the ITER IT. This report, which is the final report for this agreement, documents the completion of the work scope under this ITER TA, designated as TA 81-08. 


\section{ACRONYMS}

\begin{tabular}{|c|c|}
\hline AAS & Accident Analysis Specification \\
\hline $\mathrm{Be}$ & Beryllium \\
\hline $\mathrm{CV}$ & Control Volume \\
\hline DV & Divertor \\
\hline FPTS & Fusion Power Termination System \\
\hline FW & First Wall \\
\hline GSSR & Generic Site Safety Report \\
\hline HS & Heat Structure \\
\hline HX & Heat Exchanger \\
\hline IB & Inboard \\
\hline INL & Idaho National Laboratory \\
\hline IT & International Team \\
\hline ITA & Implementing Task Agreement \\
\hline ITER & International Thermonuclear Experimental Reactor \\
\hline LOCA & Loss of Coolant Accident \\
\hline PHTS & Primary Heat Transport System \\
\hline PT & Participant Team \\
\hline $\mathrm{RPrS}$ & Report Preliminary on Safety \\
\hline SADL & Safety Analysis Data List \\
\hline SNAP & Symbolic Nuclear Analysis Package \\
\hline TA & Task Agreement \\
\hline TCWS & Tokamak Cooling Water System \\
\hline VV & Vacuum Vessel \\
\hline
\end{tabular}




\section{CONTENTS}

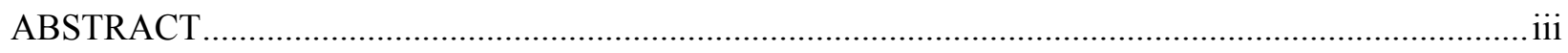

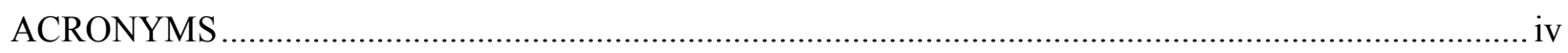

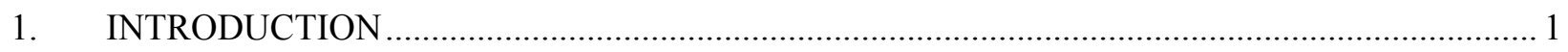

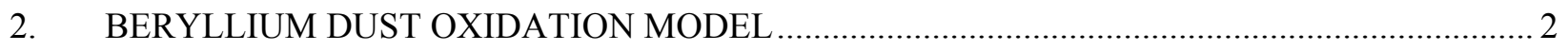

2.1 Dust Layer Steam Oxidation ............................................................................. 2

2.2 Dust Layer Effective Thermal Conductivity ............................................................... 5

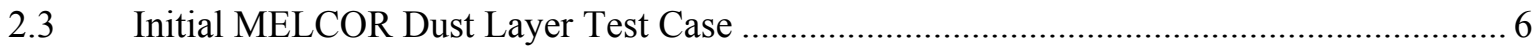

2.4 Application of Dust Layer to ITER Wet Bypass Scenario ….......................................... 7

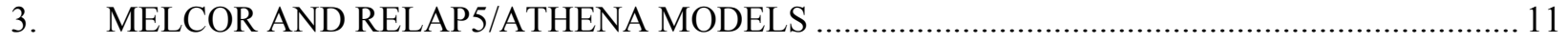

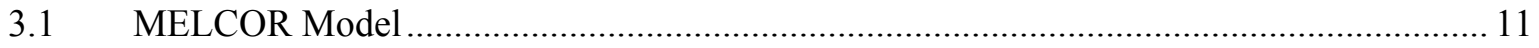

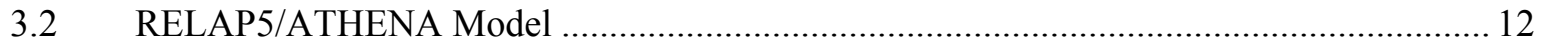

3.3 Comparison of MELCOR and RELAP5/ATHENA Results ........................................... 13

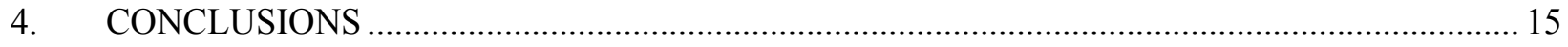

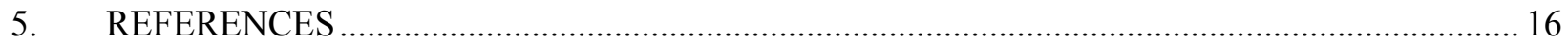




\section{Figures}

Figure 1. Comparison of INL BET measured specific surface area for beryllium dust to the predictions for Equation 4.

Figure 2. Comparison of INL beryllium-steam oxidation rate equations based on the test specimen geometric surface area with the predictions of Equation 10.

Figure 3. Relative steam concentration in a $2 \mathrm{~mm}$ beryllium layer at various layer temperatures as predicted by Equation 9

Figure 4. Beryllium dust layer effective thermal conductivity based on Equation 19

Figure 5. Inboard first wall surface temperature comparison with and without a beryllium dust layer during normal operating conditions.

Figure 6. Inboard first wall surface temperature comparison with differing beryllium dust layer effective thermal conductivity during an in-vessel steam loss-of-coolant accident.

Figure 7. Measure variation of gap conductance with gas pressure and mechanical load in experiment 1 of Reference 22 .

Figure 8. Schematic of MELCOR 2D dust heat conduction model. 25

Figure 9. Dust surface temperature during a wet bypass accident for different dust to tile gap conductances.

Figure 10. Dust surface temperature during a wet bypass accident when Equation 20 is used to predict dust to tile gap conductance.

Figure 11. Dust to tile gap conductance during a wet bypass accident when Equation 20 is used to predict gap conductance. 
Figure 12. Schematic of the MELCOR Divertor Loop Model as represented in the feat2004.divsimpf.inp computer deck.

Figure 13. Schematic of the MELCOR Suppression System Model as represented in the feat2004.divsimpf.inp computer deck.

Figure 14. Schematic of the MELCOR Vault System Model as represented in the feat2004.divsimpf.inp computer deck.

Figure 15. Schematic of the RELAP5/ATHENA Divertor Loop Model. 28

Figure 16. Schematic of the left side of the RELAP5/ATHENA Divertor Loop Model.

Figure 17. Schematic of the right side of the RELAP5/ATHENA Divertor Loop Model. 30

Figure 18. Schematic of the RELAP5/ATHENA Suppression System Model 31

Figure 19. Schematic of the RELAP5/ATHENA Vault System Model. 32

Figure 20. Comparison of the MELCOR and RELAP5/ATHENA total loop mass flow rates. .33

Figure 21. Comparison of the MELCOR and RELAP5/ATHENA mass flow from the ex-vessel break to the TCWS vault.

Figure 22. Comparison of the MELCOR and RELAP5/ATHENA integrated mass flow from the exvessel break to TCWS vault. 35

Figure 23. Comparison of MELCOR and RELAP5/ATHENA in-vessel break mass flow rates. 36

Figure 24. Comparison of the MELCOR and RELAP5/ATHENA integrated mass flow from the invessel break to the vacuum vessel. 
Figure 25. Comparison of the MELCOR and RELAP5/ATHENA pressure histories in the TCWS vault

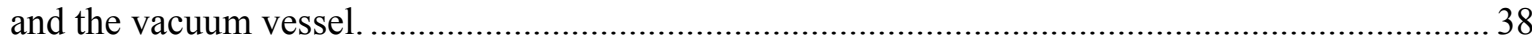

Figure 26. Comparison of the MELCOR and RELAP5/ATHENA mass flow from the vacuum vessel to the drain tank.

Figure 27. Comparison of the MELCOR and RELAP5/ATHENA integrated mass flow from the vacuum vessel to the drain tank.

Figure 28. Comparison of the MELCOR and RELAP5/ATHENA integrated mass flow from the vacuum vessel to the suppression tank.

Figure 29. Comparison of the MELCOR and RELAP5/ATHENA air mass flow from the in-vessel break to the vacuum vessel.

Figure 30. Comparison of the MELCOR and RELAP5/ATHENA integrated air mass flow from the vacuum vessel to the suppression tank.

Figure 31. TCWS vault wall heat transfer rate to the atmosphere. 


\section{INTRODUCTION}

As part of an ITER Implementing Task Agreement (ITA) [1] between the ITER US Participant Team (PT) and the ITER International Team (IT), the INL Fusion Safety Program was tasked to provide the ITER IT with the following items : 1) upgraded fusion version of the MELCOR 1.8.5 and compare with early versions, 2) develop and include in MELCOR new ice layer/cryogenic model and upgrade the MELCOR model developed for the cryostat water/air/helium ingress , 3) provide required support and assistance in operation of the codes on request of ITER IT, 4) develop and include in the MELCOR code a hydrogen production model for high beryllium $(\mathrm{Be})$ dust inventory (up to $100 \mathrm{~kg}$ ) and upgrade the MELCOR model developed for the wet bypass event, 5) develop a RELAP5/ATHENA input deck for the ITER divertor cooling loop to model the large ex-vessel pipe break with air bypass, and compare results to a similar MELCOR model.

Task 1 of this ITA was completed and docummented in 2005 [2]. Task 2 listed above was completed and documented in 2006 [3]. The ice/cryogenic models discussed in Reference 3 are available in the present fusion version of MELCOR 1.8.5. The executables for this version of this code were sent to ITER IT after the completion of Task 2. Task 3 of the ITA was included to insure that the INL would provide the required support and assistance in the operation of the fusion version of the MELCOR 1.8.5 code. This phase of the TA 81-08 has been fulfilled.

The remaining two modeling tasks, Task 4 and 5 listed above are discussed in the following sections of this report. Section 2 presents the beryllium dust oxidation model developed under Task 4, and Section 3 presents the RELAP5/ATHENA model developed under Task 5 . The final section of this report presents conclusions drawn from the work of the final tasks of this TA. 


\section{BERYLLIUM DUST OXIDATION MODEL}

The purpose of this model is to allow the ITER IT to investigate hydrogen production from beryllium dust layers on hot surfaces inside the ITER vacuum vessel (VV) during in-vessel lossof-coolant accidents (LOCAs). The accidents of concern are very small LOCAs that produce slow VV pressurization events that will not re-suspend this dust from these in-vessel surfaces.

\subsection{Dust Layer Steam Oxidation}

Reference 4 gives the following steady state, equimolar counter diffusion equation for Gas A $\left(\mathrm{H}_{2} \mathrm{O}\right)$ into $\mathrm{Gas} \mathrm{B}\left(\mathrm{H}_{2}\right)$ when a chemical reaction occurs:

$-D_{\mathrm{AB}} \frac{\mathrm{d}^{2} \mathrm{c}_{\mathrm{A}}}{\mathrm{d}^{2} \mathrm{z}}+\mathrm{R}=0$

where

$D_{A B}$ is the binary diffusion coefficient of Gas A in Gas B $\left(\mathrm{m}^{2} / \mathrm{s}\right)$

$\mathrm{c}_{\mathrm{A}} \quad$ is the molar concentration of Gas A $\left(\mathrm{mole} / \mathrm{m}^{3}\right)$

$\mathrm{z} \quad$ is the distance perpendicular to the dust film surface $(\mathrm{m})$

$\mathrm{R} \quad$ is the bulk reaction rate $\left(\right.$ mole $\left.-\mathrm{H}_{2} \mathrm{O} / \mathrm{m}^{3}-\mathrm{s}\right)$

For the case of a porous film, the binary diffusion coefficient in Equation 1 should be replaced by an effective diffusion coefficient that accounts for the porosity of the film and the tortuous diffusion path Gas A must make in order to diffuse through the film [5], defined as follows:

$\mathrm{D}_{\text {eff }}=\tau \varepsilon \mathrm{D}_{\mathrm{AB}}$

where

$\tau \quad$ is the tortuousity defined as the differential perpendicular distance of $\mathrm{z}$ to that of the actual path length $\mathrm{s}=(\mathrm{dz} / \mathrm{ds})^{2}$

$\varepsilon \quad$ is the porosity of the film

The bulk reaction rate of Equation 1 can be related to the INL beryllium/steam oxidation rate equations for full dense beryllium by adopting the specific surface area measured for beryllium dust by Reference [6], as follows:

$$
\mathrm{R}=\mathrm{s}_{\mathrm{D}} \rho_{\mathrm{D}} \mathrm{R}_{\mathrm{Be}}^{\mathrm{INL}} \kappa
$$

where

$\mathrm{S}_{\mathrm{D}} \quad$ specific surface area for the dust particle $\left(\mathrm{m}^{2} / \mathrm{kg}\right)$

$\rho_{\mathrm{D}} \quad$ dust density $\left(\mathrm{kg} / \mathrm{m}^{3}\right)$

$\mathrm{R}_{\mathrm{Be}}{ }^{\mathrm{INL}}$ INL beryllium/steam oxidation rate equation for fully dense beryllium $\left(\mathrm{kg}-\mathrm{Be} / \mathrm{m}^{2}-\mathrm{s}\right)$

$\kappa \quad$ is a conversion factor from $\mathrm{kg}$ of $\mathrm{Be}$ to mole of $\mathrm{H}_{2} \mathrm{O}$ for this reaction 
The conversion factor $\kappa$ equals $1000 / 9$, and converts $\mathrm{kg}$-Be to $\mathrm{g}$ - $\mathrm{Be}$, g-Be to mole- $\mathrm{Be}$, and accounts for the stoichiometry of the beryllium-steam reaction which is one mole of $\mathrm{H}_{2} \mathrm{O}$ per mole of Be.

Reference 6 measured the specific surface area of five beryllium dust samples by the BET gas absorption technique. The results have been correlated (correlation coefficient of 98.9\%) against the measured dust particle mass mean diameter, $d_{p}(\mu \mathrm{m})$, giving the following linear fit:

$\mathrm{s}_{\mathrm{D}}=1693.7-33.6 \mathrm{~d}_{\mathrm{p}}$

Figure 1 contains a comparison plot of the specific surface area data from Reference 6 and the predictions of Equation 4.

Reference 7 contains the INL beryllium-steam reaction equations for fully dense beryllium, which after conversion from STD liters of $\mathrm{H}_{2} / \mathrm{m}^{2}-\mathrm{s}$ to $\mathrm{kg}-\mathrm{Be} / \mathrm{m}^{2}-\mathrm{s}$ are as follows:

$$
\begin{array}{lr}
\mathrm{R}_{\mathrm{Be}}^{\mathrm{INL}}=1.205 \times 10^{-1} \mathrm{e}^{-13465 / \mathrm{T}} & \mathrm{T}<793 \mathrm{~K} \\
\mathrm{R}_{\mathrm{Be}}^{\mathrm{INL}}=2.571 \times 10^{7} \mathrm{e}^{-28789 / \mathrm{T}} & 793 \mathrm{~K}<\mathrm{T}<1133 \mathrm{~K} \\
\mathrm{R}_{\mathrm{Be}}^{\mathrm{INL}}=3.536 \times 10^{1} \mathrm{e}^{-13387 / \mathrm{T}} & \mathrm{T}>1133 \mathrm{~K}
\end{array}
$$

The INL beryllium-steam reaction equations were developed at a steam pressure of $0.86 \mathrm{~atm}$. In SADL [8], it is assumed that the beryllium-steam reaction will vary as steam pressure raised to the 0.9 power $\left(\mathrm{p}^{0.9}\right)$. We can approximate this assumption by allowing for a first-order chemical reaction defined as:

$$
\mathrm{R}=\mathrm{k} \mathrm{c}_{\mathrm{a}}
$$

where reaction rate coefficient $\mathrm{k}$ is related to Equation 3 as follows:

$\mathrm{k}=\frac{\mathrm{s}_{\mathrm{D}} \rho_{\mathrm{D}} \mathrm{R}_{\mathrm{Be}}^{\mathrm{INL}} \kappa}{\mathrm{c}_{\mathrm{H} 2 \mathrm{O}}}$

where $\mathrm{c}_{\mathrm{H} 2 \mathrm{O}}$ is the molar concentration of the steam at the INL test conditions $\left(27.7 \mathrm{~mole} / \mathrm{m}^{3}\right)$.

With these definitions, Equation 1 becomes

$$
-D_{\text {eff }} \frac{d^{2} c_{A}}{d^{2} z}+k c_{A}=0
$$

Reference 9 solves this equation for boundary conditions of a defined concentration at $\mathrm{z}$ equals zero of $\mathrm{c}_{\mathrm{A}}{ }^{\circ}$ and a non-flow boundary at $\mathrm{z}$ equal the layer thickness, $\delta(\mathrm{m})$, to obtain the steam concentration profile in the film as:

$$
\mathrm{c}_{\mathrm{A}}=\mathrm{c}_{\mathrm{A}}^{\mathrm{o}}\left[\cosh \left(\sqrt{\mathrm{k} / \mathrm{D}_{\text {eff }}} \mathrm{z}\right)-\tanh \left(\sqrt{\mathrm{k} / \mathrm{D}_{\text {eff }}} \delta\right) \sinh \left(\sqrt{\mathrm{k} / \mathrm{D}_{\text {eff }} \mathrm{z}}\right)\right]
$$


We can now derive a steam reaction rate based on the geometric surface area of the film $\mathrm{R}_{\mathrm{s}}(\mathrm{kg}-$ $\mathrm{Be} / \mathrm{m}^{2}$-s) by substituting Equation 9 into Equation 6, and integrating over the thickness of the film. The resulting equation is:

$$
\begin{aligned}
\mathrm{R}_{\mathrm{s}} & =\frac{\mathrm{kc}_{\mathrm{A}}^{\mathrm{o}}}{\kappa \sqrt{\mathrm{k} / \mathrm{D}_{\text {eff }}}}\left\{\sinh \left(\sqrt{\mathrm{k} / \mathrm{D}_{\text {eff }}} \delta\right)+\tanh \left(\sqrt{\mathrm{k} / \mathrm{D}_{\text {eff }}} \delta\right)\left[1-\cosh \left(\sqrt{\mathrm{k} / \mathrm{D}_{\text {eff }}} \delta\right)\right]\right\} \\
& =\frac{\mathrm{kc}_{\mathrm{A}}^{\mathrm{o}}}{\kappa \sqrt{\mathrm{k} / \mathrm{D}_{\text {eff }}}} \tanh \left(\sqrt{\mathrm{k} / \mathrm{D}_{\text {eff }}} \delta\right)
\end{aligned}
$$

What remains to be defined are the binary diffusion coefficient, and the film properties of porosity, particle diameter and film thickness. Reference 10 gives the following formula for the diffusion of $\mathrm{H}_{2} \mathrm{O}$ into $\mathrm{H}_{2}$ :

$$
\mathrm{D}_{\mathrm{AB}}=\mathrm{D}_{\mathrm{AB}}^{\mathrm{o}}\left(\frac{\mathrm{p}_{\mathrm{o}}}{\mathrm{p}}\right)\left(\frac{\mathrm{T}}{\mathrm{T}_{\mathrm{o}}}\right)^{3 / 2} \frac{\Omega_{\mathrm{T}_{\mathrm{o}}}}{\Omega_{\mathrm{T}}}
$$

where

$$
\begin{aligned}
& \mathrm{D}^{\mathrm{o}}{ }_{\mathrm{AB}} \quad \begin{array}{l}
\text { is a measured binary diffusion coefficient for steam in hydrogen at } \\
\text { pressure } \mathrm{p}_{\mathrm{o}}=1 \mathrm{~atm} \text { and temperature } \mathrm{T}_{\mathrm{o}}=293 \mathrm{~K} \text { equal to } 8.5 \times 10^{-5} \mathrm{~m}^{2} / \mathrm{s} \text { for steam } \\
\text { in hydrogen }
\end{array} \\
& \Omega_{\mathrm{T}} \quad \text { is the Lennard-Jones collision integral }
\end{aligned}
$$

Fortran functions subroutines that contain this oxidation model appear in Appendix A. These subroutines were developed for application with the MELCOR code.

Based on a recent communication, the dust layer (film) density is to be assumed as $1 \mathrm{~g} / \mathrm{cm}^{3}$ and the film thickness as $2 \mathrm{~mm}$ [11]. At this density, the layer porosity is 0.45 . If the dust particle diameter is set at the mass mean diameter for dust callout in SADL [8] of $2 \mu \mathrm{m}$, then all of the quantities necessary to allow a comparison between Equation 10 and the INL beryllium-steam oxidation rate equations for fully dense beryllium have been defined. This comparison appears in Figure 2. Also presented in this figure are the measured INL oxidation rates for beryllium dust and $88 \%$ dense beryllium from References 6,12 and 13 . The dust data presented assumes a specimen geometric surface area equal to that of the crucible that the tests were conducted in. As can be seen, the reaction rate from Equation 10 for $2 \mu \mathrm{m}$ particles is greater than either fully dense or $88 \%$ dense beryllium over the temperature range investigated. There is also some agreement between the dust reaction rates measured at $400^{\circ} \mathrm{C}$ and the prediction of Equation 10 for a dust density and particle size more typical of that of the INL dust $\left(0.7 \mathrm{~g} / \mathrm{cm}^{3}\right.$ and $\left.20 \mu \mathrm{m}\right)$.

Figure 3 illustrates the diffusion depth of water in a $2 \mathrm{~mm}$ beryllium layer as a function of layer temperature for this oxidation model. What is plotted in this figure is the predictions of Equation 9 divided by the left-side boundary condition $\mathrm{c}_{\mathrm{A}}{ }^{\circ}$. Below $600^{\circ} \mathrm{C}$ the limiting rate process appears to be surface oxidation of the dust particles. It is not until $900^{\circ} \mathrm{C}$ that steam diffusion begins to significantly limit the reaction rate in the back half of the layer. 


\subsection{Dust Layer Effective Thermal Conductivity}

The effective thermal conductivity of the beryllium dust layer is based on a correlation developed for pebble bed fission reactors [14]. As described in Reference [14] the overall effective conductivity is calculated from three different individual effective conductivities. The individual effective conductivities are summed to obtain the overall effective conductivity of a given region. These three individual effective conductivities are defined as (1) void radiation plus solid conduction, (2) gas conduction plus solid conduction, and (3) contact conduction plus solid conduction.

Equation (12) describes the effective conductivity due to void radiation plus solid conduction and is based on the cell model defined by Zehner and Schlünder [15] and modified by G. Breitbach and Barthels [16].

$$
\lambda_{\mathrm{er}}=\left[\left(1-\left(1-\varepsilon_{\mathrm{p}}\right)^{\frac{1}{2}}\right) \cdot \varepsilon_{\mathrm{p}}+\left(\frac{\left(1-\varepsilon_{\mathrm{p}}\right)^{\frac{1}{2}}}{\frac{2}{\varepsilon_{\mathrm{r}}}-1}\right) \cdot \frac{\mathrm{B}+1}{\mathrm{~B}} \cdot \frac{1}{1+\frac{1}{\left(\frac{2}{\varepsilon_{\mathrm{r}}}-1\right) \cdot \Lambda}}\right] \cdot 4 \sigma \mathrm{T}^{3} \mathrm{~d}
$$

where

$$
\begin{gathered}
\mathrm{B}=1.25\left(\frac{1-\varepsilon_{\mathrm{p}}}{\varepsilon_{\mathrm{p}}}\right)^{\frac{10}{9}} \\
\Lambda=\frac{\lambda_{\mathrm{s}}}{4 \sigma \mathrm{T}^{3} \mathrm{~d}}
\end{gathered}
$$

The variables in Eq.'s (12), (13) and (14) are $\sigma$ the Stefan-Bolzmann constant, $\lambda_{\mathrm{s}}$ the thermal conductivity of beryllium, $\varepsilon_{\mathrm{p}}$ the porosity of the pebble bed $(0.55), \varepsilon_{\mathrm{r}}$ the emissivity of the beryllium dust $(0.3), \mathrm{d}$ the mean diameter of the dust particles $(2.1 \mu \mathrm{m})$, and $\mathrm{T}$ is the average temperature of the dust particles in the control volume.

The second term describes the effective conductivity due to gas conduction plus solid conduction. This equation was formulated by Zehner and Schlünder and tested by V. Prasad et, al [17]. 


$$
\lambda_{\mathrm{eg}}=\left[1-\sqrt{1-\varepsilon_{\mathrm{p}}}+\frac{2 \cdot \sqrt{1-\varepsilon_{\mathrm{p}}}}{1-\lambda \cdot \mathrm{B}} \cdot\left(\left(\frac{(1-\lambda) \cdot \mathrm{B}}{(1-\lambda \cdot \mathrm{B})^{2}}\right) \cdot \ln \left(\frac{1}{\lambda \cdot \mathrm{B}}\right)-\left(\frac{\mathrm{B}+1}{2}\right)-\left(\frac{\mathrm{B}-1}{1-\lambda \cdot \mathrm{B}}\right)\right)\right] \cdot \lambda_{\mathrm{g}}
$$

where

$$
\lambda=\frac{\lambda_{\mathrm{g}}}{\lambda_{\mathrm{s}}}
$$

In equations (15) and (16) $\lambda_{\mathrm{g}}$ is the thermal conductivity of gas in the space between the pebbles in the pebble bed.

The third term describes the effective conductivity due to contact conduction between dust particles plus solid conduction within the pebbles. The effective conductivity component is the result of compressive loads on the spheres due to the weight of the particles in the dust layer.

$$
\lambda_{\text {ec }}=\left[\frac{3 \cdot\left(1-\mu_{\mathrm{p}}^{2}\right)}{4 \cdot \mathrm{E}_{\mathrm{s}}} \cdot \mathrm{f} \cdot \frac{\mathrm{d}}{2}\right]^{\frac{1}{2}} \cdot \frac{1}{0.531 \cdot \mathrm{S}_{\mathrm{s}}} \cdot\left(\frac{\mathrm{N}_{\mathrm{A}}}{\mathrm{N}_{\mathrm{L}}}\right) \cdot \lambda_{\mathrm{s}}
$$

where

$$
\mathrm{f}=\mathrm{p} \frac{\mathrm{S}_{\mathrm{F}}}{\mathrm{N}_{\mathrm{A}}}
$$

For a bed assumed to have a simple cubic arrangement of the spheres, $\mathrm{S}_{\mathrm{S}}, \mathrm{S}_{\mathrm{F}}, \mathrm{N}_{\mathrm{A}}$ and $\mathrm{N}_{\mathrm{L}}$ are given as $\mathrm{S}_{\mathrm{S}}=1, \mathrm{~S}_{\mathrm{F}}=1, \mathrm{~N}_{\mathrm{A}}=1 /\left(4 \mathrm{R}^{2}\right), \mathrm{N}_{\mathrm{L}}=1 /(2 \mathrm{R})$ where $\mathrm{R}$ is the radius of a particle. In Eq. (17) $\mu_{\mathrm{p}}=$ 0.032 and $E_{S}=287 \times 10^{9}\left(\mathrm{~N} / \mathrm{m}^{2}\right)$. These two values are Poisson's ratio and Young modulus, respectively. The variable $\mathrm{p}$ is the external pressure and is estimated by the weight of the pebbles in the pebble bed.

The effective thermal conductivity of the dust layer is the sum of the three terms given above:

$$
\mathrm{k}_{\mathrm{eff}}=\lambda_{\mathrm{er}}+\lambda_{\mathrm{eg}}+\lambda_{\mathrm{ec}}
$$

The above equations were programmed into Mathcad [18] using temperature dependent steam [19] and beryllium [8] thermal conductivities to generate the effective thermal conductivity used in this oxidation model. The generated effective thermal conductivity is shown in Figure 4.

\subsection{Initial MELCOR Dust Layer Test Case}

As an initial test case simulating the introduction of steam into the ITER vacuum vessel at the end of a plasma pulse was examined to ascertain the response of this beryllium dust oxidation model. A MELCOR input deck was developed for this test case by extracting component from a 
MELCOR input deck used for the ITER-FEAT Generic Site Safety Report [20]. These components include the inboard (IB) first wall (FW), the cooling volume for the FW, and the VV volume. FW heating surface and nuclear heating was included in the model. The thermodynamic properties of VV volume for this test case where defined through user input to give a vacuum during the power pulse, followed by a steam environment at one atmosphere within one second of the pulse termination. Because the beryllium dust oxidation model has not been incorporated into the MELCOR code, the response of this model was simulated by two MELCOR user functions that returned oxidation rate and surface heating. To illustrate the impact of this model, a second inboard FW structure was added to this model that contained a $2 \mathrm{~mm}$ thick dust layer on the VV side of this wall, to the surface of which the additional chemical heating was added. A copy of this MELCOR input deck can be found in Appendix B.

Figure 5 illustrates the impact that a $2 \mathrm{~mm}$ beryllium dust layer would have on the IB FW. The dust layer surface temperature is $700 \mathrm{~K}$ hotter than an IB FW surface without a dust layer due to the low effective thermal conductivity of this dust layer. The consequence of this higher temperature is an immediate ignition of the dust layer once steam fills the $\mathrm{VV}$, as can be seen in Figure 6. Because this condition is a function of the heat transfer conditions available to this layer (e.g., surface convection, surface thermal radiation, and conduction to the beryllium substrate of the FW), parameter studies were undertaken to determine how high the dust layer conductivity would have to be to avoid ignition for these pseudo-accident conditions of this test case. As can be seen, if the effective conductivity of the dust layer were to be increased by a factor about 2.5, then the energy balance is such that ignition is avoided.

It should be noted that this test case does not represent a real accident condition for ITER-FEAT, but has been used in this summary report to demonstrate the progress that has been made regarding this model's development. Should the ITER IT approve of this beryllium dust layer oxidation model, then it will be incorporated into the MELCOR code so that more realistic accident scenarios can be examined.

\subsection{Application of Dust Layer to ITER Wet Bypass Scenario}

The postulated initiating event for this accident is an ex-vessel divertor primary heat transport system (PHTS) pipe break. A description of this accident can be found in the GSSR-Volume 7 [20]. It is postulated that during a plasma burn, a double-ended pipe rupture of the largest pipe (total flow area of $\sim 0.4 \mathrm{~m}^{2}$ ) is assumed to occur in the ex-vessel section of a divertor primary heat transfer system coolant loop (DV ex-vessel coolant pipe break). Coolant is discharged at a high rate into the heat transfer system vault. The fusion power termination system will actuate on a high pressure signal from a pressure sensor in the vault or low pressure signal from a pressure sensor in the primary cooling system, terminating the plasma burn by five seconds into this event. Even though the plasma burn is terminated, there is a possibility that the divertor cooling channels will undergo damage by melting due to the high heat flux before plasma termination.

One task of the ITA is to apply this dust layer model to the GSSR ITER Wet Bypass accident. The MELCOR input deck modified for this application was obtained from the ITER IO and was that used for analyzing this accident in the GSSR [20]. The modifications made to this deck, called "feat2001.divsim.inp", appear in Appendix C. Several assumptions had to be made in order to apply this dust layer model to this accident. The first assumption was whether or not the dust layer (100 kg is to be considered according to the ITA) resides over the entire surface of ITER FW beryllium tiles or if the dust layer lies in the grooves between FW beryllium titles. If 
$100 \mathrm{~kg}$ of dust is distributed over the entire FW surface area $\left(680 \mathrm{~m}^{2}\right)$ then the depth of this dust layer (density $=1000 \mathrm{~kg} / \mathrm{m}^{3}$ ) would be $\sim 0.15 \mathrm{~mm}$. Given the results of the previous section, a dust layer that is $0.15 \mathrm{~mm}$ thick will probably not undergo a thermal runaway during the transient conditions predicted for a wet bypass accident. The surface area of the groves between tiles is estimated to be $\sim 36 \mathrm{~m}^{2}$. This area estimate is based on a FW tile dimension of $53.4 \mathrm{~mm} \times 53.4$ $\mathrm{mm} \times 10 \mathrm{~mm}$, with a gap between tiles of $1.5 \mathrm{~mm}$ [21]. Based on these dimensions, there are $\sim 225,600 \mathrm{FW}$ tiles, which results in a gap area of $36.6 \mathrm{~m}^{2}$. A dust layer of this surface area would have a thickness of $\sim 2.8 \mathrm{~mm}$. Based on the results of the previous section, a dust layer of this thickness could undergo a thermal runaway during a wet bypass accident provided that:

1) the dust layer experiences the same surface heating as the rest of the FW, an assumption that conservatively ignores the shadowing effect of the thicker beryllium tile (10 $\mathrm{mm}$ thick), and

2) the heat transfer between the Be dust and Be tiles or copper substrate is sufficiently low.

The second assumption involves interface heat transfer between the dust and the tiles or copper substrate. Typically, heat transfer at such interfaces is modeled with a gap conductance heat transfer coefficient. It is assumed here that this approach is applicable to a dust-tile or dustsubstrate interface. However, a correlation for dust gap conductance coefficients was not found in literature.

Reference 22 does present an overview of the effects of gas pressure and mechanical load on the thermal gap conductance. This reference compares the predictions of eight gap conductance correlations against data from stainless steel and nickel alloy gap conductance tests. As demonstrated in this article (note Figure 7 which is a reproduction of Figure 3 from Reference 22 ), the thermal conductance of a gap decreases with gap gas pressure and with the mechanical load used to press the two metal surfaces together. The reported variation with gap gas pressure shows a decrease in gap conductance from $4 \mathrm{~kW} / \mathrm{m}^{2}-\mathrm{K}$ for nitrogen in the gap at a pressure of 100 $\mathrm{kPa}$ to $0.6 \mathrm{~kW} / \mathrm{m}^{2}-\mathrm{K}$ for a gas pressure of $1.3 \mathrm{kPa}$ for the lowest mechanical load studied ( 400 $\mathrm{kPa}$ ). Since the gap conductance is thought to be the sum of two contributions, that from metal contact plus that from the interstitial gas conduction in the gap [23], then by lowering the gas pressure as shown in Reference 22 the gas contribution to the gap conductance would be less. This would suggest that the gas contribution was on the order of $3.4 \mathrm{~kW} / \mathrm{m}^{2}-\mathrm{K}$ for this tests.

Reference 23 suggests that the gas contribution $\left(\mathrm{h}_{\mathrm{g}}, \mathrm{W} / \mathrm{m}^{2}-\mathrm{K}\right)$ can be estimated based on the gas thermal conductivity $\left(\mathrm{k}_{\mathrm{g}}, \mathrm{W} / \mathrm{m}-\mathrm{K}\right)$ by the following equation:

$$
h_{g} \approx \frac{k_{g}}{2.7 \sigma}
$$

where $\sigma(\mathrm{m})$ represents the effective root mean square surface roughness at the gap defined as:

$$
\sigma=\sqrt{\sigma_{1}^{2}+\sigma_{2}^{2}}
$$

where the subscripts $(1,2)$ refer to the two materials forming the gap. Applying Equation 20 to the test conditions reported in Reference 20, the gas contribution to the gap conductance would be $\sim 4.0 \mathrm{~kW} / \mathrm{m}^{2}-\mathrm{K}$, which is close to that suggested by the data for Experiment 1 of Reference 22 . 
However, since the thermal conductivity of a mono-atomic gas is in theory independent of pressure for collisional gases [24], the dramatic fall off in reported gap conductance with pressure below $27 \mathrm{kPa}$ cannot be simulated with Equation 20 by merely using measure nitrogen gas thermal conductivities. However, if a formula for effective gas conductivity in powder beds, cited in Reference 25, is used in Equation 20, then the correct trend can be obtained. This formula is as follows:

$$
k_{g}^{e f f}=\frac{k_{g}}{\frac{B}{p_{g} \sigma}+1}
$$

where $\mathrm{p}_{\mathrm{g}}$ is the gas pressure $(\mathrm{Pa})$. The coefficient $\mathrm{B}$ of Equation 22 is defined as

$$
B=\frac{4 \gamma}{\gamma+1} \frac{2-A}{A} \frac{\Lambda_{o} p_{o}}{\operatorname{Pr}}
$$

where

$\begin{array}{lll}\gamma & - & \text { gas specific heat ratio } \\ \mathrm{A} & - & \text { gas accommodation coefficient (taken as } 1) \\ \Lambda_{\mathrm{o}} & - & \text { molecular mean free path }(\mathrm{m}) \text { of gas at pressure } \mathrm{p}_{\mathrm{o}} \\ \mathrm{p}_{\mathrm{o}} & - & \text { reference pressure (set at } 100 \mathrm{kPa}) \\ \mathrm{Pr} & - & \text { gas Prandlt number }\end{array}$

When the thermal conductivity of Equation 22 is used in Equation 20, then the predicted gap gas conductance for the test conditions of Experiment 1 of Reference 20 is $3.6 \mathrm{~kW} / \mathrm{m}^{2}-\mathrm{K}$ at $100 \mathrm{kPa}$ (760 torr), $2.2 \mathrm{~kW} / \mathrm{m}^{2}-\mathrm{K}$ at $13.3 \mathrm{kPa}$ (100 torr), and $0.4 \mathrm{~kW} / \mathrm{m}^{2}-\mathrm{K}$ at $1.3 \mathrm{kPa}(10$ torr). These coefficients are in agreement with those cited in Figure 3 of Reference 20. While the correct gap conductance could lie within this range of values, this study will investigate the response of the dust layer to a range of gap conductances to understand the predicted gap conductance required to avoid a thermal runaway condition.

Lateral conduction from the dust layer to the FW tiles is calculated using the following formula for the overall heat transfer heat coefficient $\left(\mathrm{h}_{\mathrm{o}}, \mathrm{W} / \mathrm{m}^{2}-\mathrm{K}\right)$ between the dust and the tile:

$$
h_{o}=\frac{1}{\frac{\delta_{T}}{k_{T}}+\frac{1}{h_{\text {gap }}}+\frac{\delta_{D}}{k_{D}}}
$$

where

$$
\begin{array}{lll}
\delta & - & \text { lateral distance heat is being conducted }(\mathrm{m}) \\
\mathrm{k} & - & \text { thermal conductivity }(\mathrm{W} / \mathrm{m}-\mathrm{K}) \\
\mathrm{h}_{\text {gap }} & - & \text { gap conductance coefficient }\left(\mathrm{W} / \mathrm{m}^{2}-\mathrm{K}\right) \\
\mathrm{D}, \mathrm{T} & - & \text { subscripts denoting dust }(\mathrm{D}) \text { and tile }(\mathrm{T}) .
\end{array}
$$

This dust lateral heat conduction is simulated through user functions in the MELCOR input file. A schematic of the 2D dust heat conduction model simulated through these user functions appears in Figure 8. The radial conductors are those of the normal MELCOR 1D heat conduction solution for MELCOR heat structures. As illustrated, there are three 1D heat structures in this 
model, one simulating radial heat conduction through the $\mathrm{Be}$ tile and adjoining $\mathrm{Cu}$ substrate and two for the Be dust and adjacent $\mathrm{Cu}$ substrate. The changes made to the GSSR MELCOR input model for the Wet Bypass accident to incorporate this dust layer conduction model appear in Appendix B.

Figure 9 contains the predicted dust layer surface temperature for gap conductance heat transfer coefficients of $500 \mathrm{~W} / \mathrm{m}^{2}-\mathrm{K}, 250 \mathrm{~W} / \mathrm{m}^{2}-\mathrm{K}$, and $100 \mathrm{~W} / \mathrm{m}^{2}-\mathrm{K}$. As can be seen, thermal runaway occurs for a gap coefficient of $100 \mathrm{~W} / \mathrm{m}^{2}-\mathrm{K}$. There are two temperature histories for a gap coefficient of $100 \mathrm{~W} / \mathrm{m}^{2}-\mathrm{K}$. The first history is for a case where beryllium evaporation is allowed to occur. This evaporation carries heat away from the surface, and thereby limits the surface temperature. For this case, the dust oxidation terminates as result of a complete oxidation of the dust layer. The second history is for a case that assumes that the dust oxidation is occurring primarily at the surface of the dust layer at high temperatures (a good assumption in light of the results presented in Figure 3). As a result, this surface oxidation will produce a growing beryllium oxide layer through which steam will have to diffuse before it could react with the beryllium beneath the developing oxide film. For this case $80 \%$ of the dust layer oxidizes before the produced oxidation energy falls below the energy lost by heat conduction to the Be tiles or $\mathrm{Cu}$ substrate.

The question becomes: what would be a good choice for this gap conductance? If the gap conductance is assumed to be only by the way of the gas in the gap (e.g., Equation 20), then the result shown in Figure 10 is obtained. As can be seen in this Figure, initial the dust layer temperature is very high $(\sim 1400 \mathrm{~K})$ because the only mode of heat transfer at the gap is radiation heat transfer. However, soon after the steam enters the VV by way of the in-vessel divertor break, the enhanced gap conductance provides a cooling rate by way of the FW tiles that is greater than the heat production due to chemical oxidation of the dust layer, resulting in a rapid drop in dust layer temperature as opposed to a thermal runaway in the dust layer. The predicted gap conductance heat transfer coefficient for the dust layer during this accident given in Figure 11. While it would appear from these results that the auto-ignition of the dust layer is unlikely, further research into dust oxidation and heat transfer is required to confirm these results. 


\section{MELCOR AND RELAP5/ATHENA MODELS}

Also included in this ITER ITA is a task to construct a RELAP5/ATHENA model of the ITER divertor cooling loop to model the draining of the loop during a large ex-vessel pipe break followed by an in-vessel divertor break. Draining the loop this way results in an air bypass between the VV and the Tokamak Cooling Water System (TCWS) vault, through which tritium and activated dust from the VV can be transported into the TCWS vault. A MELCOR model for this accident has already been developed; however, the ITER IT wanted to compare the results obtained from a RELAP5/ATHENA model with the MELCOR model results because a previous ATHENA model of the first wall blanket cooling loop (FW/BLK) predicted much faster draining of the FW/BLK loop than a similar MELCOR model. The comparision of the results obtained from the two models should help resolve the discrepancy between ATHENA and MELCOR models of similar accidents.

\subsection{MELCOR Model}

The MELCOR model (input deck feat2004.divsimpf.inp) of the divertor ex-vessel pipe break whose results are to be compared to results from a comparable RELAP5/ATHENA model that was obtained from the ITER IO. The accident being modeled is a postulated double ended pipe break in the divertor cooling loop downstream of the divertor loop pump (see Figure 12). Since the location of the pipe where the break occurs is in the TCWS vault, the coolant from the exvessel break will discharged into the TCWS vault causing a presssure increase in this vault. The plasma is postulated to continue to burn until terminated by the fusion power termination system (FPTS), 3 seconds after the initiation of the ex-vessel break. The termination of the plasma burn causes a plasma disruption followed by a break in the divertor (DV) cooling pipes, allowing coolant to discharge into the VV. A more detailed description of this accident can be found in the accident analysis specification (AAS) [26] document.

Figures 12, 13, and 14 contain schematics of the MELCOR models for the divertor cooling loop, the suppression system and the vault system, respectively. The divertor cooling loop model shown in Figure 12 contains the divertor loop pump, the loop heat exchanger, the hot collector, the cold distributor, the divertor cassettes, the pressurizer, and the piping connecting the main components. Also shown in the figure are the locations of the assumed ex-vessel break and the resulting in-vessel break.

The ex-vessel double ended guillotine break is simulated in the model by using flow paths 38 and 39 which contain valves that are programed to immediately open at the time the accident is initiated. Flow path 38 connects the upstream side of the break (CV435) to the TCWS vault while flow path 39 connects the downsteam side of the break (CV425) to the TCWS vault. An isolation valve is used in flow path 415 to isolate the upstream side of the break from the downstream side of the break. The isolation valve is programed to immediately close at the time the accident is initiated.

The in-vessel break is simulated using two flow paths, 36 and 37. These two break flow paths (shown in Figure 12) connect divertor components CV413 and CV417 to the vacuum vessel 
CV100 by way of CV450. Valves in the two flow paths are programed to start opening five seconds after the initiation of the accident and to become fully open at seven seconds.

The suppression system (see Figure 13) and the vault system (see Figure 14) are an integral part of the divertor loop model due to the fact that the ex-vessel break mass flow discharges into the TWCS vault and the in-vessel break mass flow discharges into the plasma chamber. The VV (plasma chamber) is connected to the suppression system by a number of flow paths. The suppression system consists of two main components, the suppression tank (CV102) and the drain tank (CV122) and the piping needed to connect the suppression tank and the drain tank to the plasma chamber. The vault system (see Figure 14) consists of the TWCS vault, the pipe chase, the gallery, and the NBI cell.

The above figures were generated by importing the MELCOR input deck for the large ex-vessel break with air bypass (feat2004.divsimpf.inp) into the Symbolic Nuclear Analysis Package (SNAP) [27]. This package is under development by Applied Programming Technology, Inc. for the US Nuclear Regulatory Commission. The package is intended to provide a consistent and easy to use interface to design and build input models and analyze output from codes such as MELCOR and RELAP5/ ATHENA.

\subsection{RELAP5/ATHENA Model}

As requested in the ITA, a RELAP5/ATHENA model was developed which models the large exvessel pipe break with air bypass similar to the MELCOR model presented above. The model was developed using the RELAP5 modeling capabilities that are an integral part of the SNAP program. Geometric data in the form of volumes, cross-sectional areas, flow path lengths, component elevations, heat structure thicknesses, etc., used to construct the model were obtained from the MELCOR computer model described in Section 3.1 and entered into the SNAP program to generate a corresponding RELAP5/ATHENA model. Also obtained from the MELCOR model were the time and spatial distribution of heating loads that were applied to the RELAP5 heat structures.

Shown in Figure 15 is a schematic of the RELAP5/ATHENA model that was generated using the SNAP program. In order to get a better view of the model presented in Figure 15; the figure was split in the middle with the right hand side of Figure 15 shown in Figure 16 and the left hand side of Figure 15 shown in Figure 17. The RELAP5/ATHENA suppression and vault system models are shown in Figures 18 and 19, respectively. These two models correspond to the MELCOR suppression and the vault system models shown in Figures 13 and 14, respectively.

Not shown or discussed in the MELCOR section is the FW primary heat transport system (PHTS) which interacts only with the DV coolant loop through radiation heat transfer and any water/steam injected into the VV by convection heat transfer since the FW PHTS remains intact during this accident. Therefore, the FW PHTS was included in the RELAP5/ATHENA model as a FW heat structure with a time dependent water temperature boundary condition obtained from the MELCOR model results.

Comparing Figures 13 and 14 to Figures 18 and 19, respectively, we see that not all the leak paths in the MELCOR suppression and vent system models are modeled in detail in the RELAP5/ATHENA model. The leak paths not modeled in detail in the RELAP5/ATHENA model are modeled as boundary conditions using time dependent junctions connected to time dependent volumes using leak flow rates predicted by MELCOR. 


\subsection{Comparison of MELCOR and RELAP5/ATHENA Results}

The initiating event for this transient is a double ended ex-vessel pipe break into the TCWS vault followed by an in-vessel break into the VV. The ex-vessel break is assumed to occur at 1000 seconds into the transient. The first 1000 seconds of transient time allows the DV coolant loop to obtain a steady state condition before the initiating of the ex-vessel break. Shown in Figure 20 is a comparision of the predicted MELCOR and RELAP5/ATHENA total mass flow rate time history of the DV loop. The predicted MELCOR and RELAP5/ATHENA steady state loop mass flow rates (time $<1000$ second) were $1019 \mathrm{~kg} / \mathrm{sec}$ and $1037 \mathrm{~kg} / \mathrm{sec}$, respectively, a $1.7 \%$ difference. This time history was taken just upstream of the loop Hx.

At time equal to 1000 seconds the ex-vessel break is programmed to occur. The total break mass flow rates for both the MELCOR (flow paths 38 and 39) and the RELAP5/ATHENA (valves 38 and 39) models are shown in Figure 21. Overall the predicted mass flow rate from MELCOR is slightly higher as evidenced in Figure 22 which shows the total integrated mass flow (water, steam, and air) through the ex-vessel break for both models. The predicted total mass flow to the TCWS vault based on the MELCOR model was $55000 \mathrm{~kg}$ compared to $51500 \mathrm{~kg}$ predicted by the RELAP5/ATHENA model. The peak integrated mass flows occurred at 1200 and 1850 second respectively. The reduction in peak mass to the TCWS vault as seen in the figure is due to air flowing from the vault to the VV once the DV loop pressure drops below that of the vault as a result of a flow path that develops through the ex-vessel in-vessel breaks by way of the partially voided DV coolant loop. The difference in the timing of the air entering the VV is probably due to the differences in the inter-phase drag correlations used in these two codes.

The mass flow rates corresponding to the in-vessel break which is programmed to occur five seconds after the ex-vessel break are presented in Figure 23. Initially the mass flow rate predicted by MELCOR is slightly higher than that predicted by RELAP5/ATHENA as seen in Figure 24 which shows the integrated mass flow through the in-vessel break for both models. The MELCOR integrated mass flow rapidly approaches $61500 \mathrm{~kg}$ at 1335 seconds, then gradually increases to $64000 \mathrm{~kg}$ at the end of 5000 seconds. The RELAP5/ATHENA results show the integrated mass flow reaching $65500 \mathrm{~kg}$ at 2150 seconds, then gradually increasing to $66200 \mathrm{~kg}$ at the end of 5000 seconds. This difference in the timing of the initial peak total mass flow between the two models is again attributed to the difference in the inter-phase drag correlation used in these codes.

The pressures in the TCWS vault and VV (plasma chamber) are shown in Figure 25 for both the MELCOR and RELAP5/ATHENA models. The pressure in the VV rises rapidly to the pressure suppression system opening set point of $150 \mathrm{kPa}$ in both cases. It takes 220 seconds for the MELCOR model to reach the set point following the in-vessel break where as the RELAP/ATHENA model takes $\sim 30$ seconds. After the pressure suppression system opens the predicted pressure corresponding to the RELAP5/ATHENA model drops lower and takes longer to recover (pressure equilibrium between TCWS vault and the VV) than for MELCOR. The pressure recovery in the VV is due to the inflow of air from the TCWS vault into the VV. As indicated in Figure 25 the flow of air from the TCWS vault to the VV begins at $\sim 1200$ seconds for MELCOR and $\sim 1700$ seconds for RELAP5/ATHENA. The peak pressure in the TCWS vault for MELCOR is $119 \mathrm{kPa}$ and that predicted by the RELAP5/ATHENA model is $129 \mathrm{kPa}$. The vault pressure in the RELAP5/ATHENA model takes longer to reach equilibrium with the VV than does the MELCOR model. The main reason for the discrepancy is again related to the ability of the models to clear the flow path of coolant so air can flow from the TCWS vault to the 
VV. The clearing of the flow path is in turn related to the difference in the inter-phase drag correlation used in the two codes.

The mass flow rate from the VV to the drain tank for both models is shown in Figure 26. The integrated mass flow corresponding to the mass flow rates contained in Figure 26 is shown in Figure 27. The results in Figure 26 show that initially the mass flow rate to the drain tank predicted by the MELCOR model is greater than that from the RELAP5/ATHENA model. The results in Figure 27 show that the total mass flow to the drain tank corresponding to the MELCOR model reaches $40000 \mathrm{~kg}$ by 1730 seconds and then gradually increases to $43100 \mathrm{~kg}$ at the end of 5000 seconds. The total mass flow to the drain tank from the RELAP5/ATHENA shows the total mass flow reaches $44000 \mathrm{~kg}$ by 2660 seconds and then slowly increases to 44150 $\mathrm{kg}$ at the end of 5000 seconds. At the end of 5000 seconds $1050 \mathrm{~kg}$ more of coolant mass is predicted to flow to the drain tank by the RELAP5/ATHENA model.

The integrated mass flow to the suppression tank for both models is shown in Figure 28. Again the total mass flow for the MELCOR model increases faster, raising from 0.0 to $12700 \mathrm{~kg}$ by 1520 seconds and then increasing to $12950 \mathrm{~kg}$ at the end of 5000 seconds. The RELAP5/ATHENA models the total mass flow rising from 0.0 to $15300 \mathrm{~kg}$ by 2220 seconds and then increasing to $15400 \mathrm{~kg}$ at the end of 5000 seconds thus $2450 \mathrm{~kg}$ more of coolant mass is predicted to flow to the suppression tank by the RELAP5/ATHENA model.

In the next two Figures, 29 and 30 we show the air mass flow rate and the integrated mass flow from the in-vessel break to the suppression tank by way of the VV for both models. The MELCOR model predicts that the air in the TCWS vault will commence flowing to the suppression tank at 1200 seconds. The RELAP5/ATHENA model predicts that the flow of air from the vault to the suppression tank will begin at 1650 seconds, a 450 second delay in clearing the flow path between the vault, the $\mathrm{VV}$, and the suppression tank of liquid coolant. Viewing Figure 30 we see that at the end of 5000 seconds the total air mass flow predicted by the RELAP5/ATHENA model is $660 \mathrm{~kg}$ vs. $533 \mathrm{~kg}$ predicted by the MELCOR model. Although delayed the total air mass from the TCWS vault to the suppression tank is greater by $127 \mathrm{~kg}$ for the RELAP5/ATHENA model.

Referring to Figures 22 and 24 we see that the predicted total mass flow to the vault is greater for the MECLOR model, however the vault pressure in Figure 24 predicted by the RELAP5/ATHENA model $(129 \mathrm{kPa})$ is greater than that predicted by the MELCOR model (119 $\mathrm{kPa}$ ). This is due to the difference in heat transfer from the vault atmosphere to the vault wall as seen in Figure 31. The difference in heat transfer rate is due to the different heat transfer/steam condensation correlations used in these codes. 


\section{CONCLUSIONS}

As documented in the preceding sections of this report the development of a beryllium dust oxidation model and the development of a RELAP5/ATHENA model of the divertor ex-vessel pipe break accident contained in ITA 81-08 have been completed as well as the other tasks listed in the TA.

Fair agreement was obtained between the RELAP5/ATHENA and MELCOR model results for the divertor ex-vessel accident. The differences being: 1) the break mass flow rates (choked flow) are higher in MELCOR, 2) air enters the VV much slower in the RELAP5/ATHENA model due to differences in the inter-phase correlations used in the models, in particular slug flow in the RELAP5/ATHENA code, and 3) vault pressure in RELAP5/ATHENA results is higher and decays slower due to different heat transfer/steam condensation correlations used in the two codes. The input deck of the final RELAP5/ATHENA model used to generate the results presented in this report is available upon request.

The development of a hydrogen production model for high Be dust inventory was completed and reported in this document. A listing of the dust oxidation functions that are required by MELCOR to analyze hydrogen production from Be dust is contained in Appendix A. The changes made to the MELCOR wet bypass input deck are listed in Appendix C. Code and deck are available for up load to IDM if needed.

The milestones for this ITA were met. However, some of the milestones were not completed on time due to unforeseen higher priorities associated with ITER, such as the pedigreeing of the fusion version of the MELCOR 1.8.2 code needed to analyze the postulated accidents required for the RPrS review [28] and the verification of the computer inputs deck used in the analyses of the postulated accidents [29]. 


\section{REFERENCES}

1. ITER Implementing Task Agreement, "Support and assistance for the latest fusion versions of computer codes," ITA 81-08, extension G 81 TD 21 FU, January (2005).

2. R. L. Moore, "Status Report on an ITER ITA on Comparison of MELCOR 1.8.5 Results to MELCOR 1.8.2 Result for a Selected Set of Accident Analysis Cases Relevant to ITER FEAT," INEEL EDF-5470, January (2005).

3. B. J. Merrill, and R. L. Moore, "Status Report on Code Safety ITER Implementing Task Agreement for Calendar Year 2005," INL-EDF-6607, January (2006).

4. J. R. Welty, C. E. Wicks, and R. E. Wilson, Fundamentals of Momentum, Heat and Mass Transfer, John Wiley \& Sons, Inc., New York, 1969, p 495.

5. B. Na, and D. L. Webb, "New Model for Frost Growth Rate," International Journal of Heat and Mass Transfer, 47 (2004), p. 925-936.

6. R. A. Anderl, R. J. Pawelko, "Steam Chemical Reactivity of Beryllium Powder," INEEL/EXT-99-00338, April 30, 1999.

7. K. A. McCarthy, et al., "The Safety Implications of Tokamak Dust Size and Surface Area," Fusion Engineering and Design, 42, 1998, p. 45-52.

8. ITER, "Safety Analysis Data List," G 81 RI 10 03-08-08 W 0.1, Version: 4.0.3 SADL, September 26, (2003)

9. F. P. Incropera, and D. P. DeWitt, Fundamentals of Heat and Mass Transfer $\left(3^{\text {rd }}\right.$ Edition), John Wiley \& Sons, Inc., New York, 1981, p. 903.

10. J. R. Welty, C. E. Wicks, and R. E. Wilson, Fundamentals of Momentum, Heat and Mass Transfer, John Wiley \& Sons, Inc., New York, 1969, p. 457.

11. Private communication by email with ITER IT ITA task officer Leonid Topilski, July 26, 2005.

12. G. Smolik et al., "Reaction of porous Beryllium in Steam", INEEL, EGG-FSP-10346, July 1992.

13. R. A. Anderl, et al.,'Steam-chemical reactivity for irradiated beryllium," Journal of Nuclear Materials, 258-263 (1998), p. 750-756.

14. H. Niessen, and S. Ball (editors), Heat Transport and Afterheat Removal for Gas Cooled Reactors Under Accident Conditions, International Atomic Energy Agency, IAEATECDOC-1163.

15. P. Zehner, and E. U. Schlünder, "Thermal Conductivity of Granular Material at Moderate Temperatures," Chemie-Ingr-Tech, 42, pp933-941, 1970. In German.

16. G. Breitbach, and H. Barthels, "The Radiant Heat Transfer in the HTR Core After Failure of the Afterheat Removal Systems," Nuclear Technology, 49, pp392-399, August 1980.

17. V. Prasad, N. Kladas, A. Bandyopadhaya and Q. Tian, "Evaluation of Correlations for Stagnant Thermal Conductivity of Liquid-Saturated Porous Beds of Spheres," International Journal of Heat and Mass Transfer, 32, p. 1783-1796 (1989).

18. Mathcad 11 User's Guide, Mathsoft Engineering \& Education, Inc. Cambridge, MA.

19. C. A. Meyer, 1967 ASME Steam Tables Thermodynamic and Transport Properties of Steam Comprising Tables and Charts for Steam and Water, American Society of Mechanical Engineers; 2nd edition (January 1, 1968).

20. ITER, "'Generic Site Safety Report: Volume VII Appendix A," G 84 RI 6 01-07-10 R 1.0, July (2004), p. VII 267-292.

21. ITER, "Safety Analysis Data List," ITER_D_24LSAE, Version: 5.2 SADL, September 5, (2007), p. 12.

22. S. Song, and M. M. Yovanovich, "Thermal Gap Conductance: Effects of Gas Pressure and Mechanical Load," Journal of Thermophysics and Heat Transfer, Vol. 6, No 1, p. 6268 (1992). 
23. W. Cheng, and C. Madhusudana, "Decrease in Thermal Contact Conductance and the Contact Pressure of Finned-Tube Heat Exchangers Assembled with Different Sixe Bullets," Journal of Heat Transfer, 129, July (2007), p. 907-911.

24. J. R. Welty, C. E. Wicks, and R. E. Wilson, Fundamentals of Momentum, Heat and Mass Transfer, John Wiley \& Sons, Inc., New York, 1969, p. 215.

25. M. Shapiro, et al., "Characterization of Powder Beds by Thermal Conductivity: Effect of Gas Pressure on the Thermal Resistance of Particle Contact Points," Particle \& Particle Systems Characterization, 21 (2004), p. 268-275.

26. ITER, "Accident Analysis Specification," ITER_D_258QGE, Version 2.5, November 30, 2007.

27. Symbolic Nuclear Analysis Package 0.27.2 (Pre-Release) March 06, 2008, Applied Programming Technology, Inc.

28. R. L. Moore, "Pedigree Analysis of the MELCOR 1.8.2 Code to be Used for ITER's Report Preliminary on Safety," INL/EXT-07-12856, June (2007).

29. R. L. Moore, "Verification of MELCOR Input Decks Used in ITER RPrS Analyses," INL/EXT-07-13305, January (2008). 


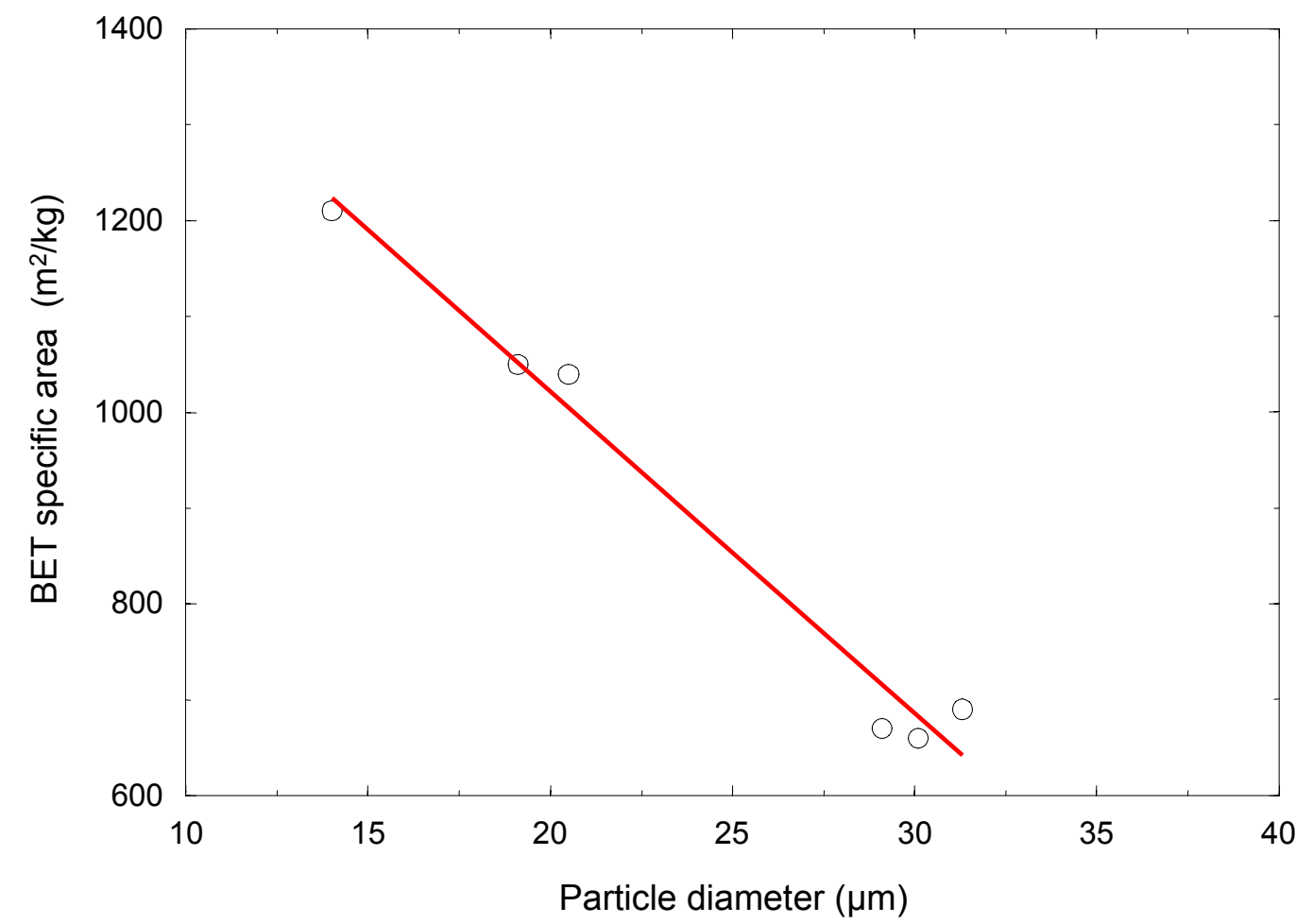

Figure 1. Comparison of INL BET measured specific surface area for beryllium dust to the predictions for Equation 4. 


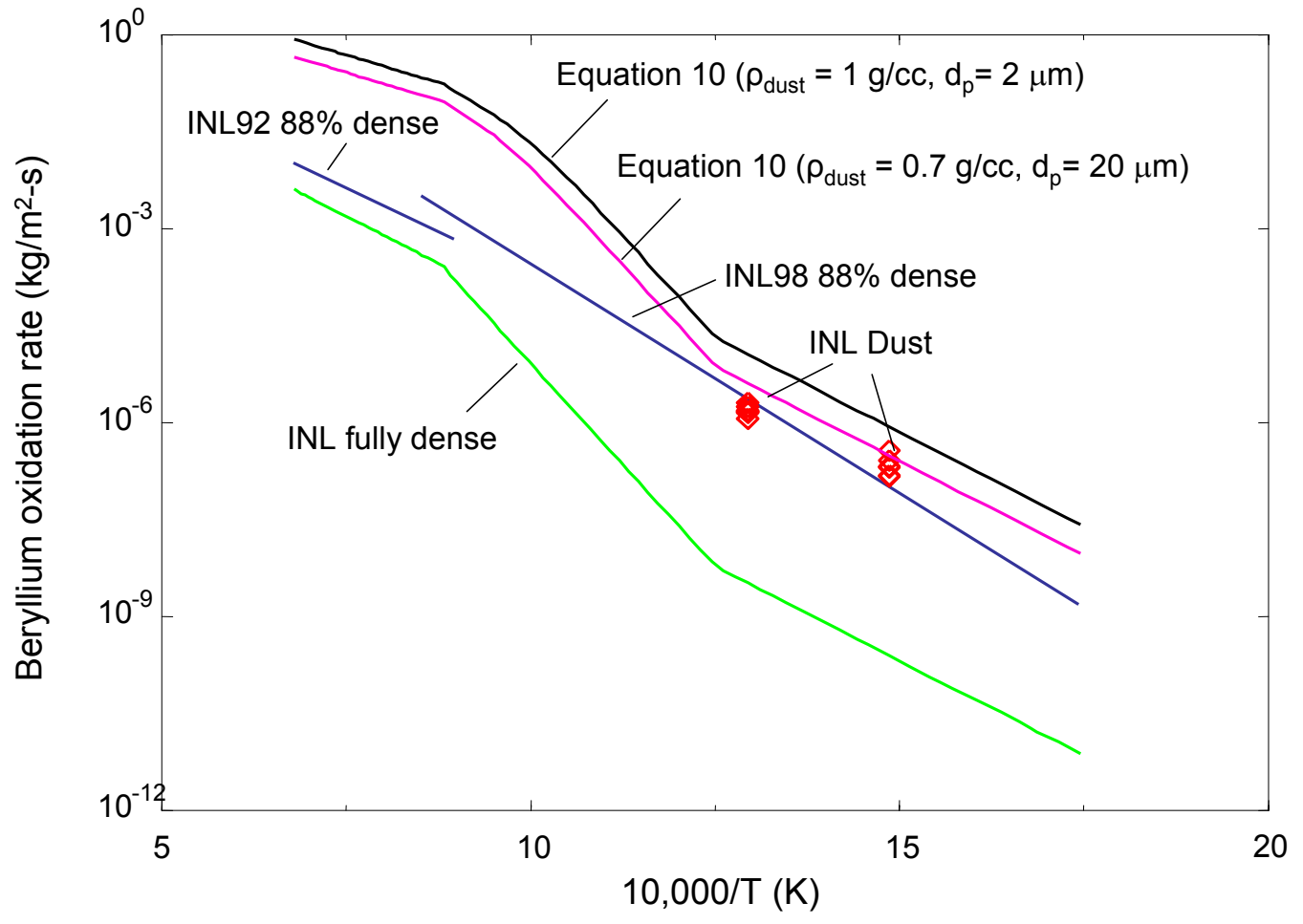

Figure 2. Comparison of INL beryllium-steam oxidation rate equations based on the test specimen geometric surface area with the predictions of Equation 10. 


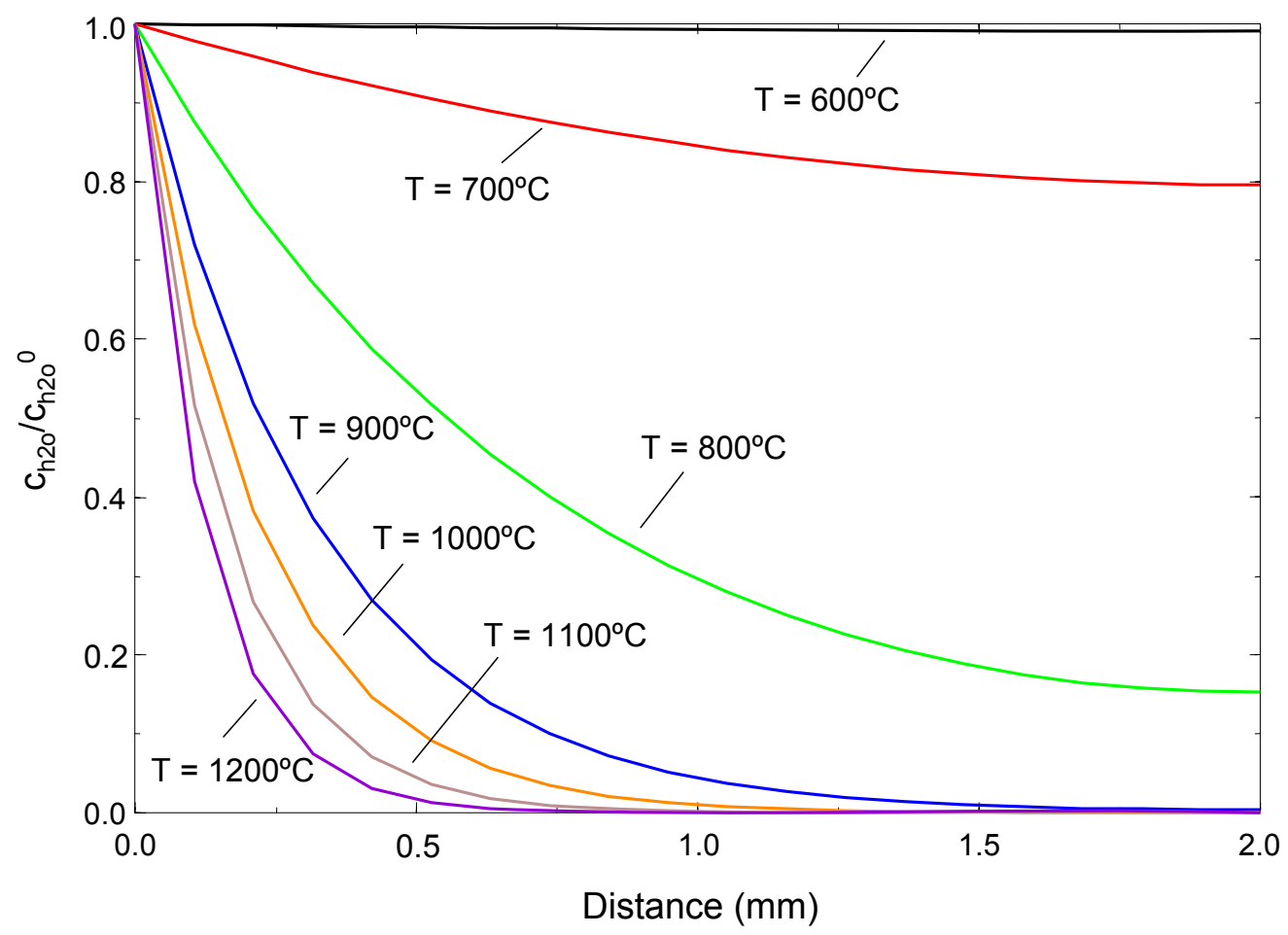

Figure 3. Relative steam concentration in a $2 \mathrm{~mm}$ beryllium layer at various layer temperatures as predicted by Equation 9 . 


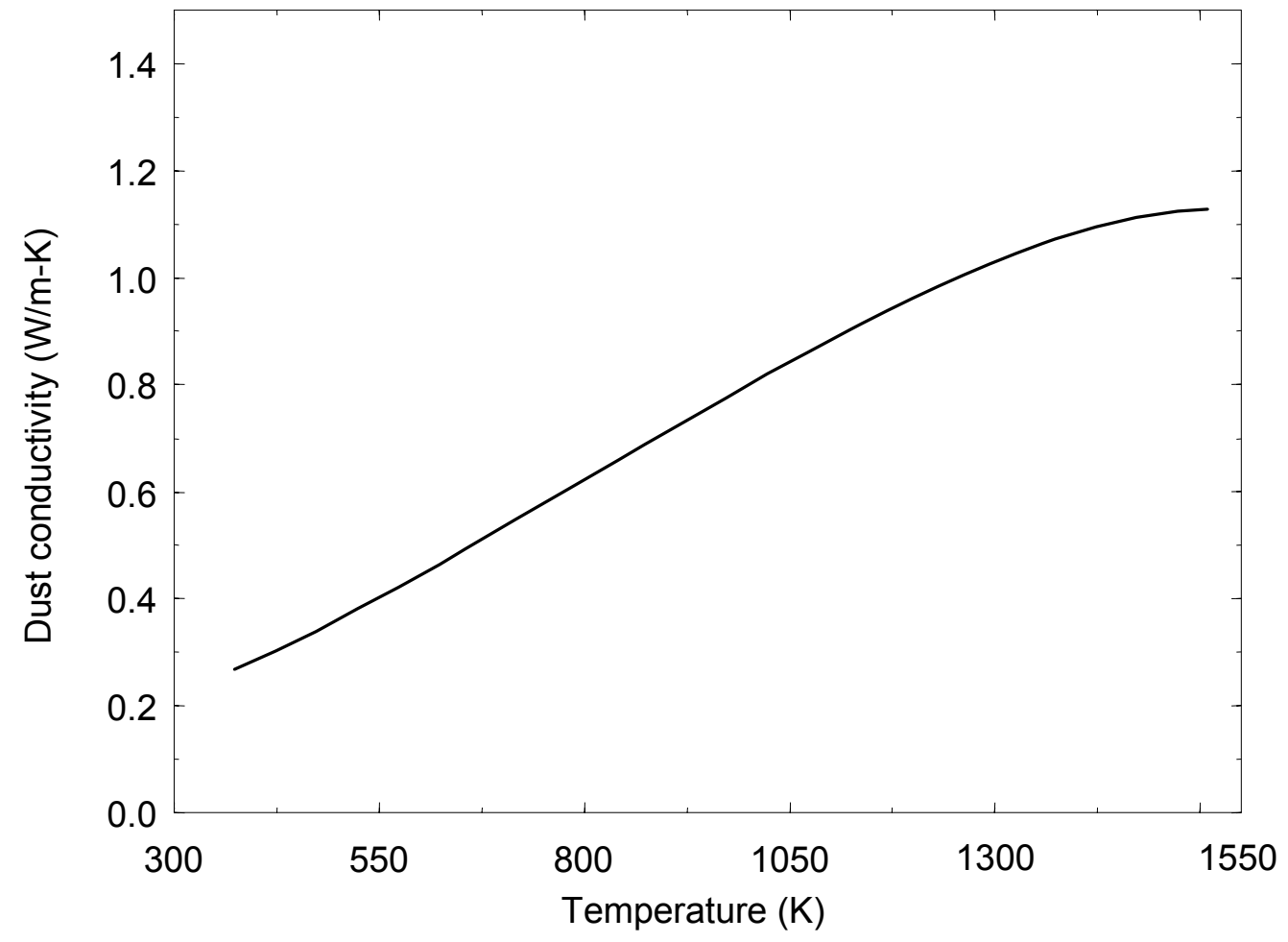

Figure 4. Beryllium dust layer effective thermal conductivity based on Equation 19. 


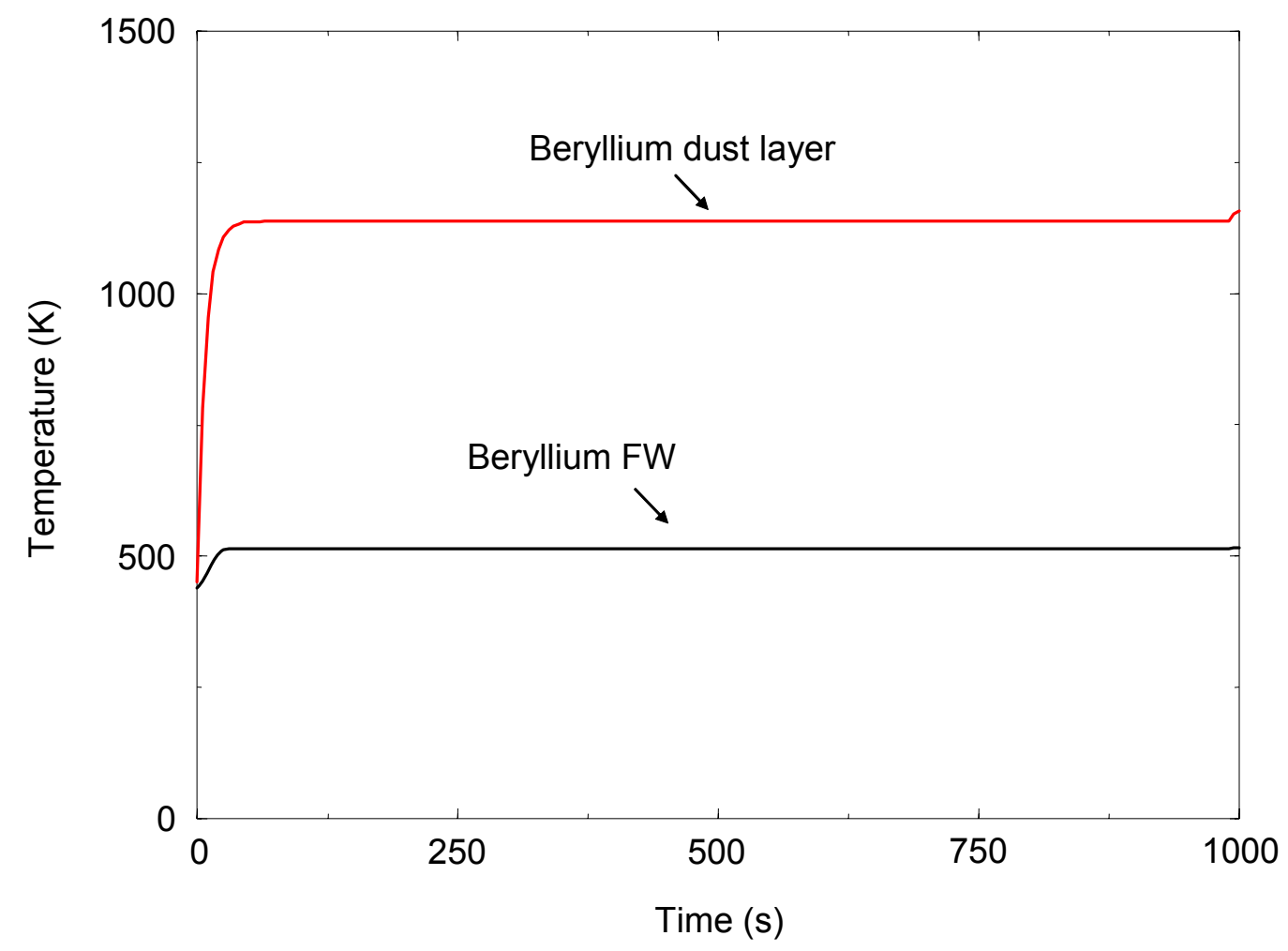

Figure 5. Inboard first wall surface temperature comparison with and without a beryllium dust layer during normal operating conditions. 


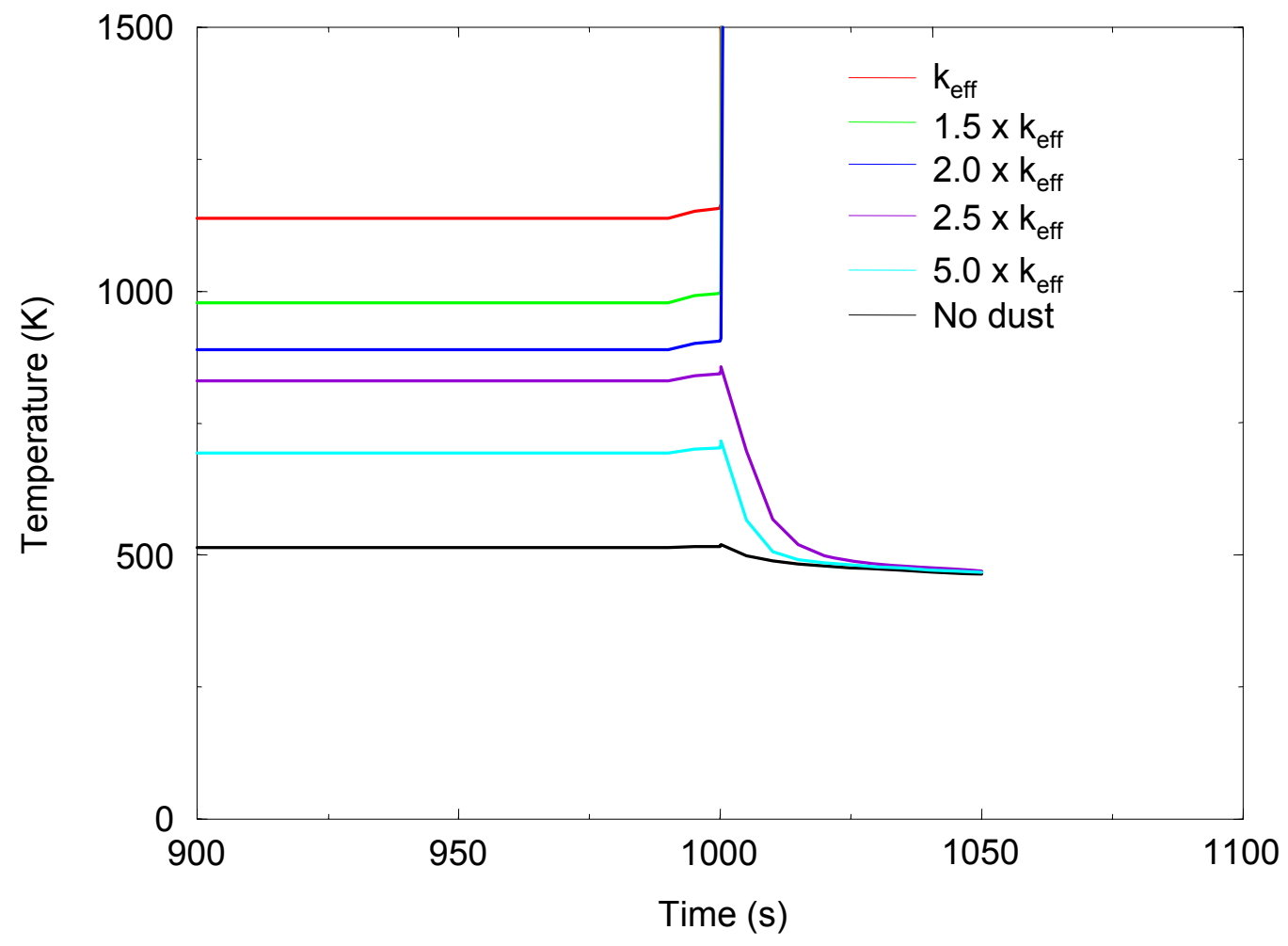

Figure 6. Inboard first wall surface temperature comparison with differing beryllium dust layer effective thermal conductivity during an in-vessel steam loss-of-coolant accident. 


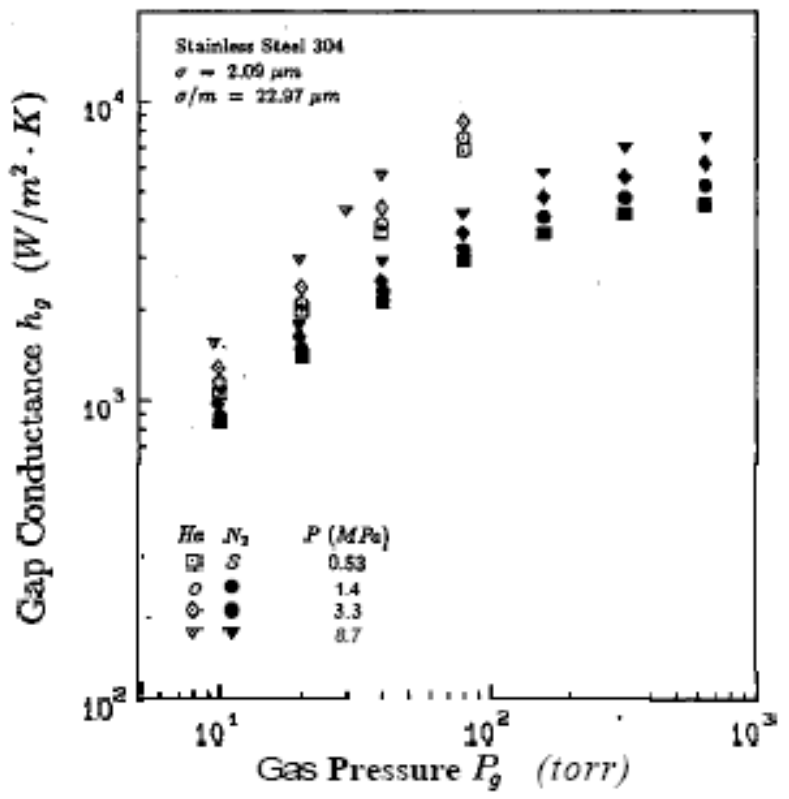

Fig. 3 Gap-conductance results of experiment 1.

Figure 7. Measure variation of gap conductance with gas pressure and mechanical load in experiment 1 of Reference 22 . 


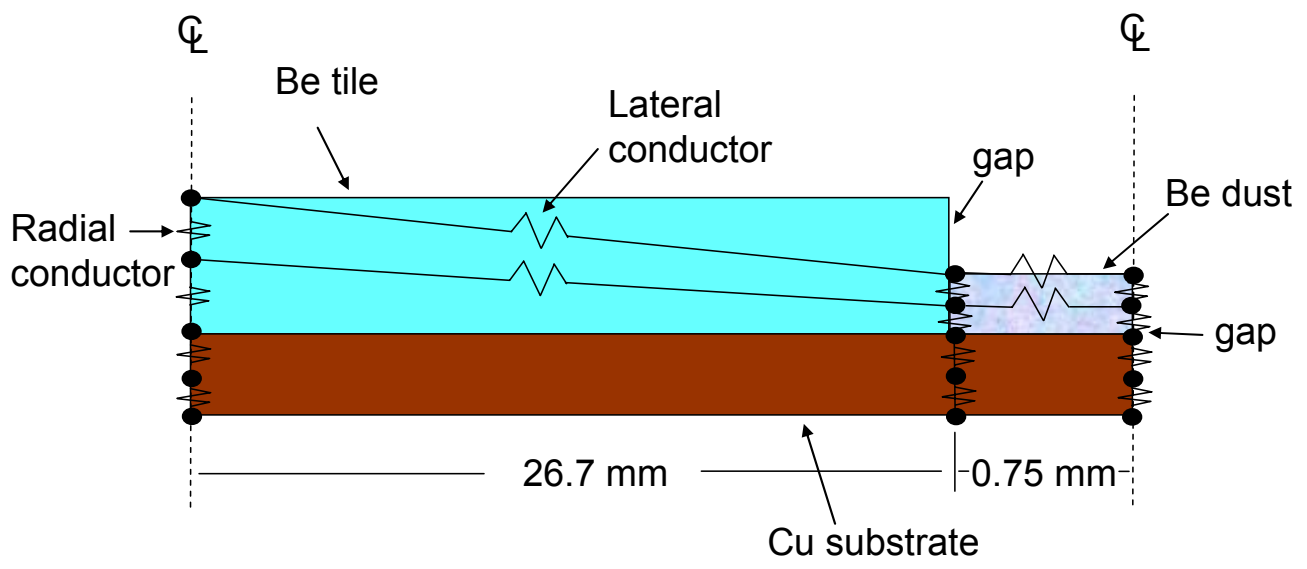

Figure 8. Schematic of MELCOR 2D dust heat conduction model. 


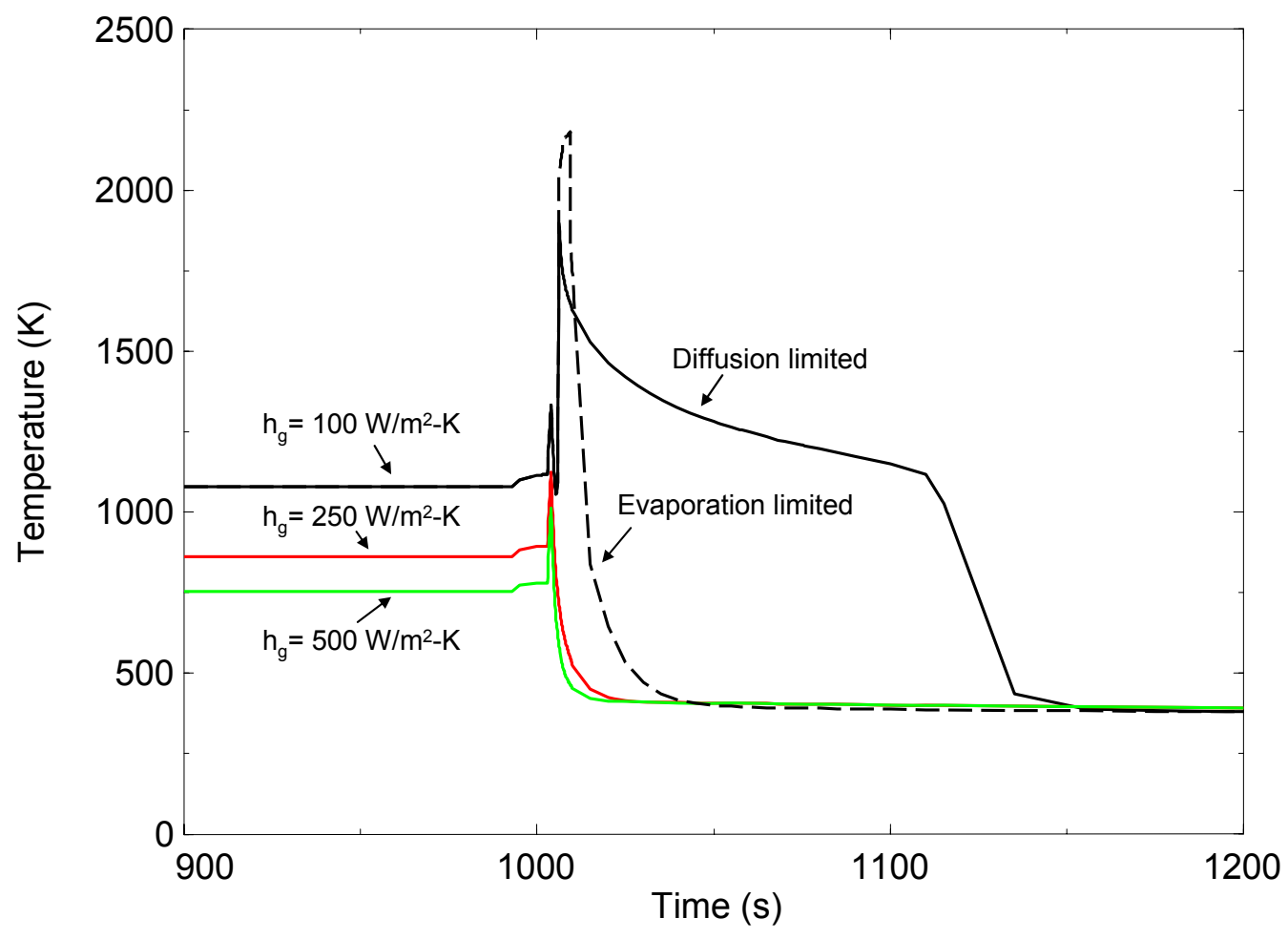

Figure 9. Dust surface temperature during a wet bypass accident for different dust to tile gap conductances. 


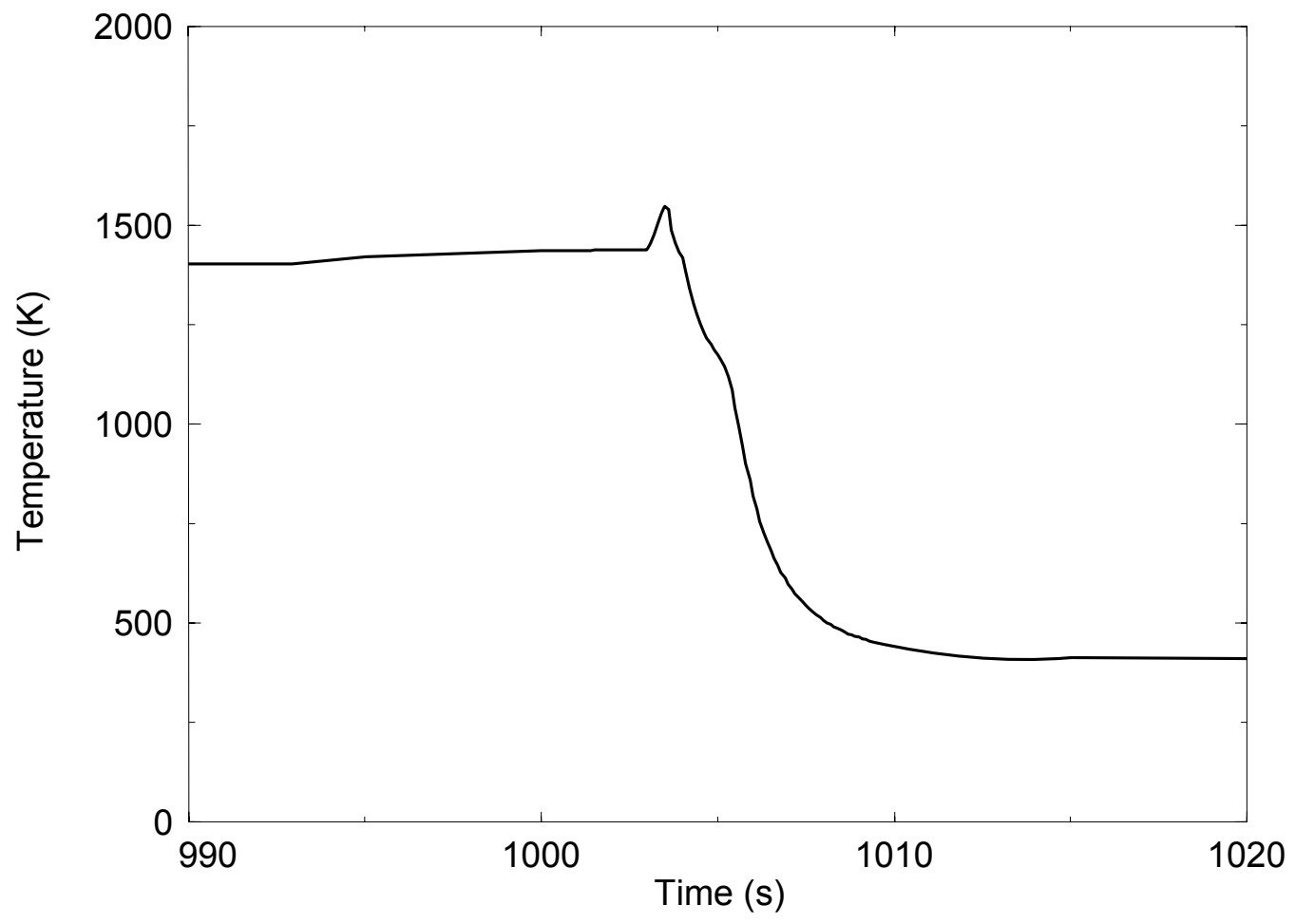

Figure 10. Dust surface temperature during a wet bypass accident when Equation 20 is used to predict dust to tile gap conductance. 


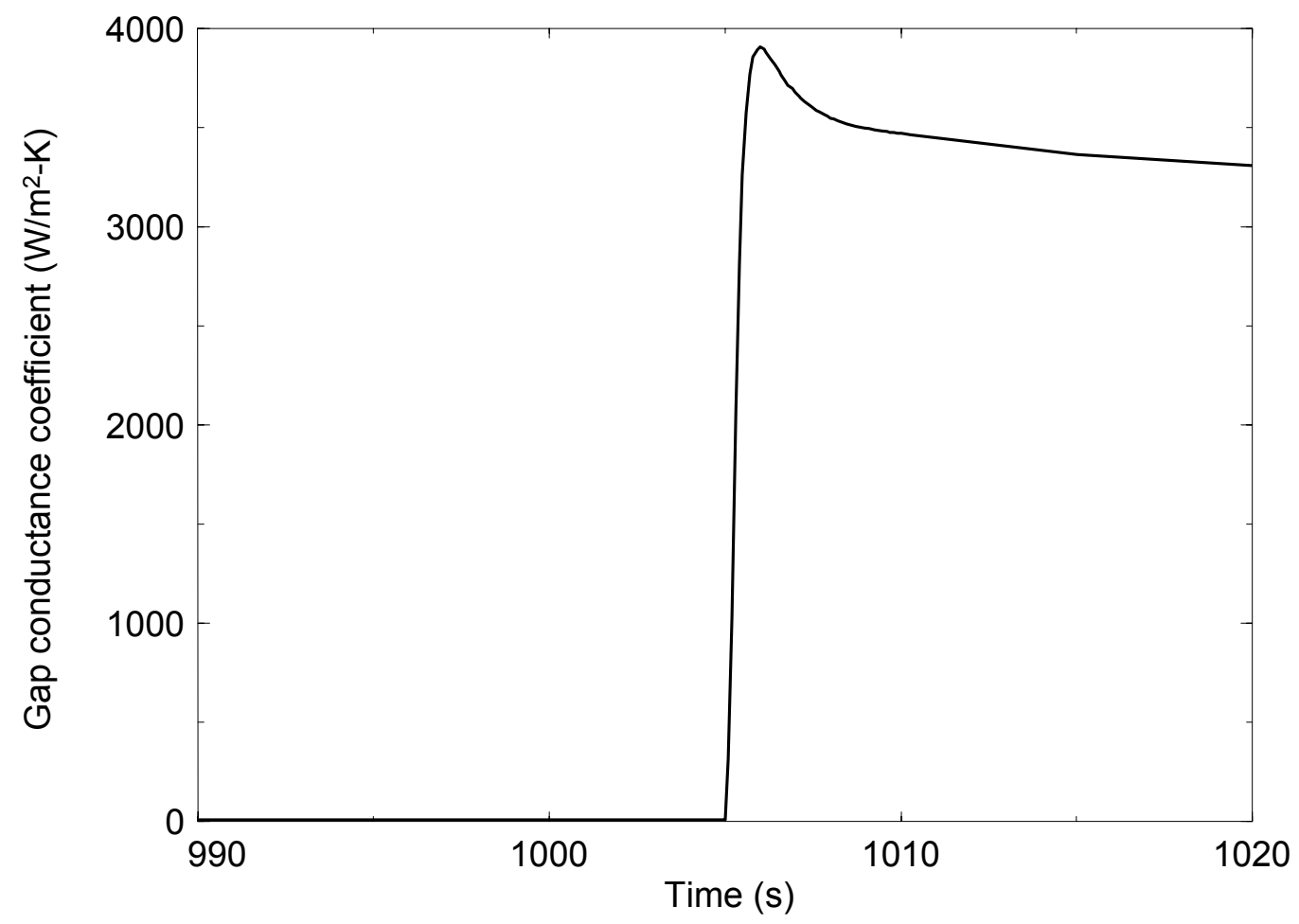

Figure 11. Dust to tile gap conductance during a wet bypass accident when Equation 20 is used to predict gap conductance. 


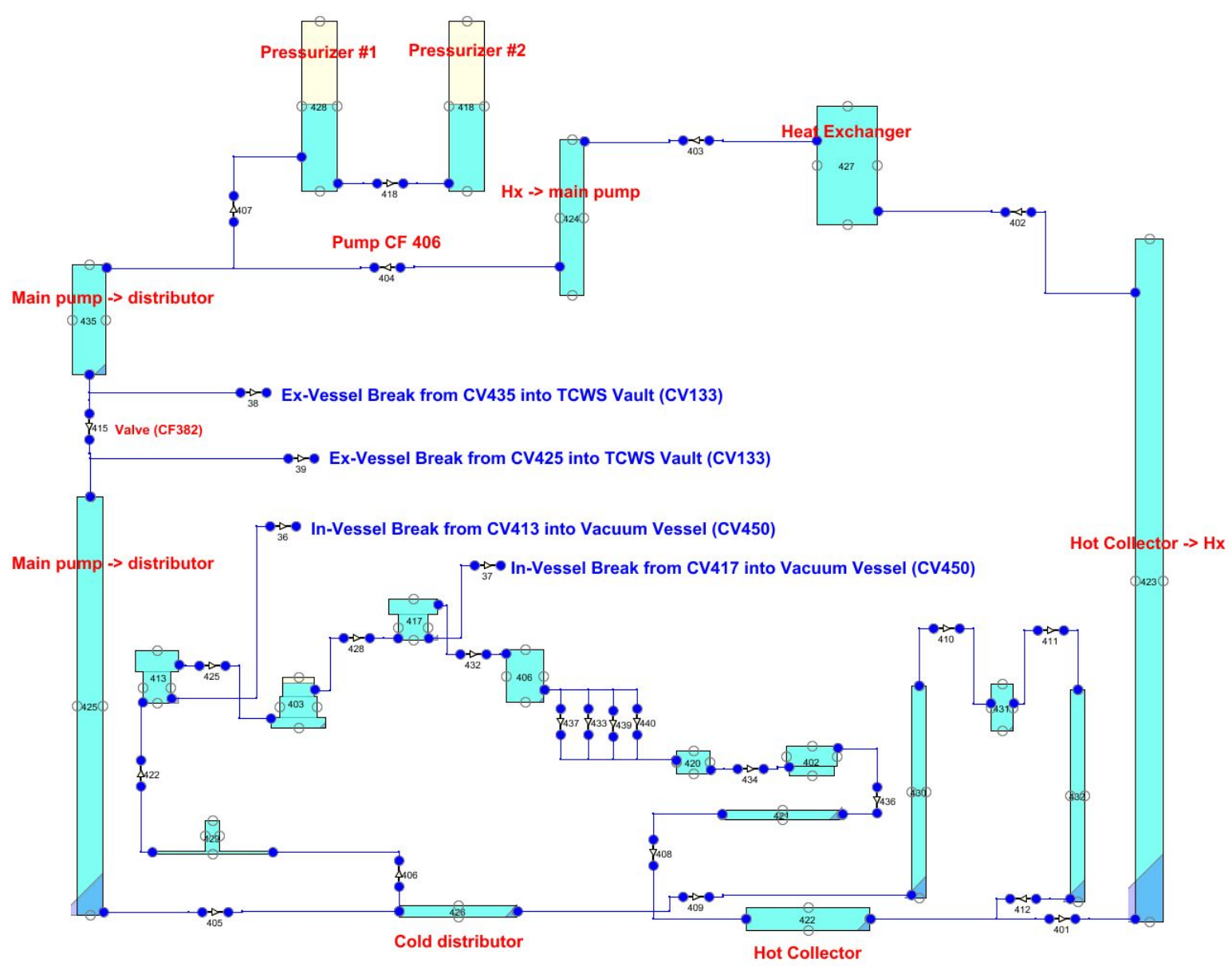

Figure 12. Schematic of the MELCOR Divertor Loop Model as represented in the feat2004.divsimpf.inp computer deck. 


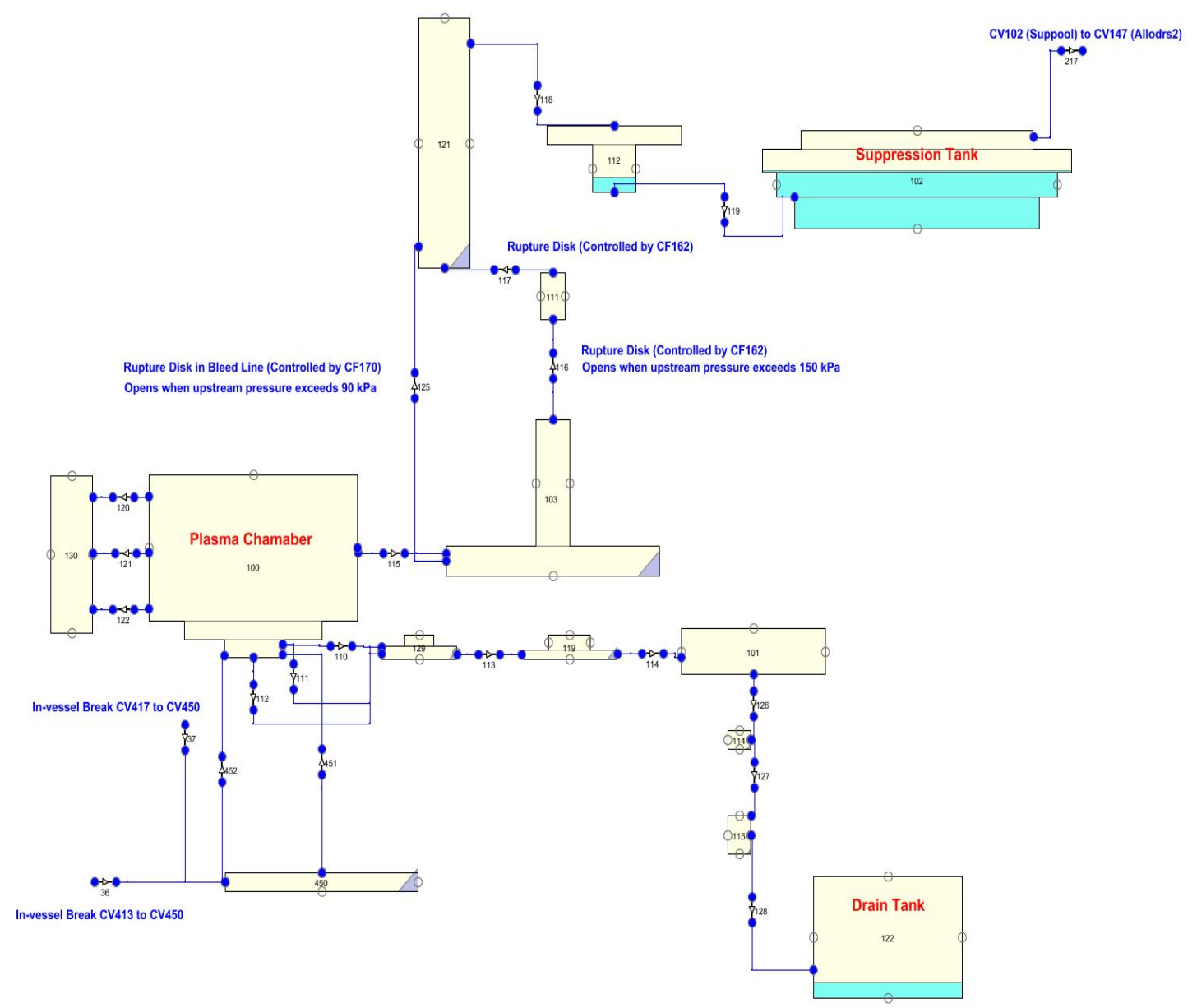

Figure 13. Schematic of the MELCOR Suppression System Model as represented in the feat2004.divsimpf.inp computer deck. 


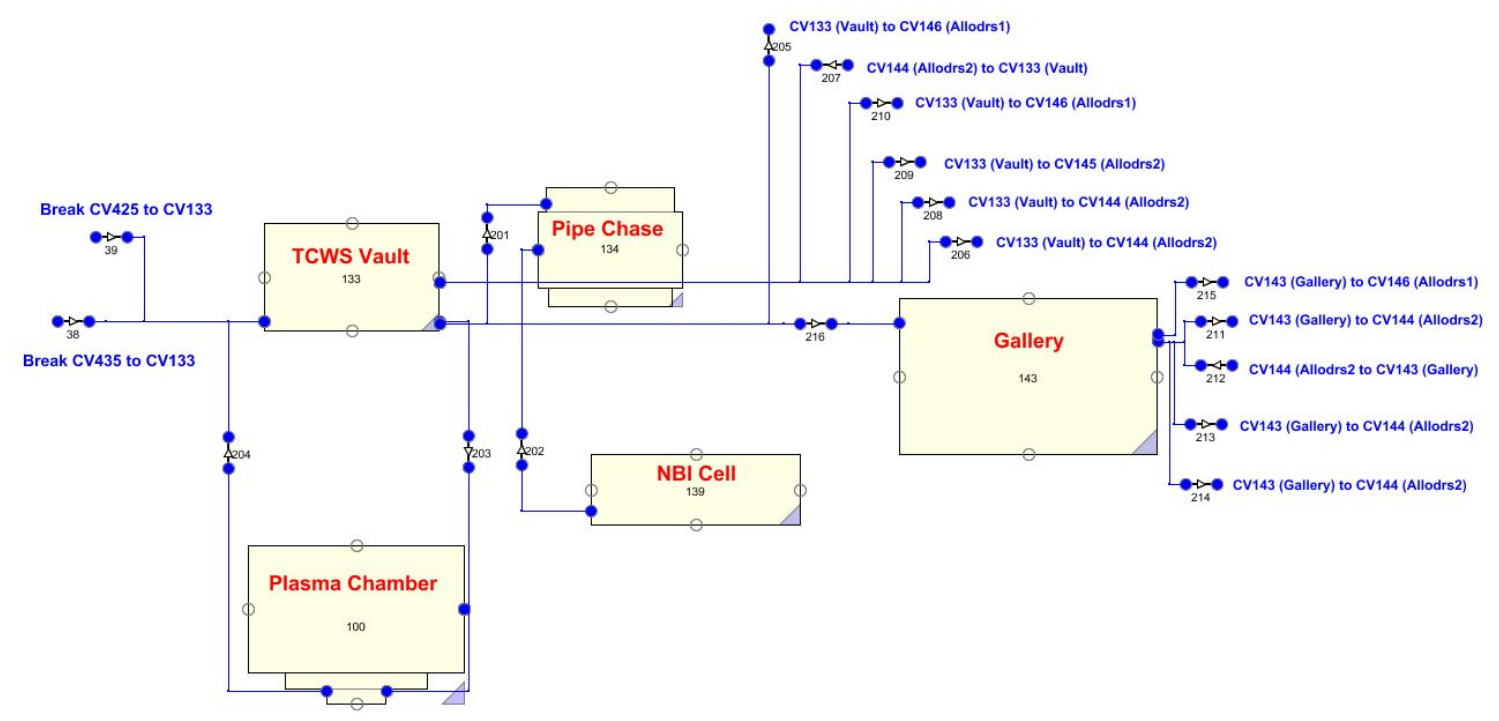

Figure 14. Schematic of the MELCOR Vault System Model as represented in the feat2004.divsimpf.inp computer deck. 


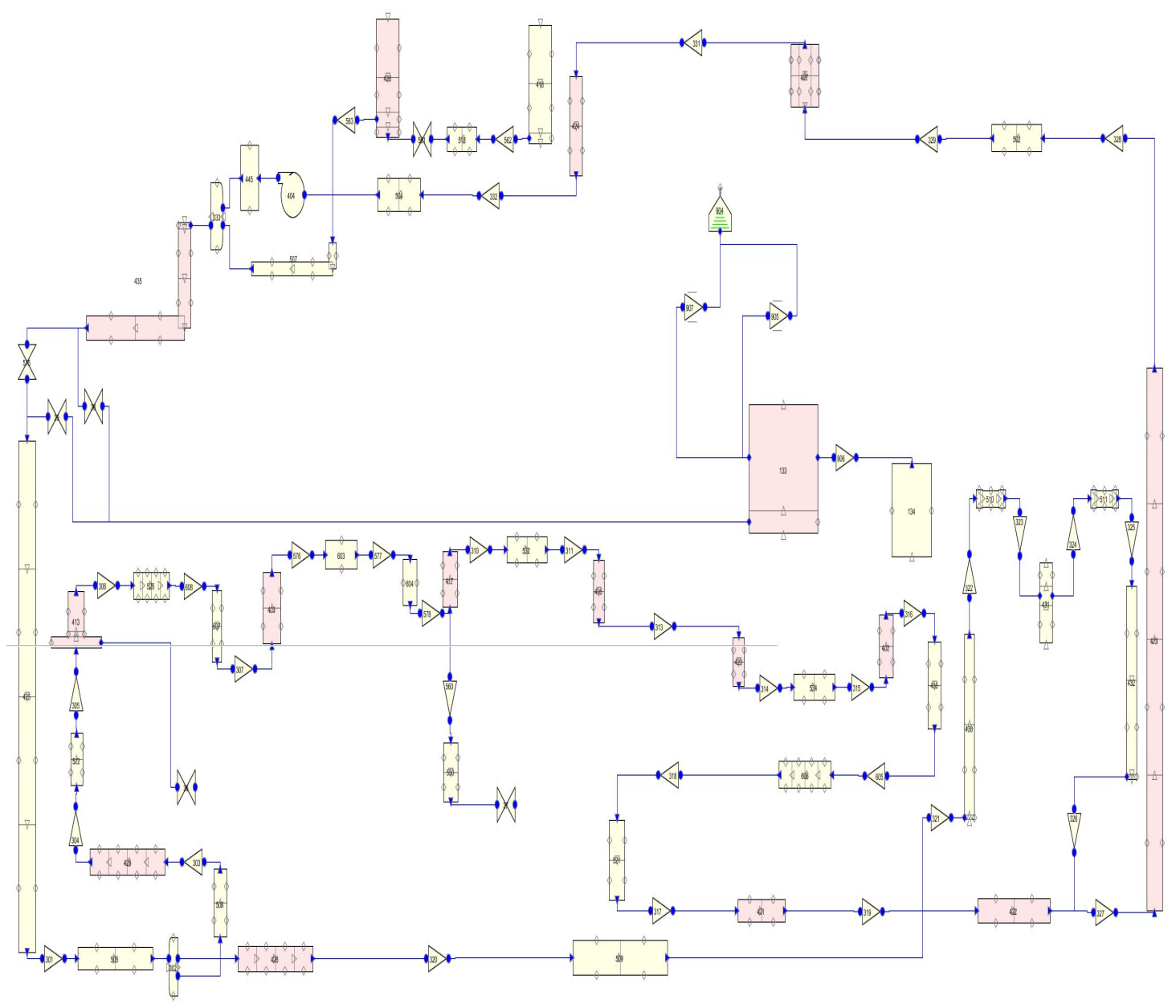

Figure 15. Schematic of the RELAP5/ATHENA Divertor Loop Model. 


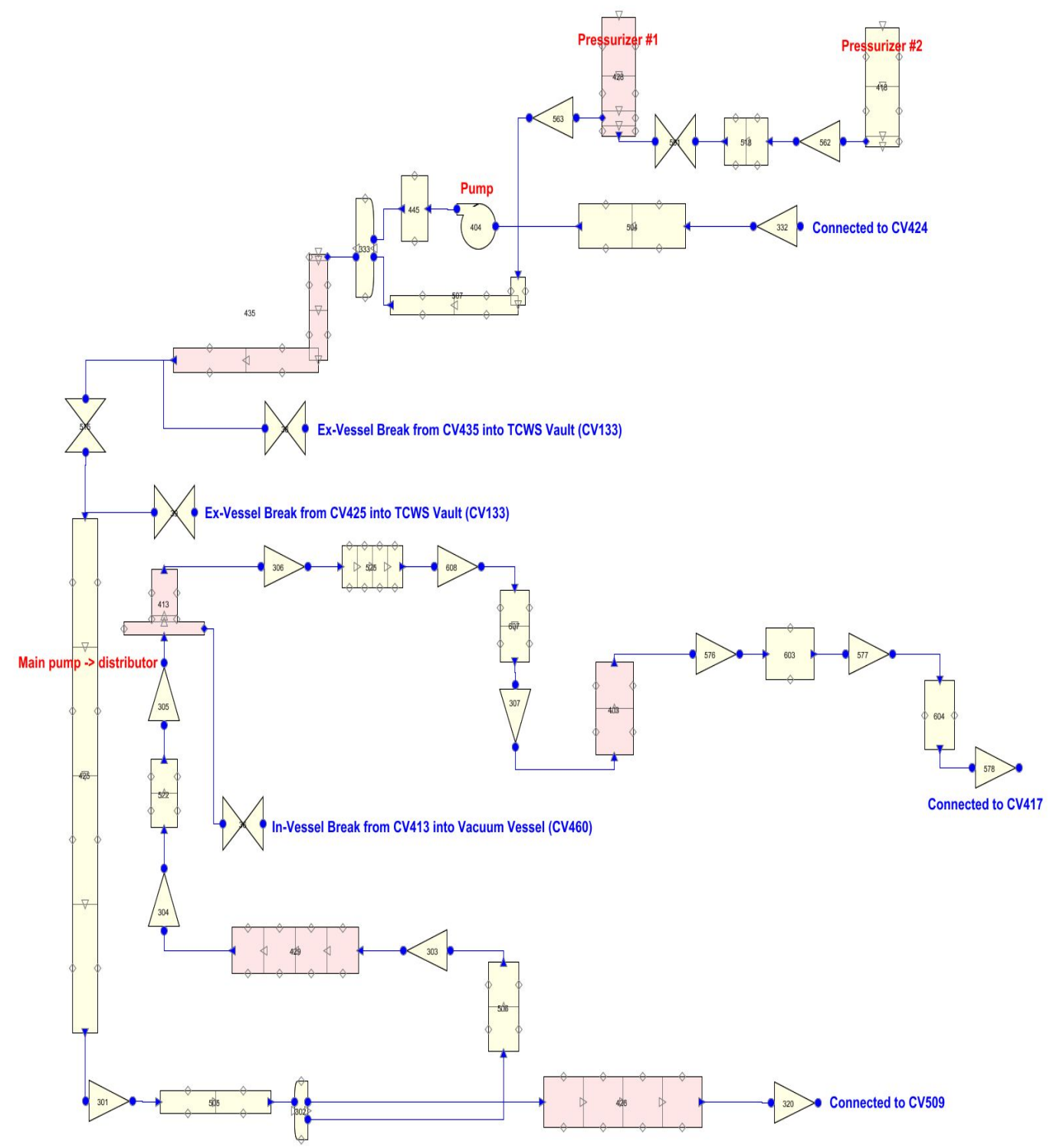

Figure 16. Schematic of the left side of the RELAP5/ATHENA Divertor Loop Model. 


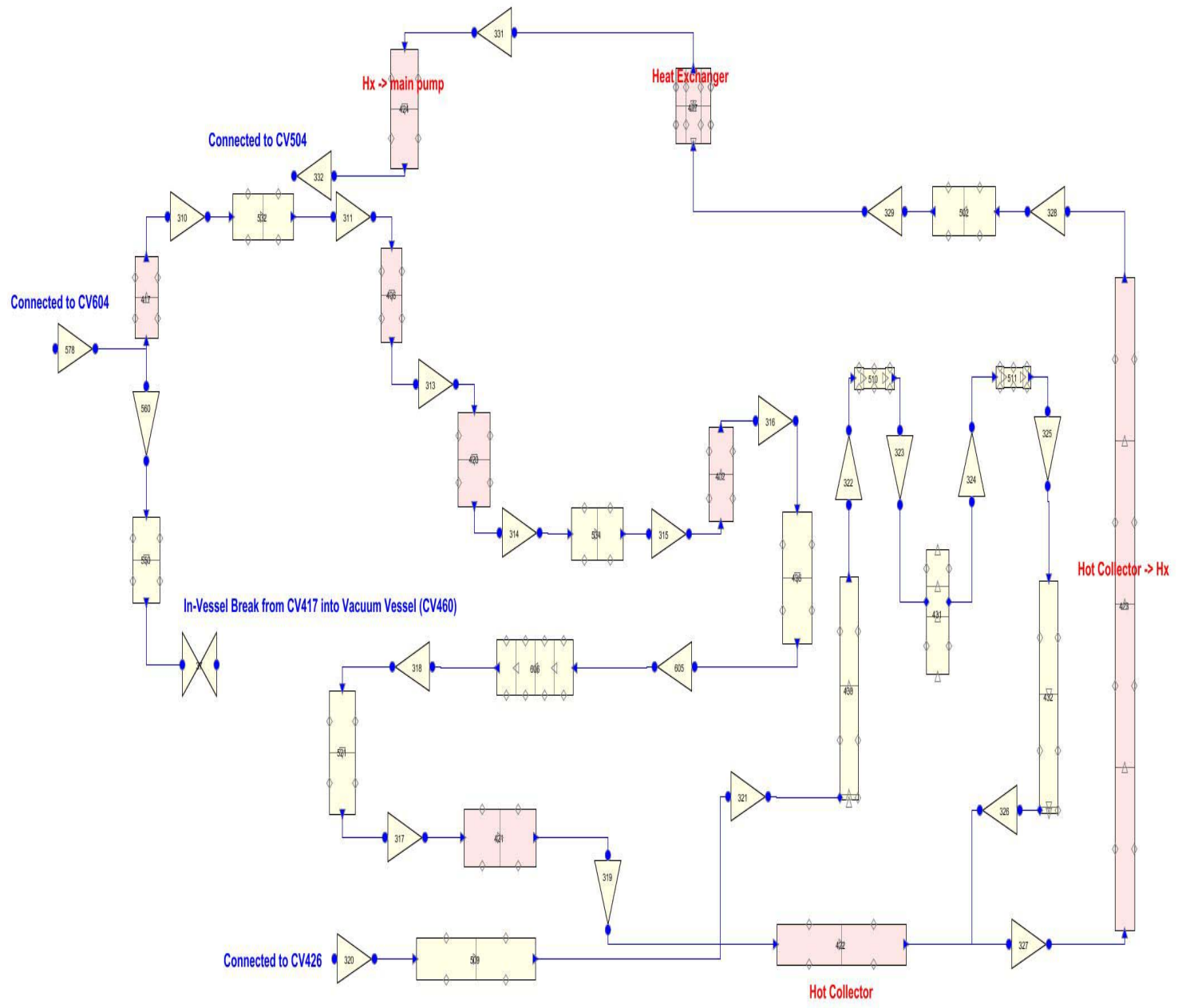

Figure 17. Schematic of the right side of the RELAP5/ATHENA Divertor Loop Model. 


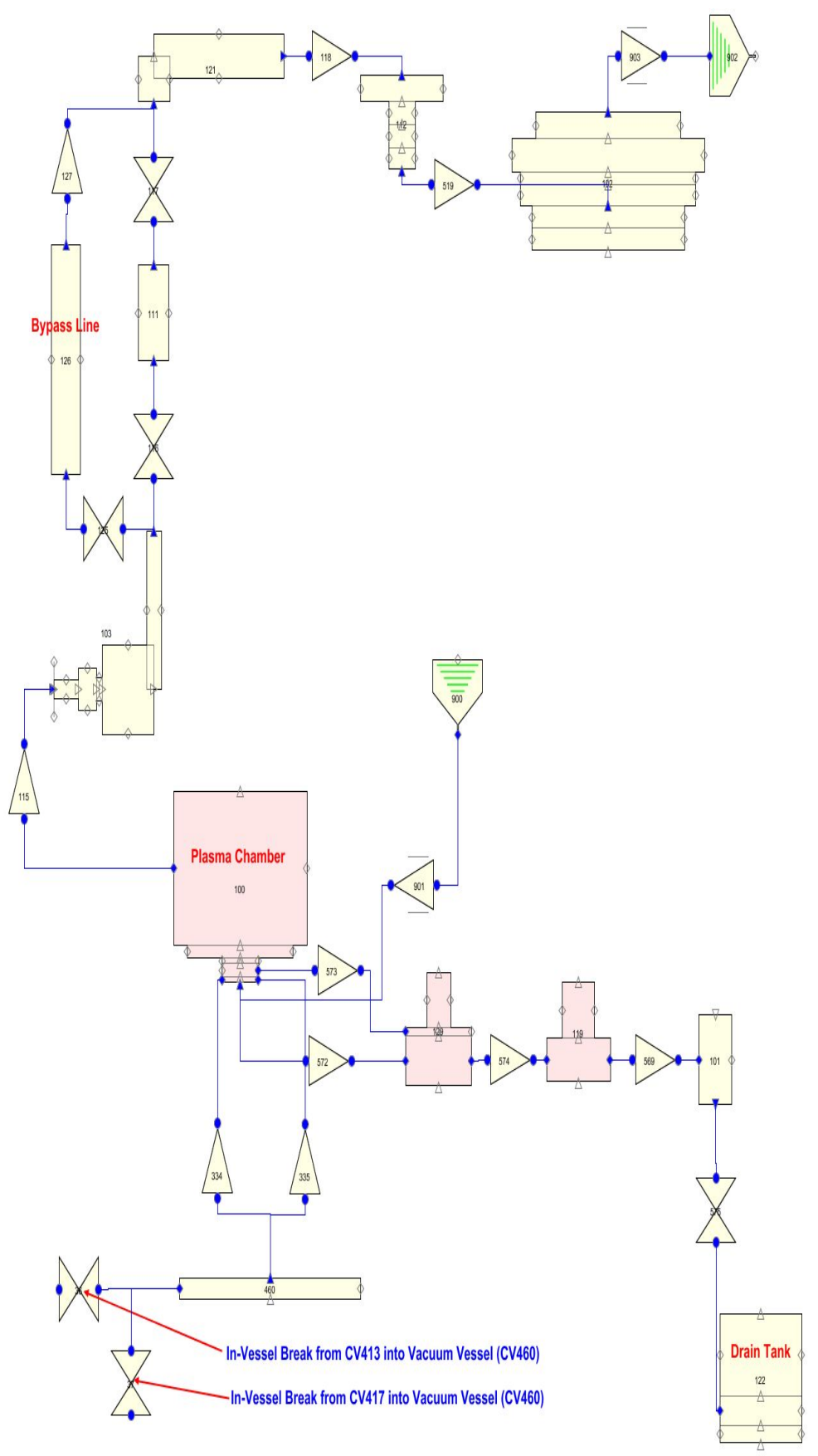

Figure 18. Schematic of the RELAP5/ATHENA Suppression System Model. 


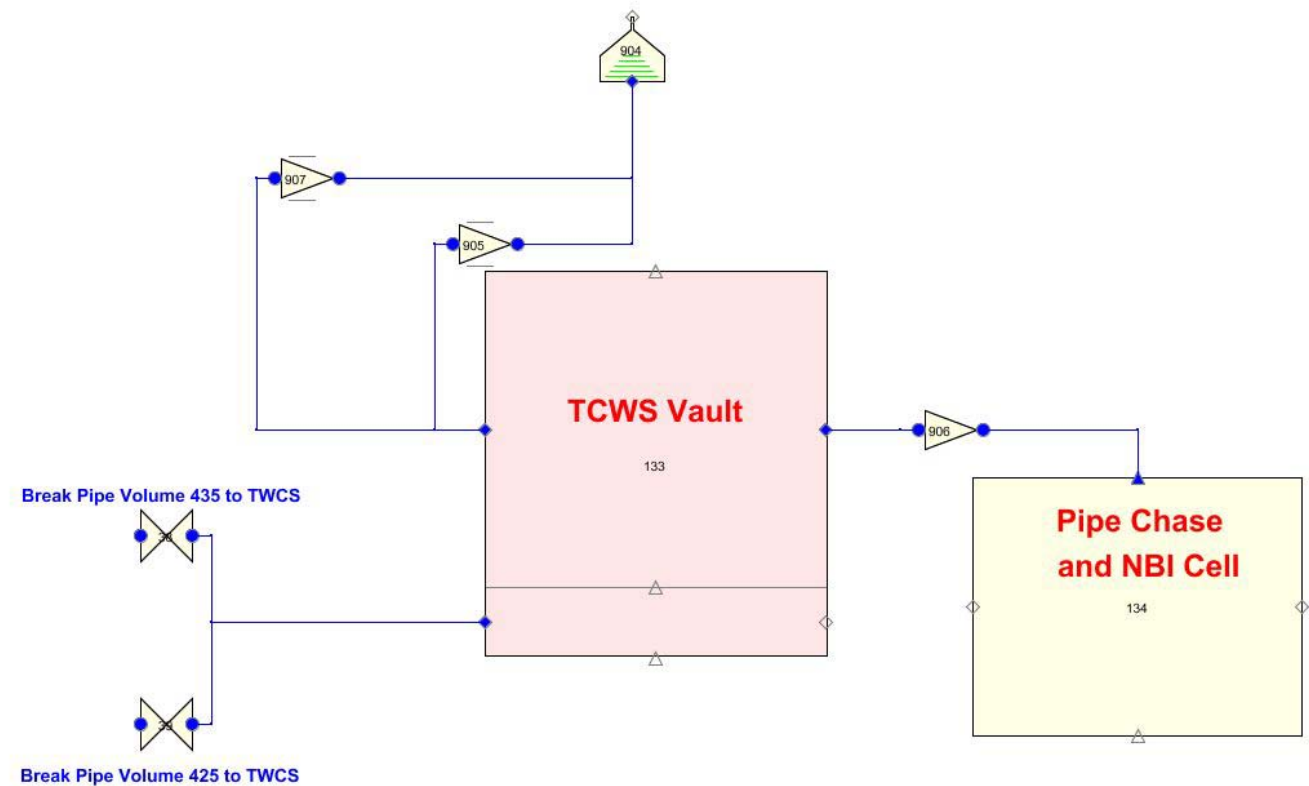

Figure 19. Schematic of the RELAP5/ATHENA Vault System Model. 


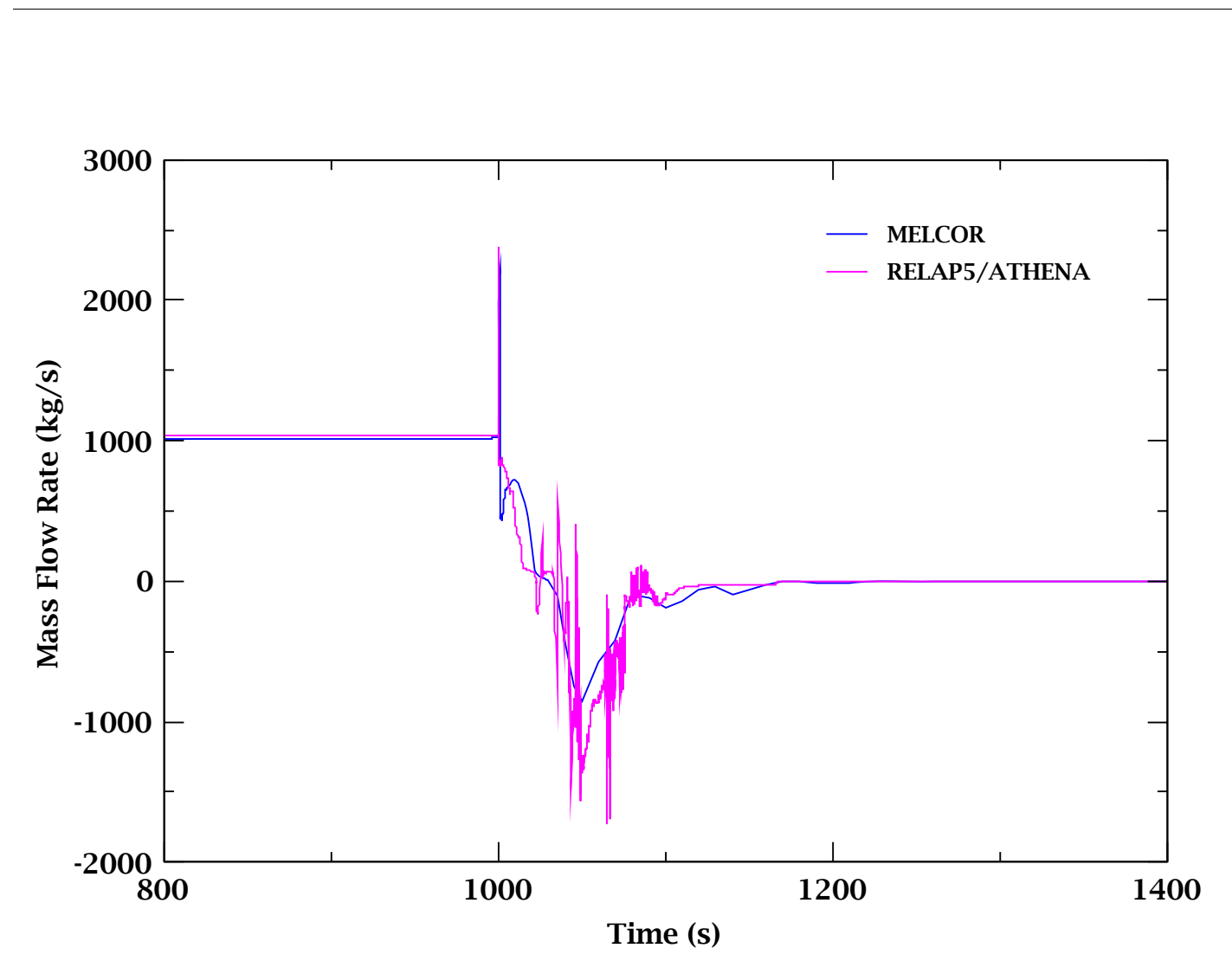

Figure 20. Comparison of the MELCOR and RELAP5/ATHENA total loop mass flow rates. 


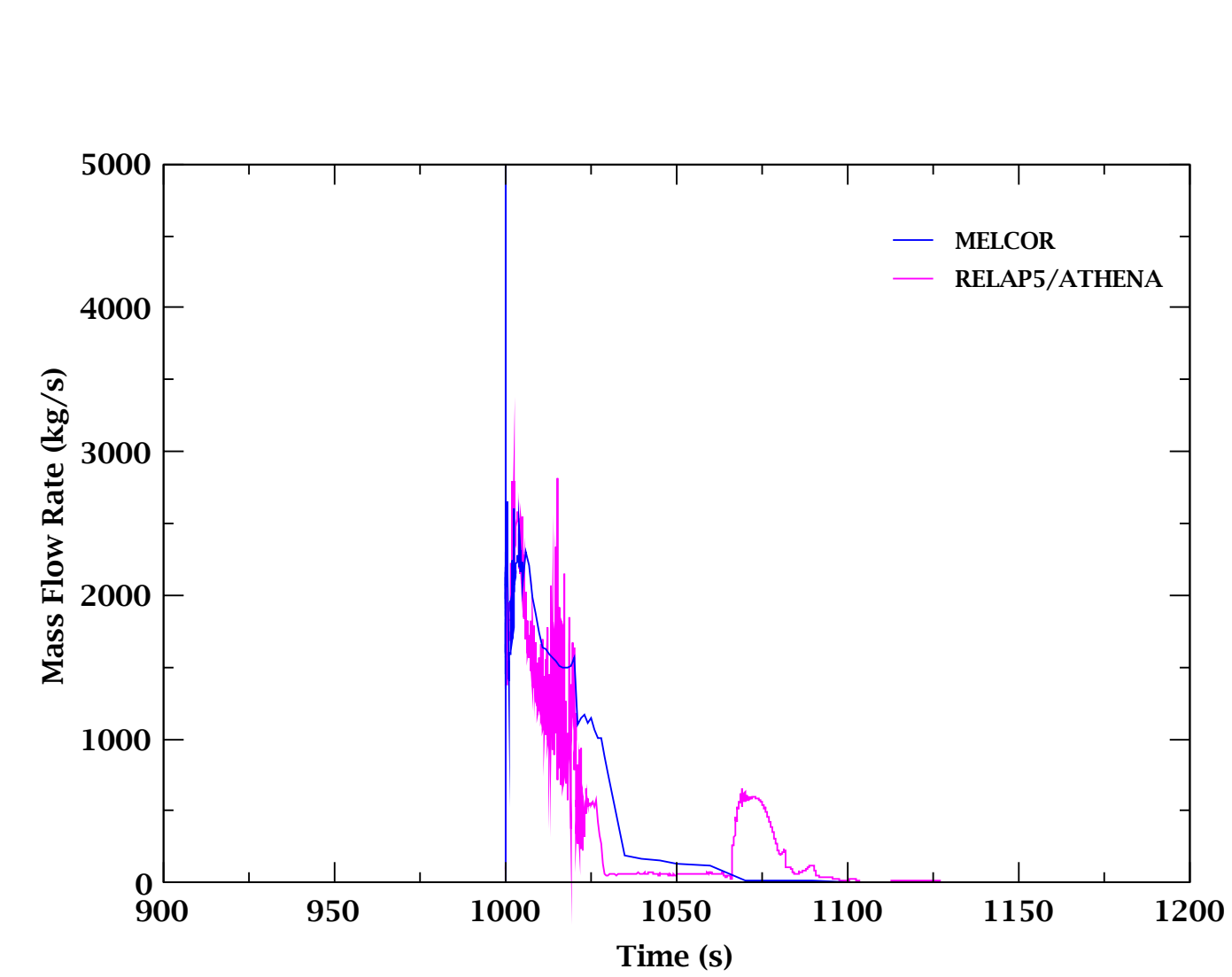

Figure 21. Comparison of the MELCOR and RELAP5/ATHENA mass flow from the ex-vessel break to the TCWS vault. 


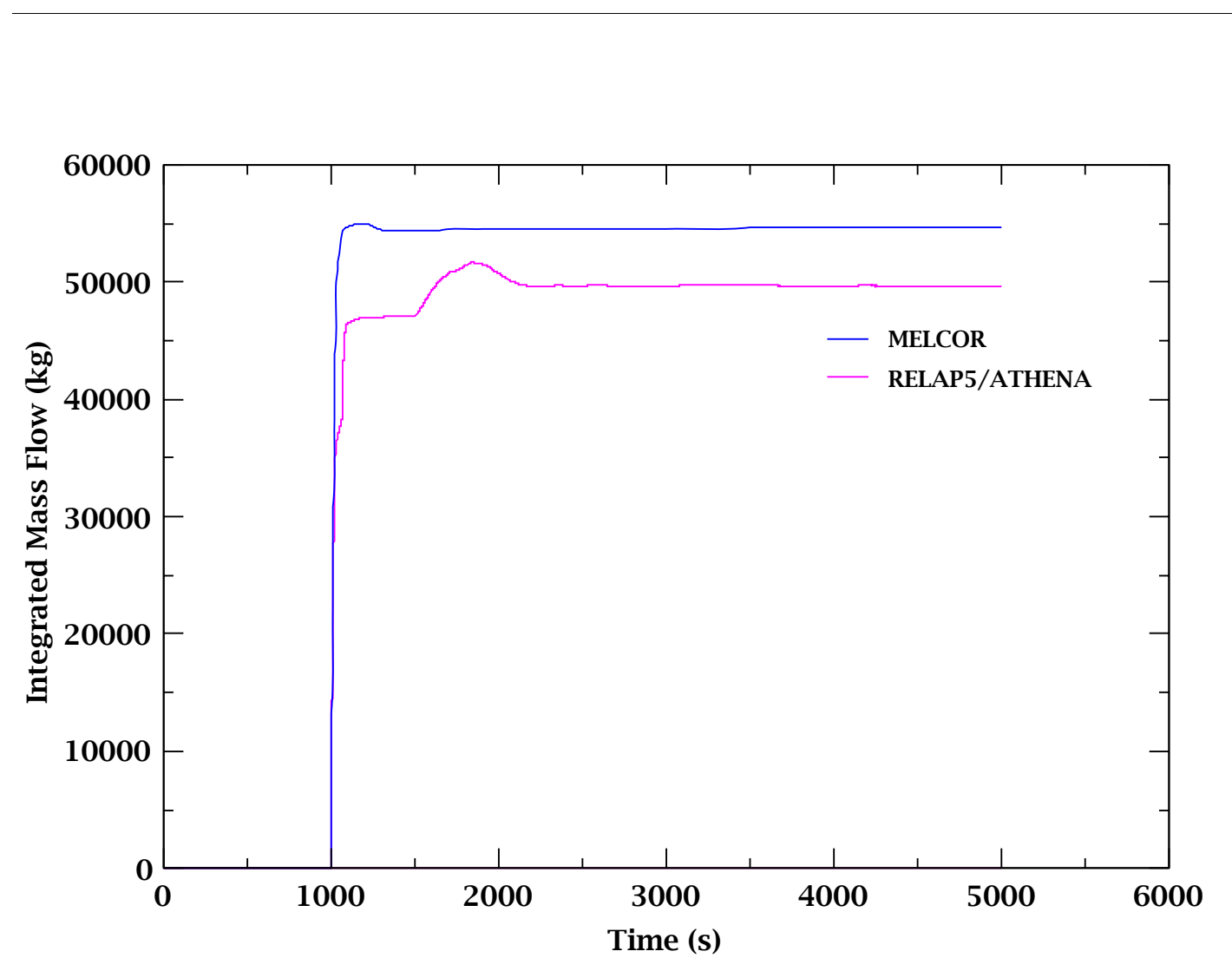

Figure 22. Comparison of the MELCOR and RELAP5/ATHENA integrated mass flow from the ex-vessel break to TCWS vault. 


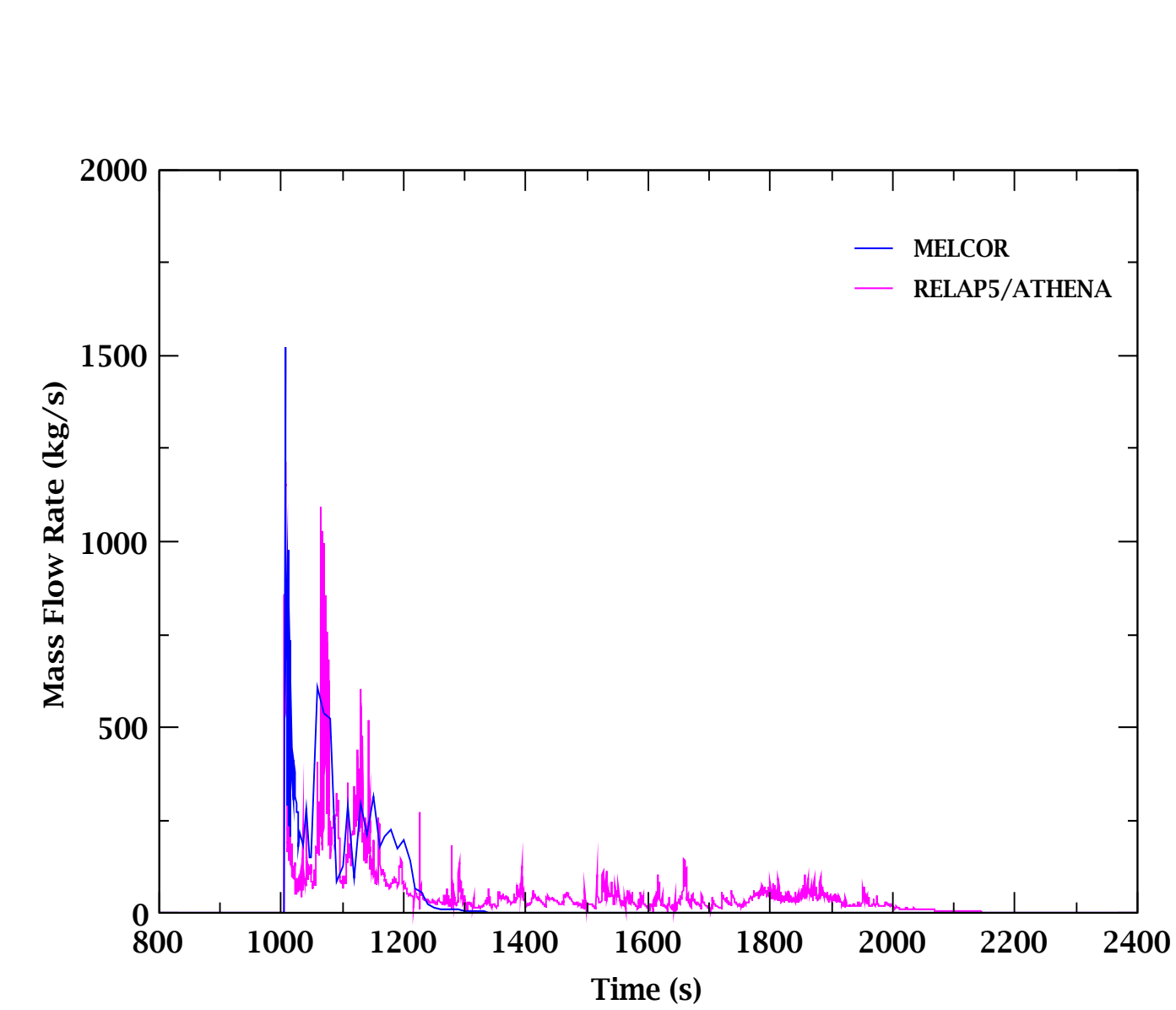

Figure 23. Comparison of MELCOR and RELAP5/ATHENA in-vessel break mass flow rates. 


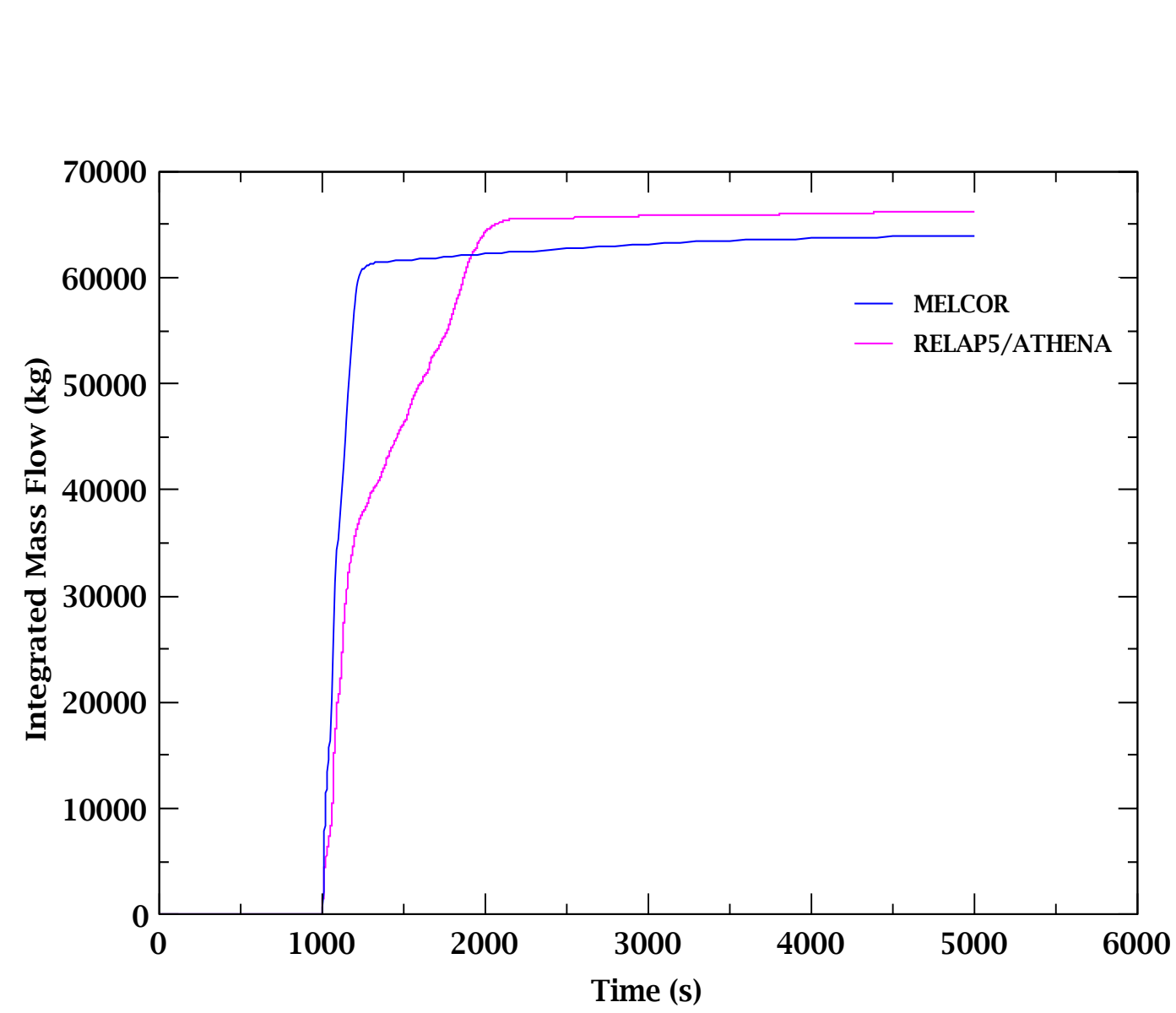

Figure 24. Comparison of the MELCOR and RELAP5/ATHENA integrated mass flow from the in-vessel break to the vacuum vessel. 


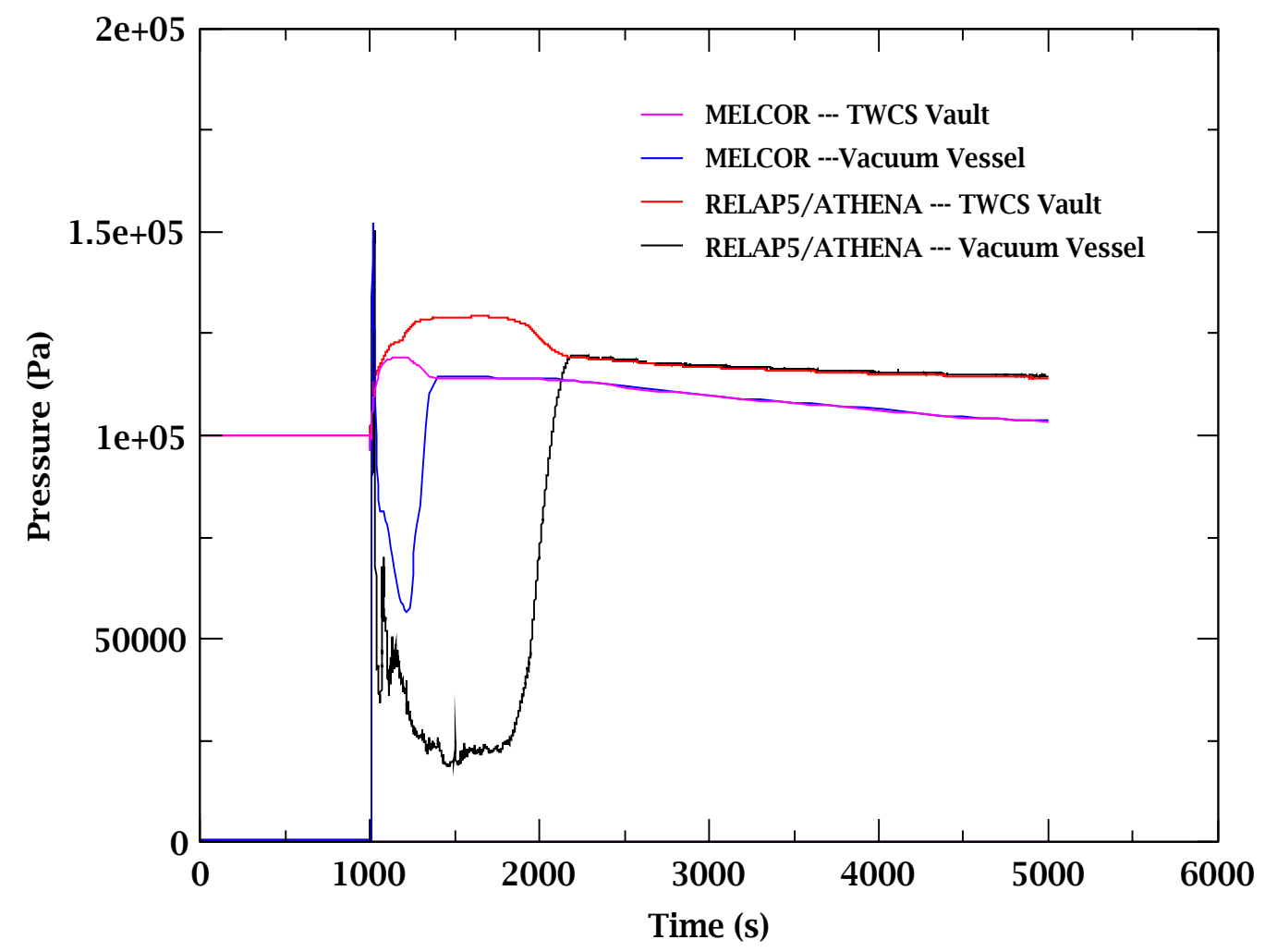

Figure 25. Comparison of the MELCOR and RELAP5/ATHENA pressure histories in the TCWS vault and the vacuum vessel. 


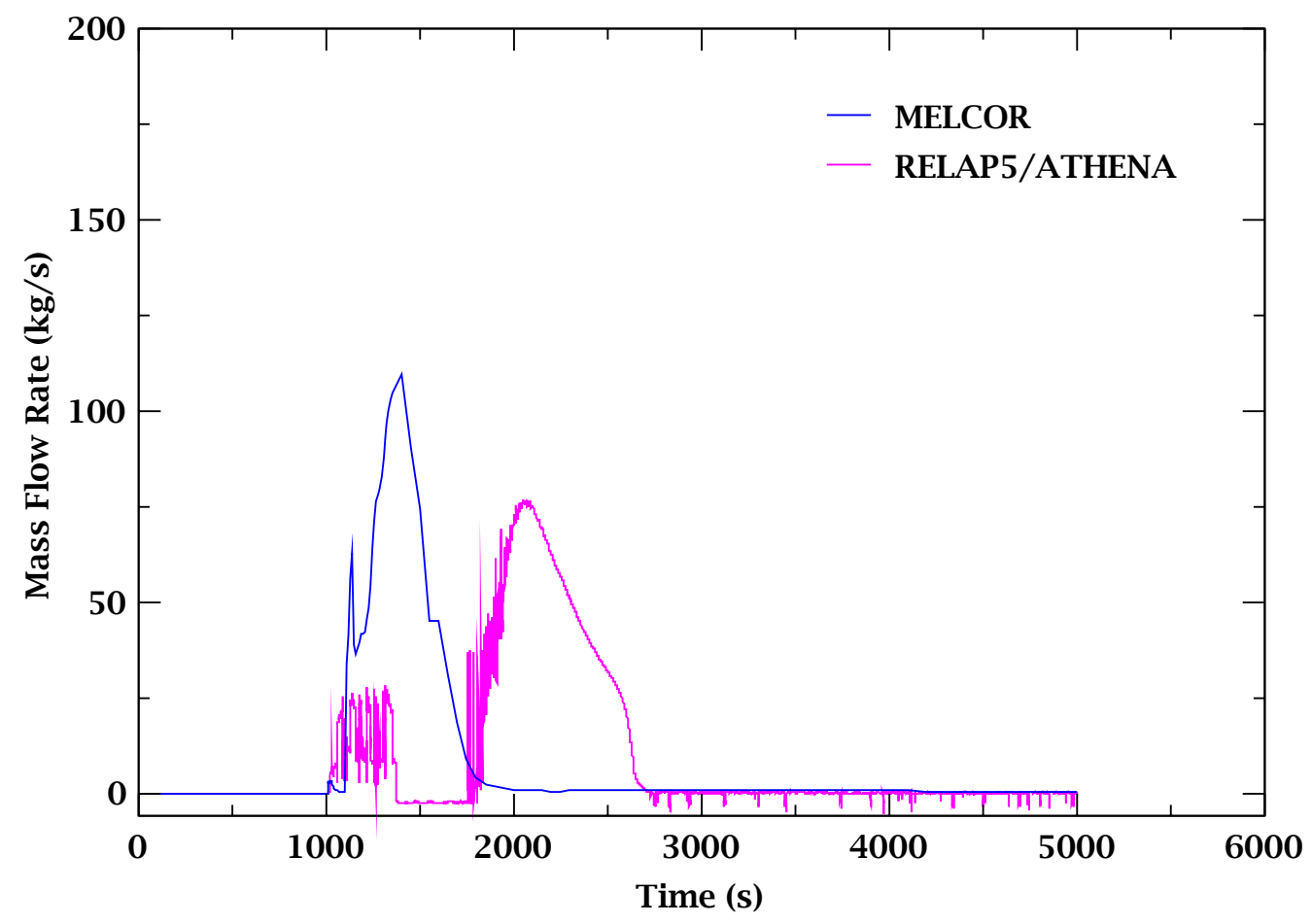

Figure 26. Comparison of the MELCOR and RELAP5/ATHENA mass flow from the vacuum vessel to the drain tank. 


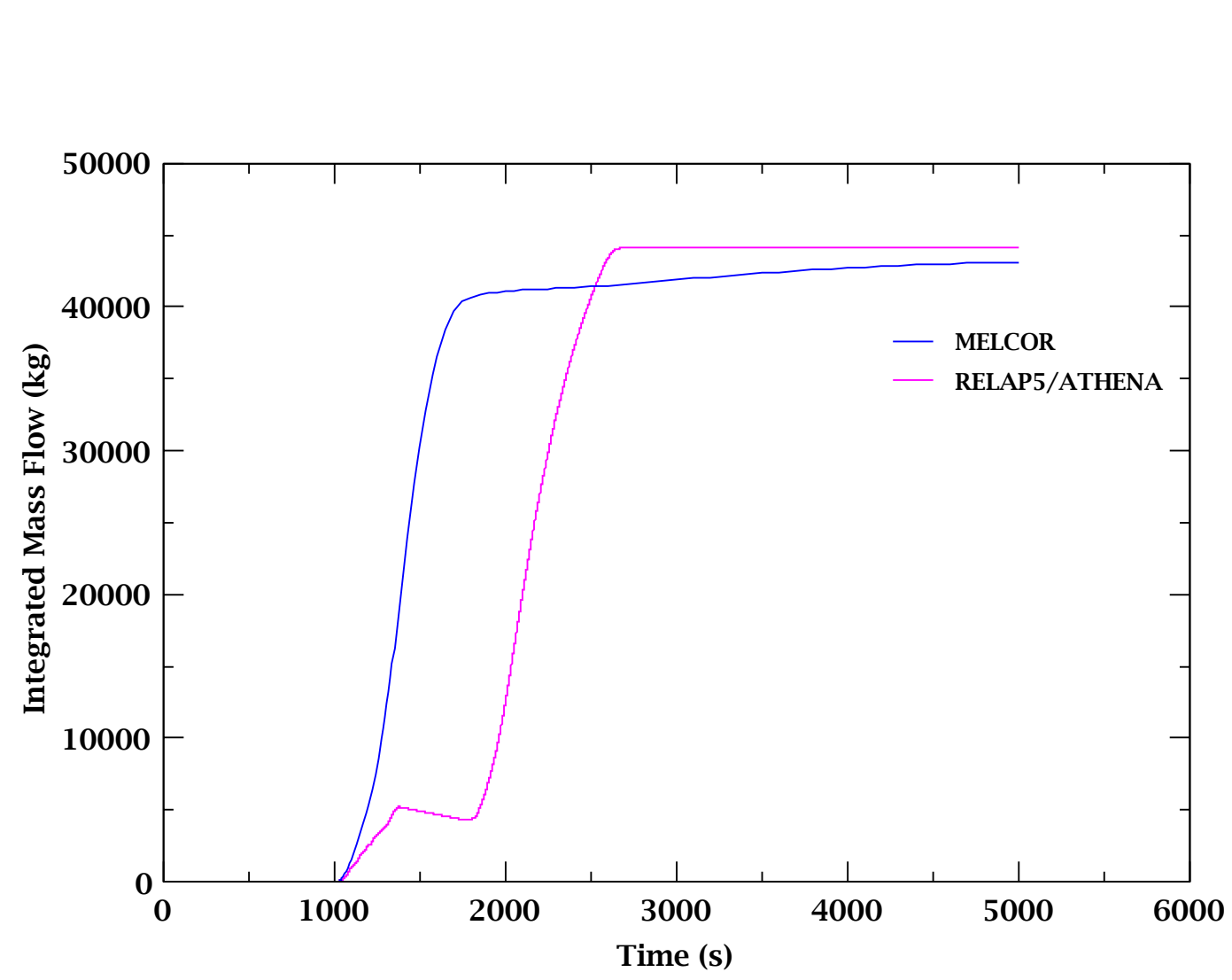

Figure 27. Comparison of the MELCOR and RELAP5/ATHENA integrated mass flow from the vacuum vessel to the drain tank. 


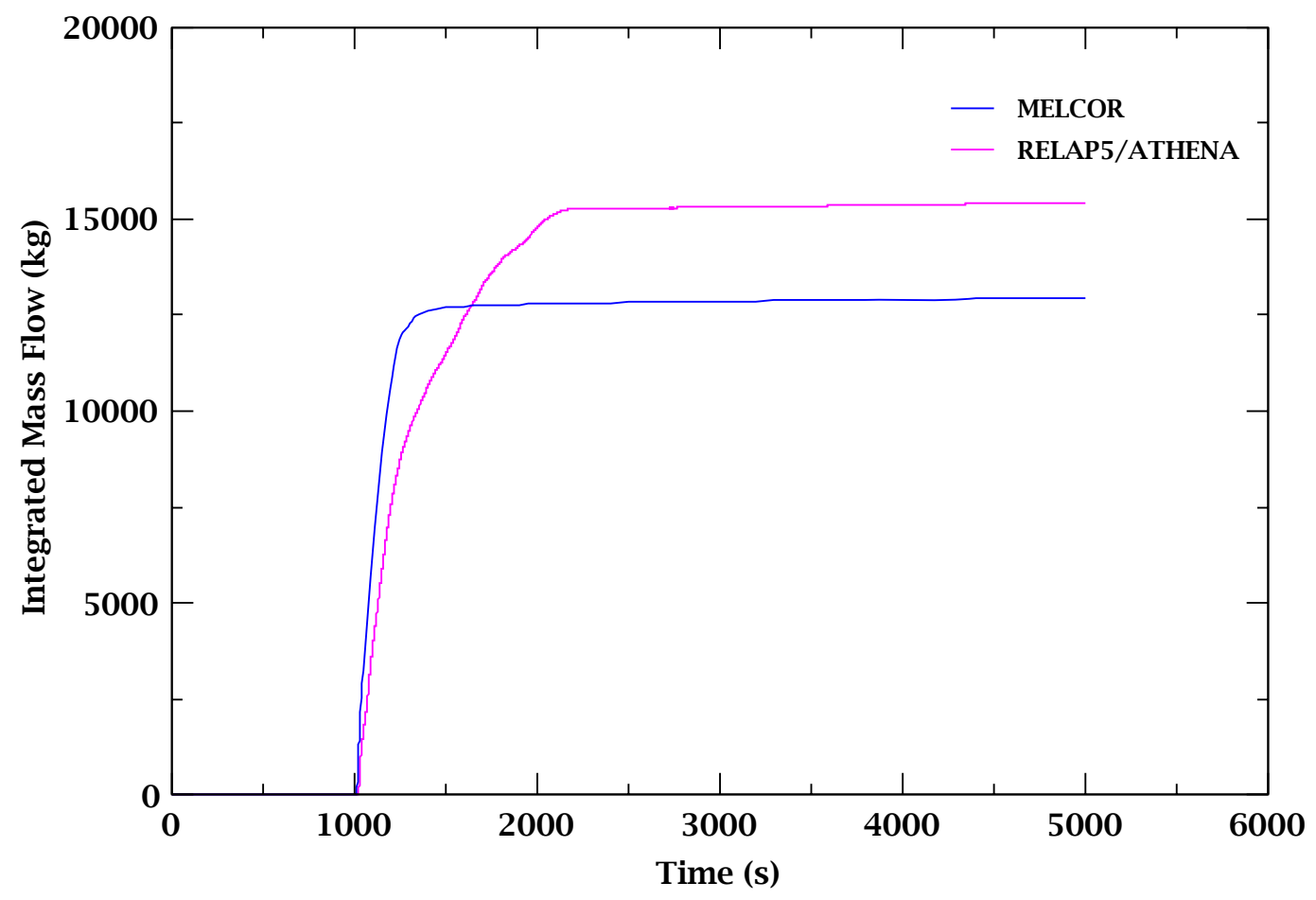

Figure 28. Comparison of the MELCOR and RELAP5/ATHENA integrated mass flow from the vacuum vessel to the suppression tank. 


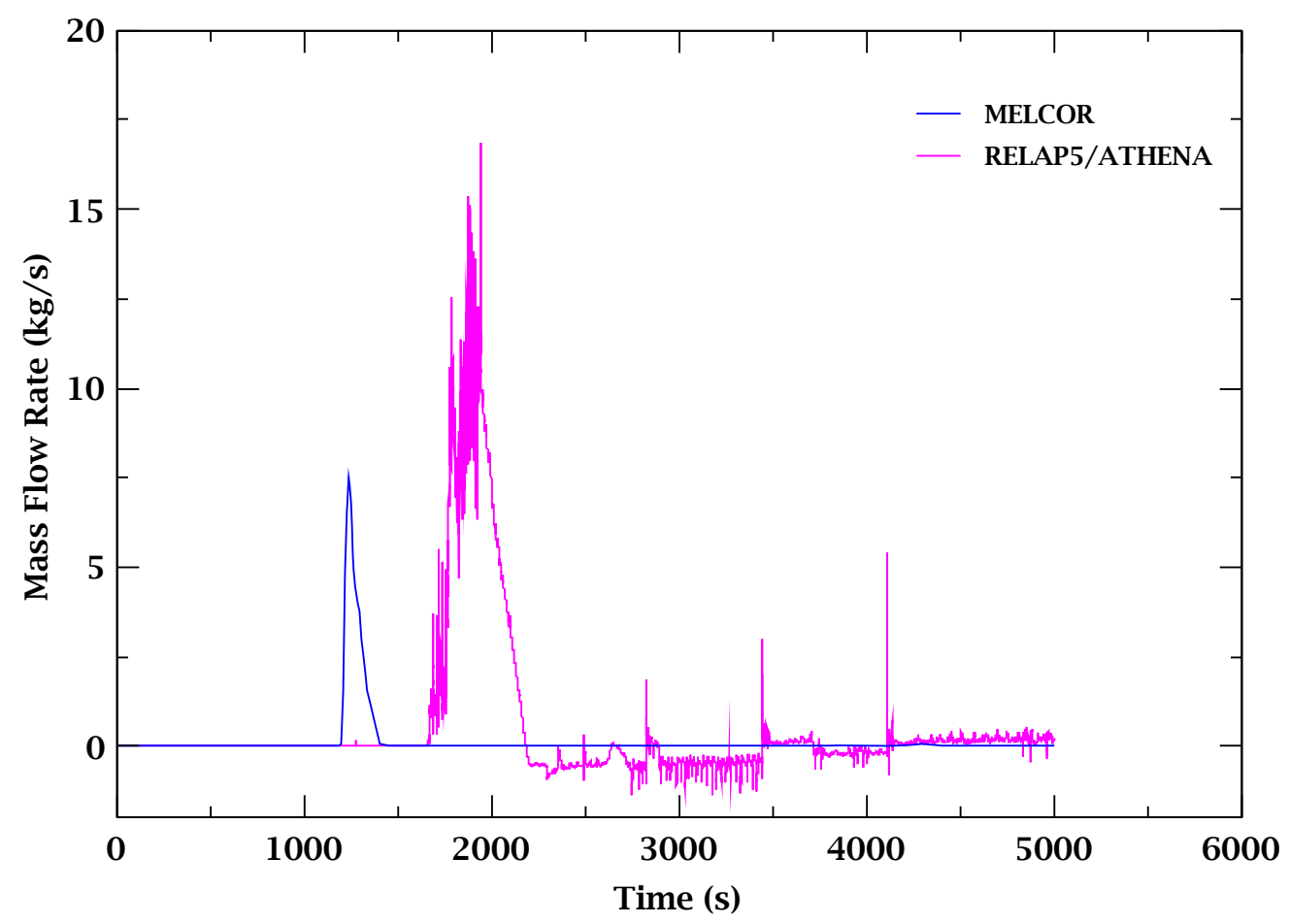

Figure 29. Comparison of the MELCOR and RELAP5/ATHENA air mass flow from the invessel break to the vacuum vessel. 


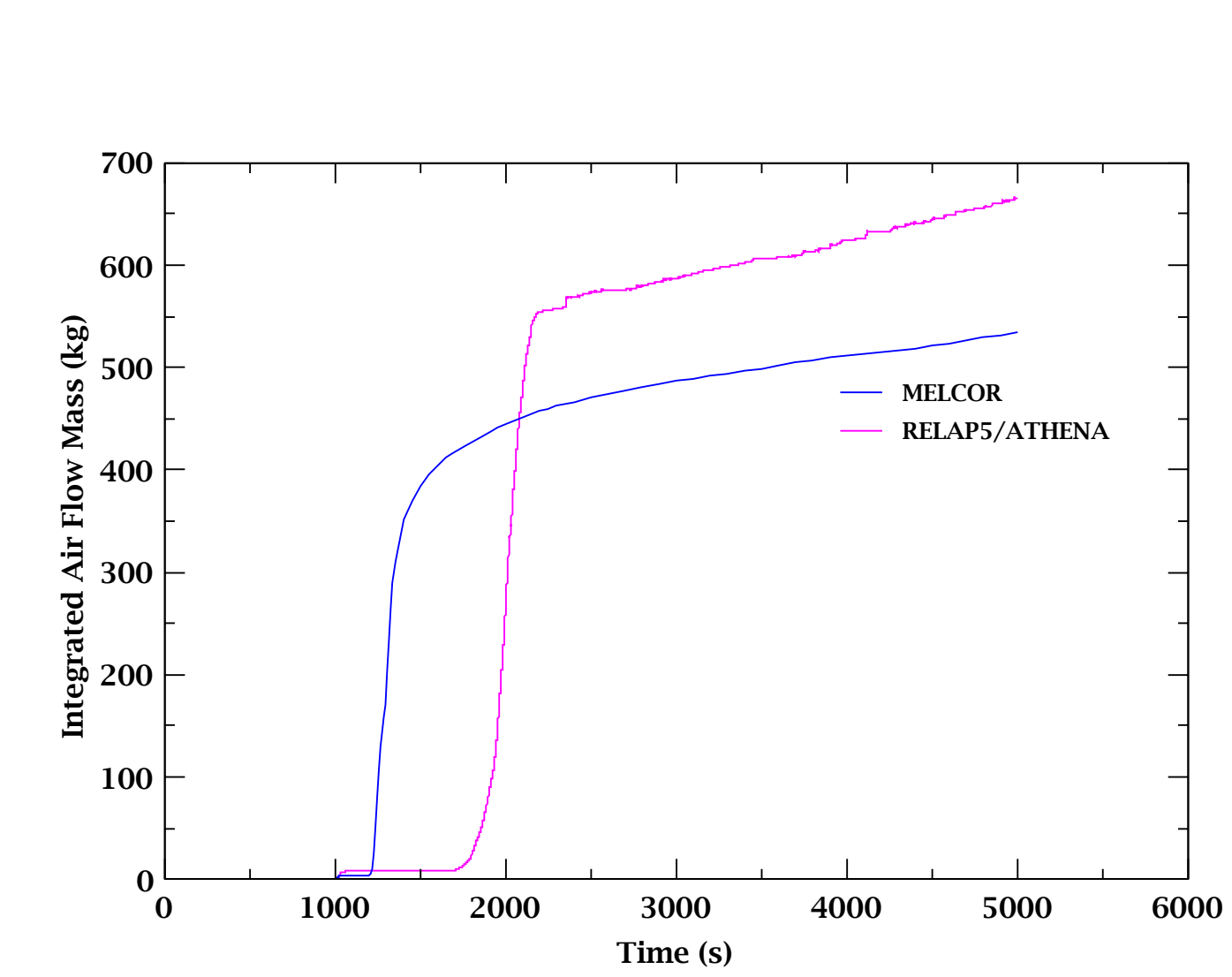

Figure 30. Comparison of the MELCOR and RELAP5/ATHENA integrated air mass flow from the vacuum vessel to the suppression tank. 


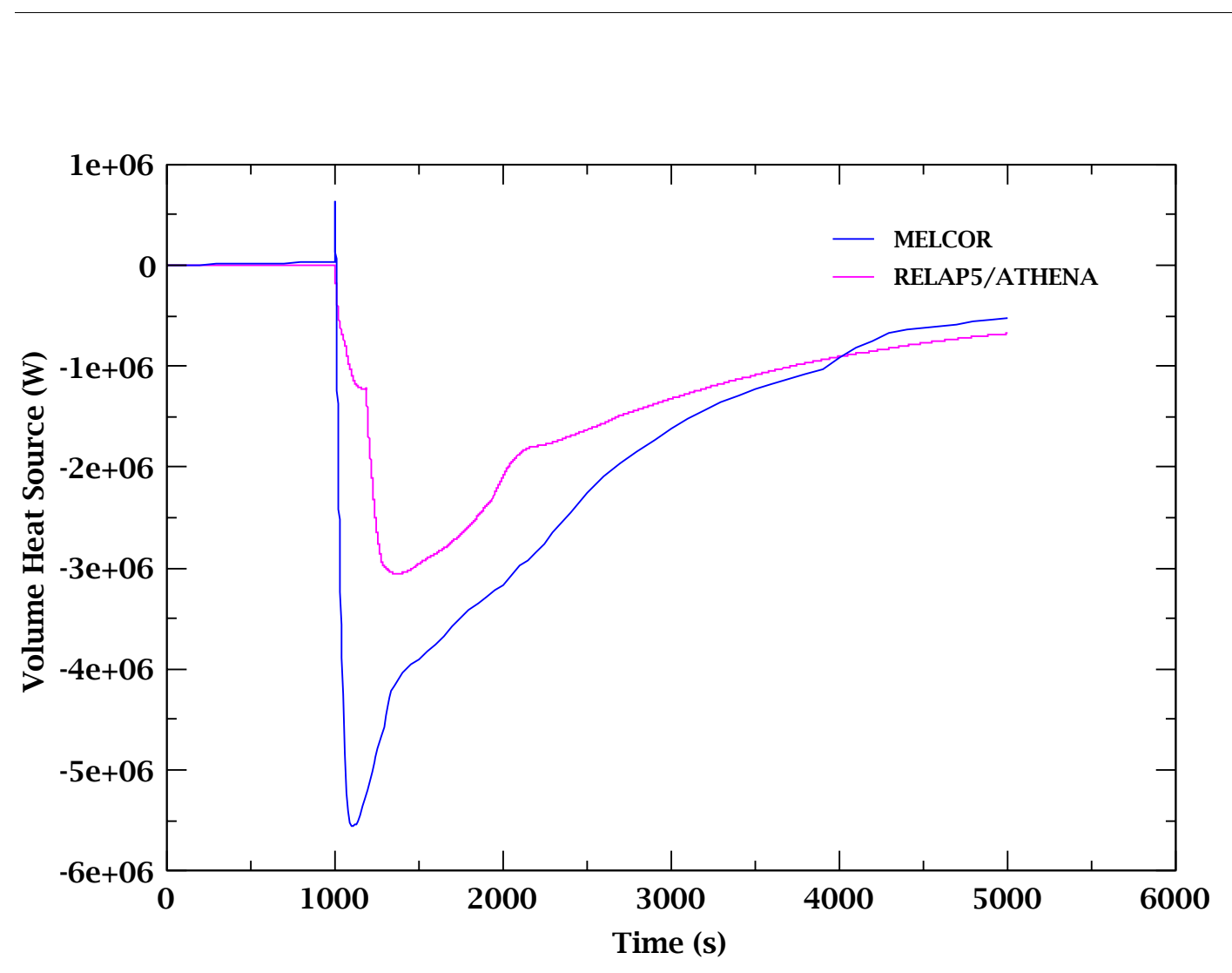

Figure 31. TCWS vault wall heat transfer rate to the atmosphere. 


\section{APPENDIX A}

Listing of Dust Oxidation Functions 
C

C

A A, B, C, D, E, F, G, H

. 1.06036, 0.15610, 0.19300, 0.47635, 1.03587, 1.52996,

. $1.76474,3.89411 /$

C * * DENSITY IN KG/M3

DATA RHODSTO / 1000 . /

DATA DPMUO / $2.1 /$

DATA PO / $1.0 /$

DATA TO / $293.0 /$

DATA EPSOK /108.9/

DATA SIGAB / 2.809/

DATA EPS / $0.45 /$

DATA TAU2 / $0.64 /$

DATA RCON / 8.315/

DATA DELTAO / 2.78D-3 /

DATA CAPPA /111.11/

DATA CH2O0 / 27.7 /

C

C

IF(DELTA .LE.0.0) DELTA = DELTAO

IF (RHODUST.LE.0.0) RHODUST $=$ RHODSTO

IF (DPMU .LE.0.0) DPMU = DPMUO

TSTAR $=$ TO/EPSOK

OMEGAO $=\mathrm{A} / \mathrm{TSTAR} * \mathrm{~B}^{*}+\mathrm{C}$ EXP $(-\mathrm{D} * \mathrm{TSTAR})+\mathrm{E}$ EXP $\left(-\mathrm{F}^{\star} \mathrm{TSTAR}\right)$

C

$\cdot$

$+\mathrm{G} * \operatorname{EXP}\left(-\mathrm{H}^{\star} \mathrm{TSTAR}\right)$

$\mathrm{CH} 2 \mathrm{O}=\mathrm{PH} 2 \mathrm{O} /\left(\mathrm{RCON}^{*} \mathrm{~T}\right)$

$\mathrm{P} \quad=\mathrm{PH} 2 \mathrm{O} / 1 . \mathrm{E} 5$

TSTAR $=$ T/EPSOK

$\mathrm{OMEGA}=\mathrm{A} / \mathrm{TSTAR}{ }^{*} \mathrm{~B}+\mathrm{C}{ }^{*} \mathrm{EXP}(-\mathrm{D} * \mathrm{TSTAR})+\mathrm{E}^{\star} \mathrm{EXP}\left(-\mathrm{F}^{*} \mathrm{TSTAR}\right)$

$\cdot$

$+\mathrm{G} * \operatorname{EXP}\left(-\mathrm{H}^{\star} \mathrm{TSTAR}\right)$

C

$\mathrm{DAB}=8.5 \mathrm{D}-5 *(\mathrm{PO} / \mathrm{P}) *(\mathrm{~T} / \mathrm{TO}) * \star 1.5 *(\mathrm{OMEGAO} / \mathrm{OMEGA})$

$\mathrm{DEFF}=\mathrm{DAB} * \mathrm{TAU} 2 * \mathrm{EPS}$

$C$ * * SPECIFIC AREA M2/KG

$\mathrm{ABET}=1000 * *(1.6937-0.0336 * \mathrm{DPMU})$

$\mathrm{AOV}=\mathrm{ABET} *$ RHODUST

C

$\mathrm{ROX}=0.1205 \mathrm{D} 0 * \operatorname{EXP}(-13465.0 / \mathrm{T})$

IF (T.GT.793.) THEN

IF (T.LT.1140.) THEN

$\mathrm{ROX}=2.571 \mathrm{D} 07 * \operatorname{EXP}(-28789.0 / \mathrm{T})$

ELSE

$\mathrm{ROX}=35.357 \mathrm{D} 0 * \operatorname{EXP}(-13387.0 / \mathrm{T})$

ENDIF

ENDIF

$\mathrm{C} \star \star \star$ PRESSURE DEPENDENCE

PRATIO $=\mathrm{PH} 20 / 0.86 \mathrm{E} 5$

PMH2O $=$ MIN $(2.14$, PRATIO **0.9)

IF (PRATIO.GT.2.0) THEN

PRATIO2 $=$ PH2O/2.E5

$\mathrm{PMH} 2 \mathrm{O}=\operatorname{PMH} 2 \mathrm{O} * \mathrm{MIN}(1.52, \operatorname{PRATIO} 2 * \star 0.6)$

ENDIF

IF (PRATIO.GT.4.0) THEN

PRATIO3 $=$ PH2O/4.E5

$\mathrm{PMH} 2 \mathrm{O}=\mathrm{PMH} 2 \mathrm{O} * \operatorname{MIN}(1.18, \operatorname{PRATIO} 3 * * 0.4)$

ENDIF 


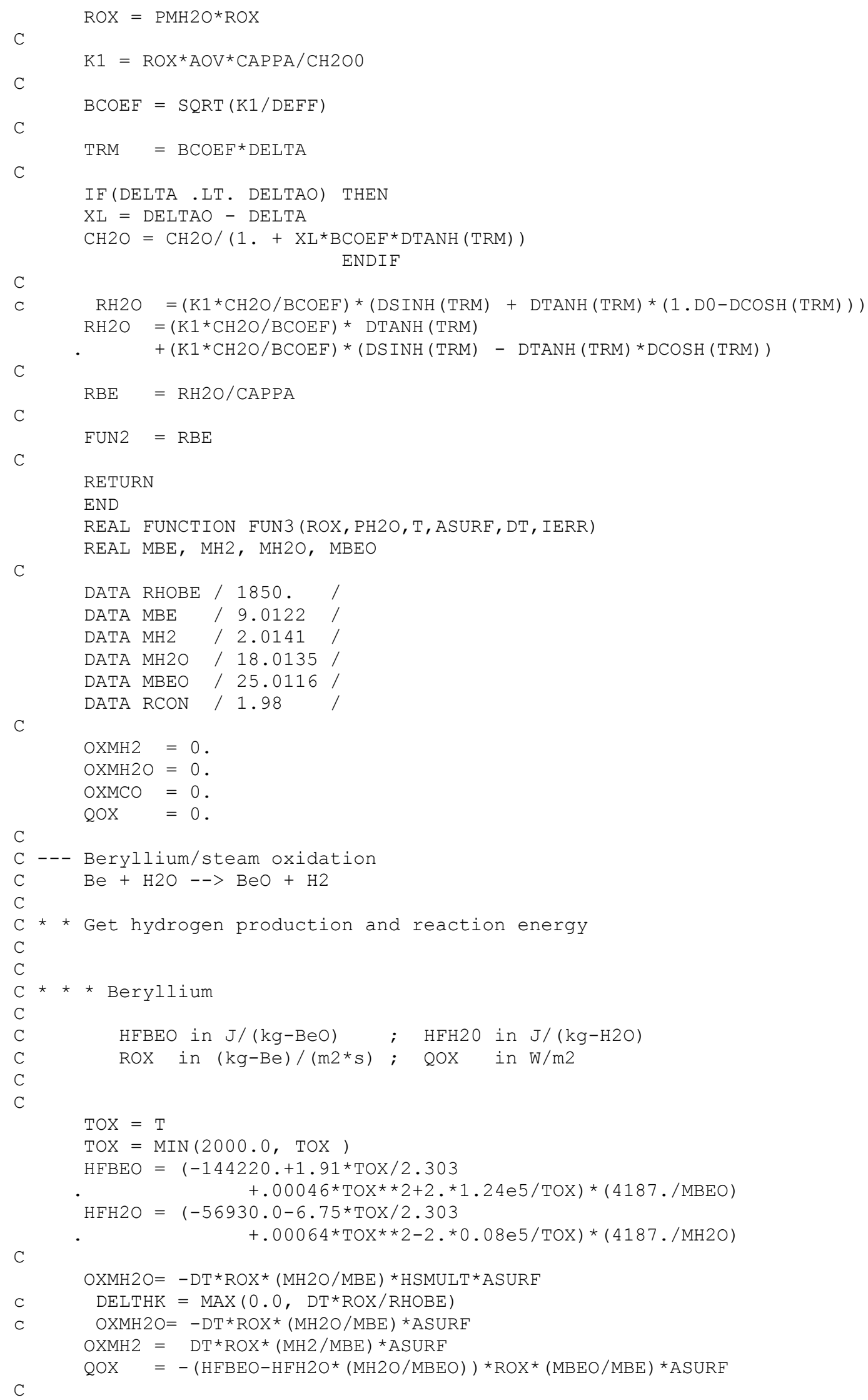

$\mathrm{C}$ 
FUN3 $=$ QOX

RETURN

END 


\section{APPENDIX B}

Test Case MELCOR Input Deck Listing 


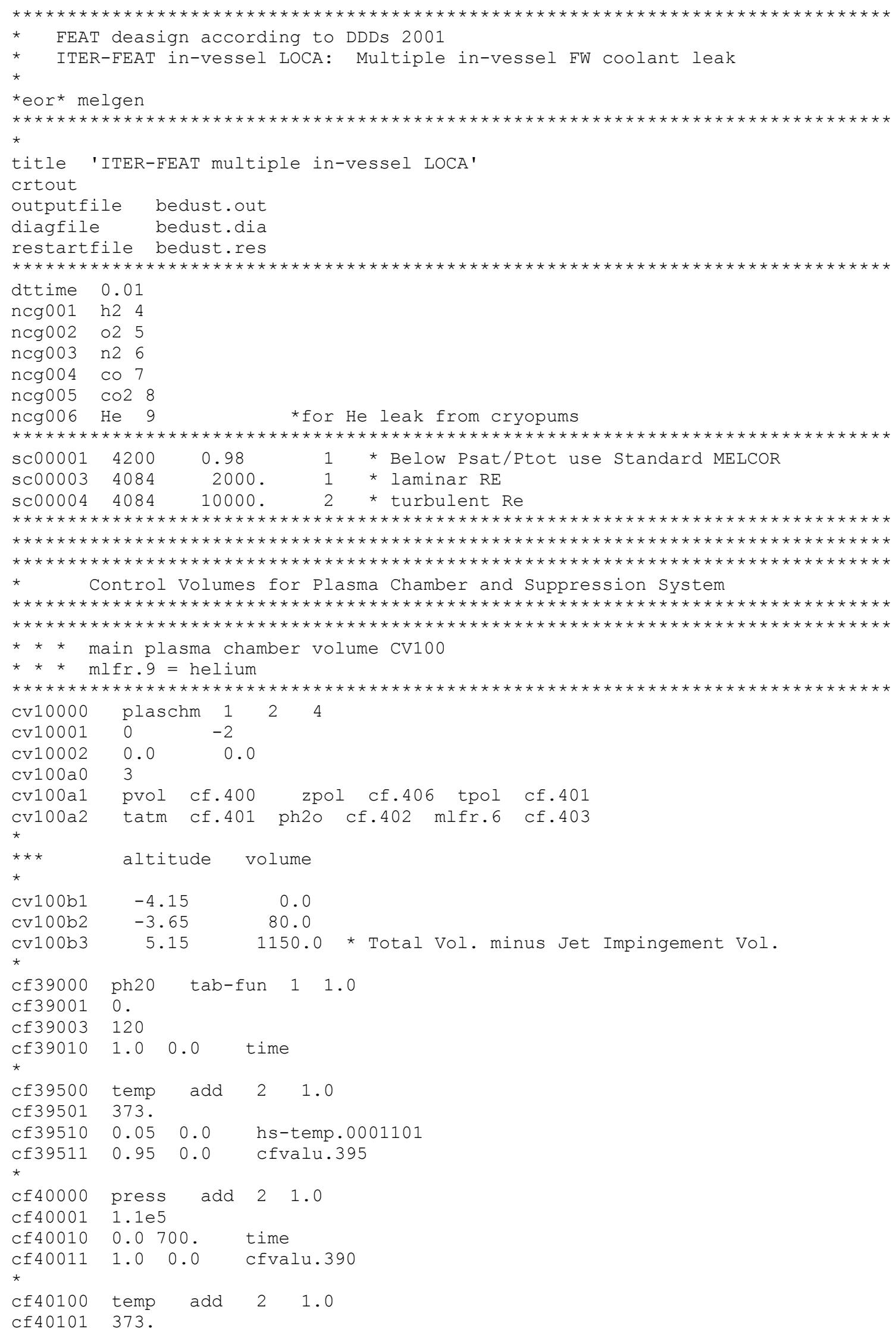




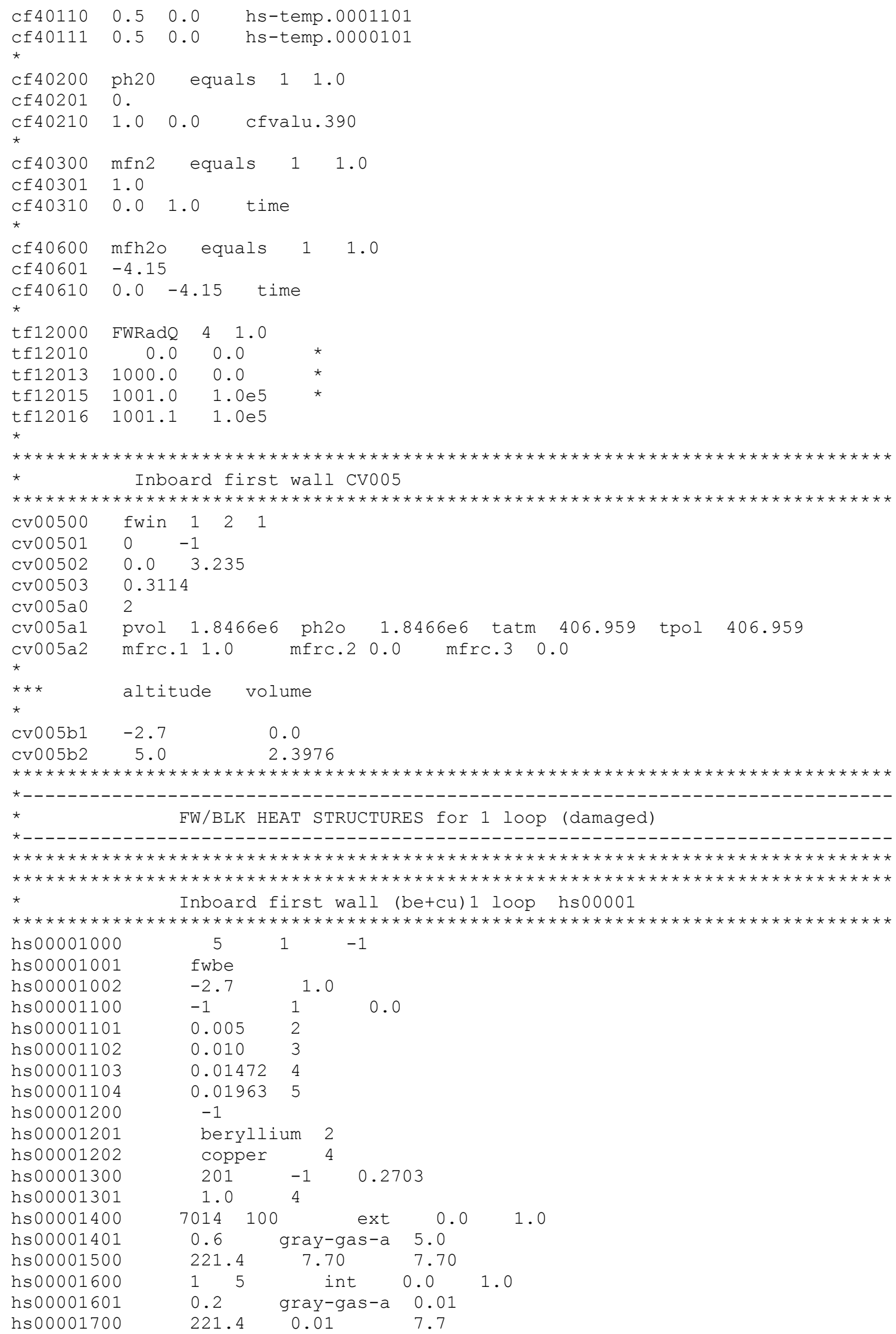




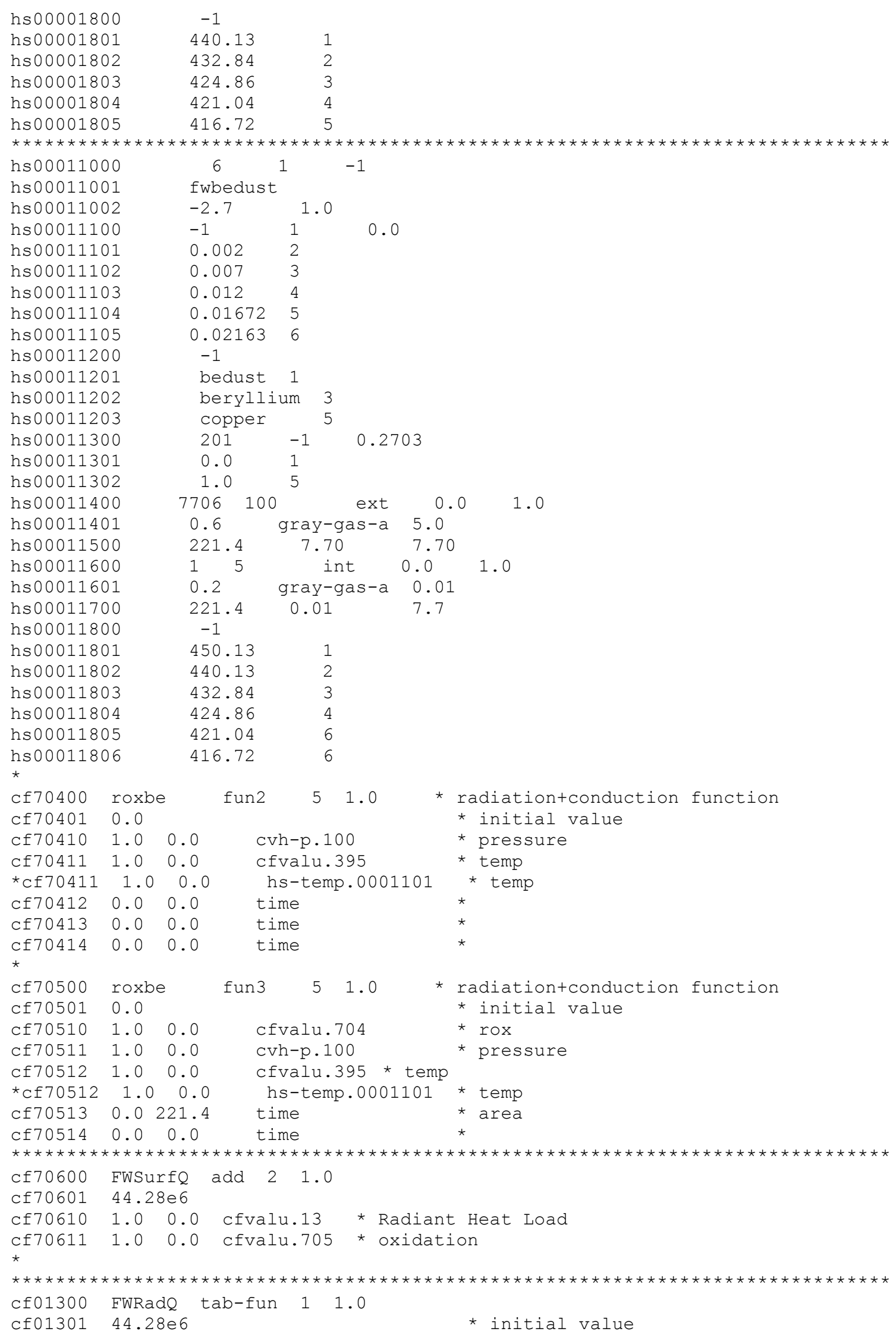




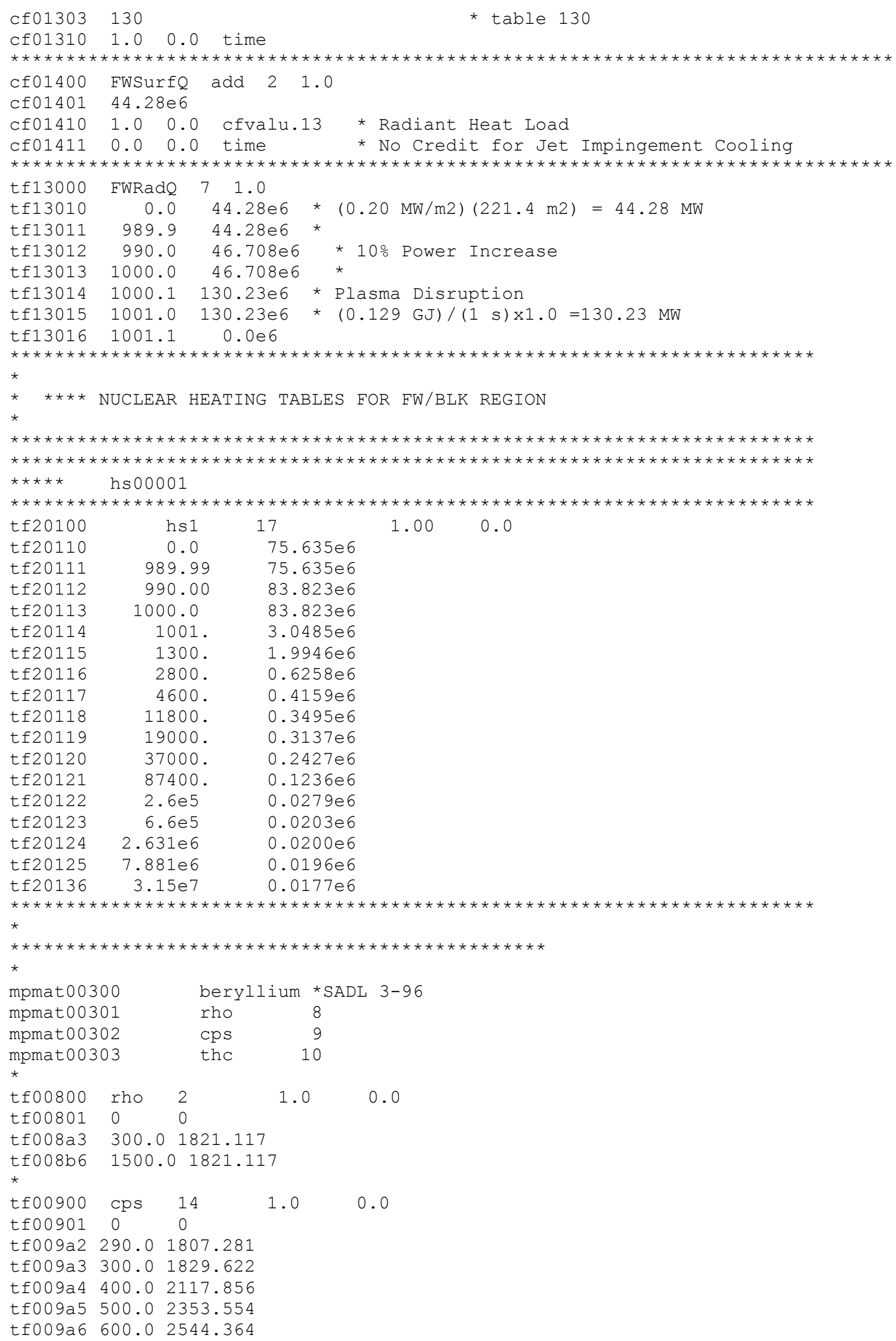




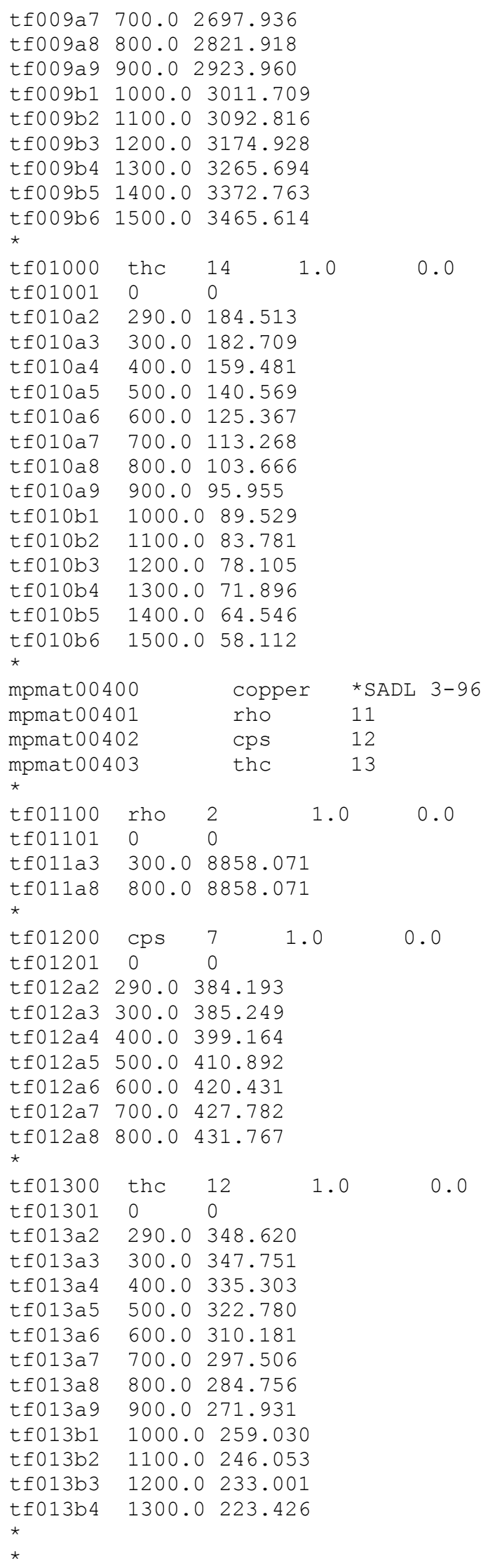




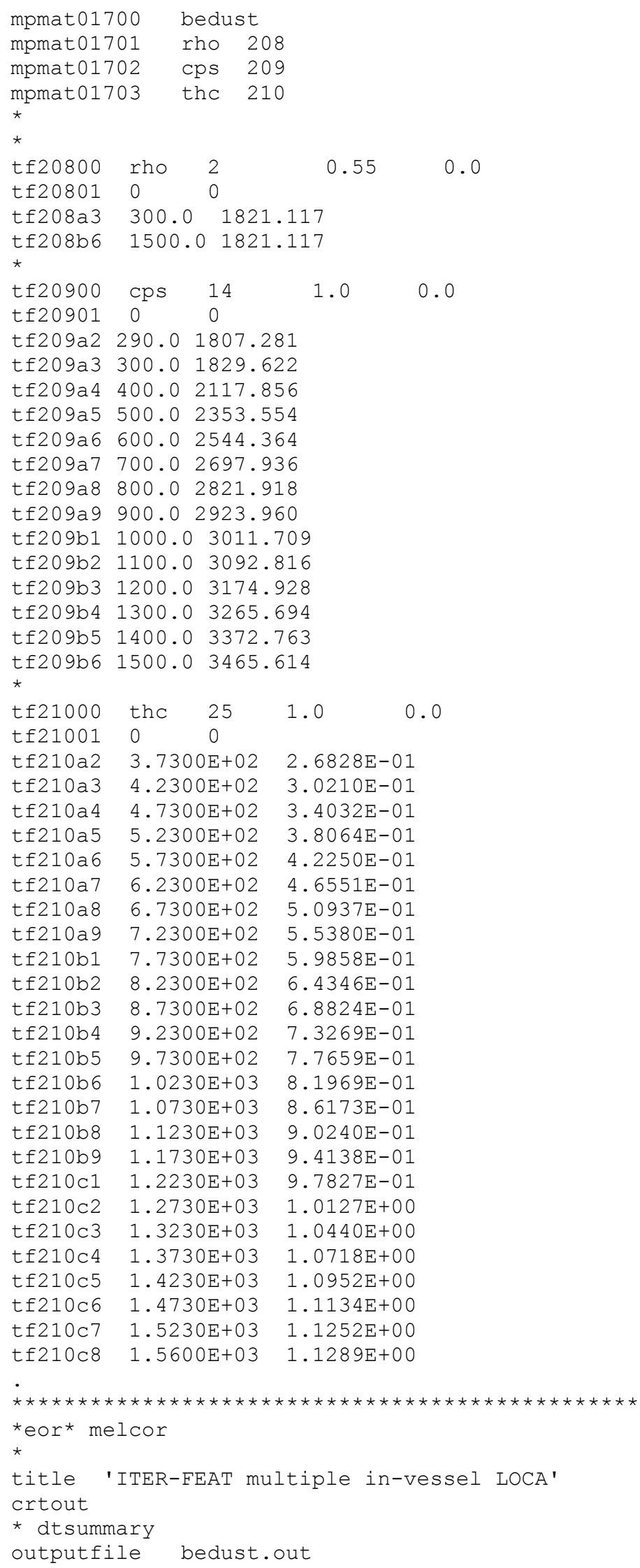




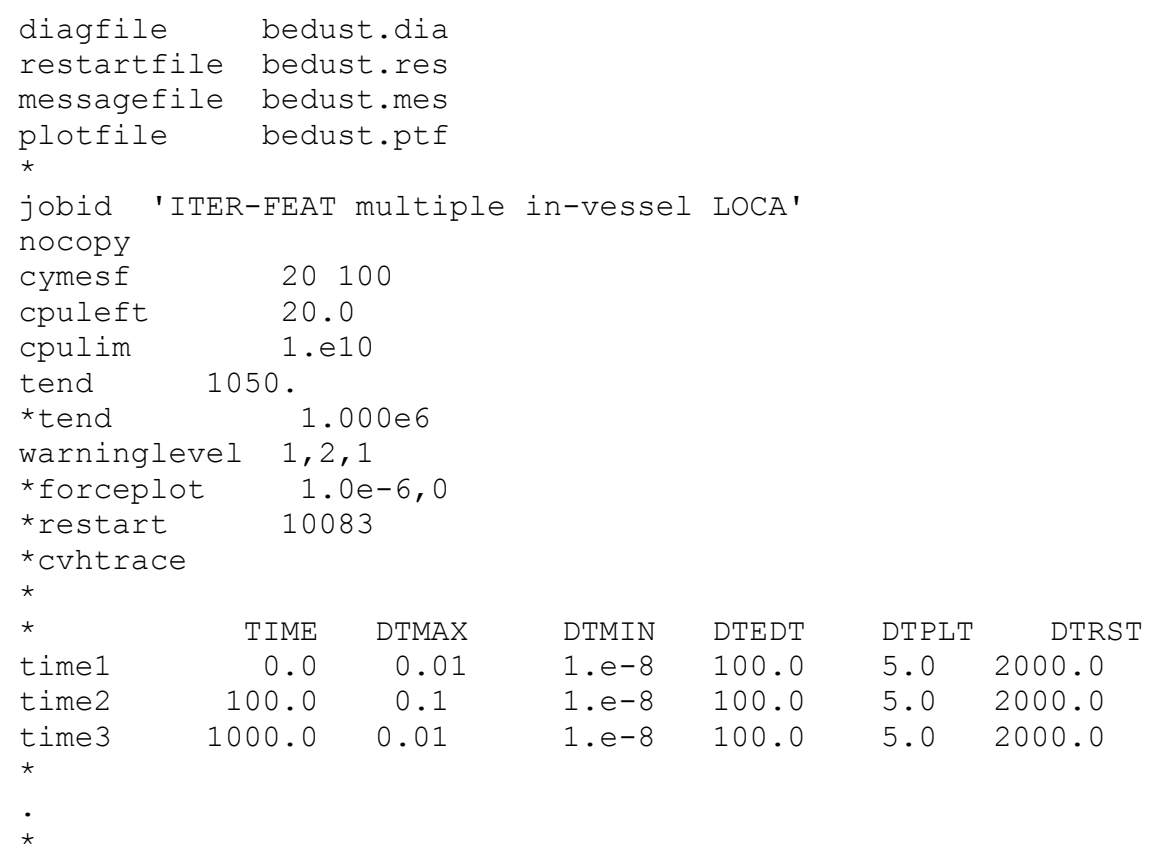




\section{APPENDIX C}

Changes Made to MELCOR Wet Bypass input Deck 


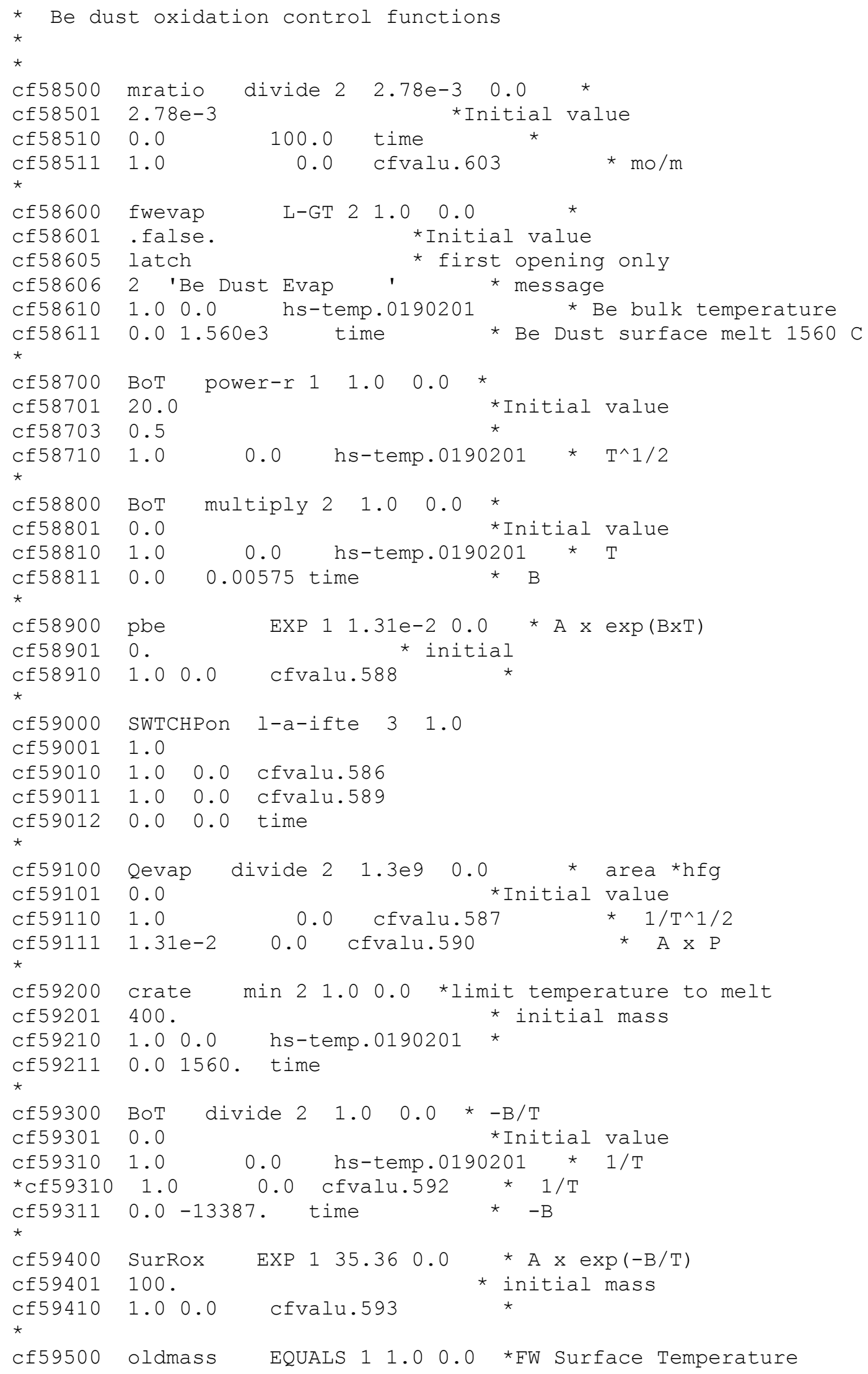




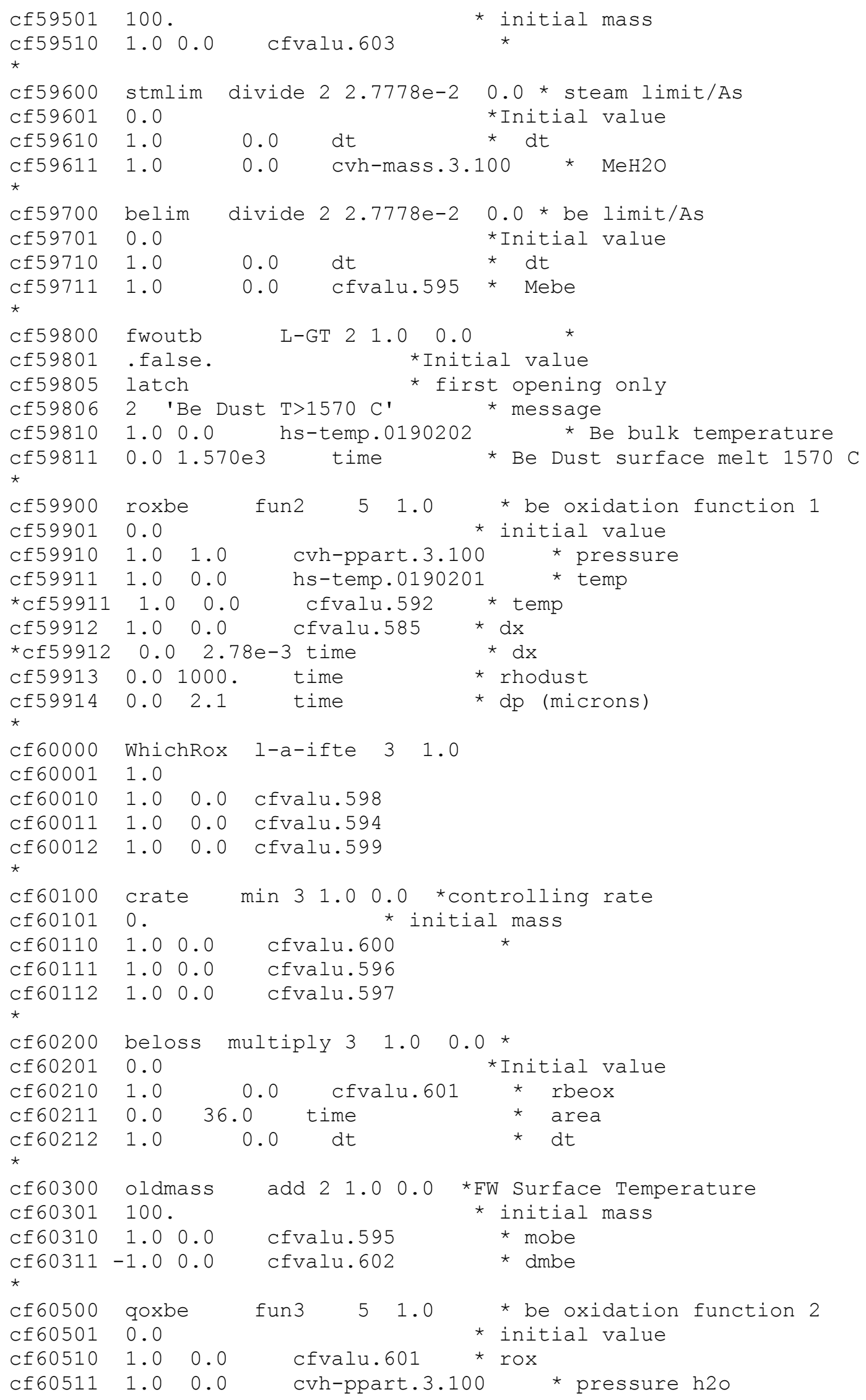




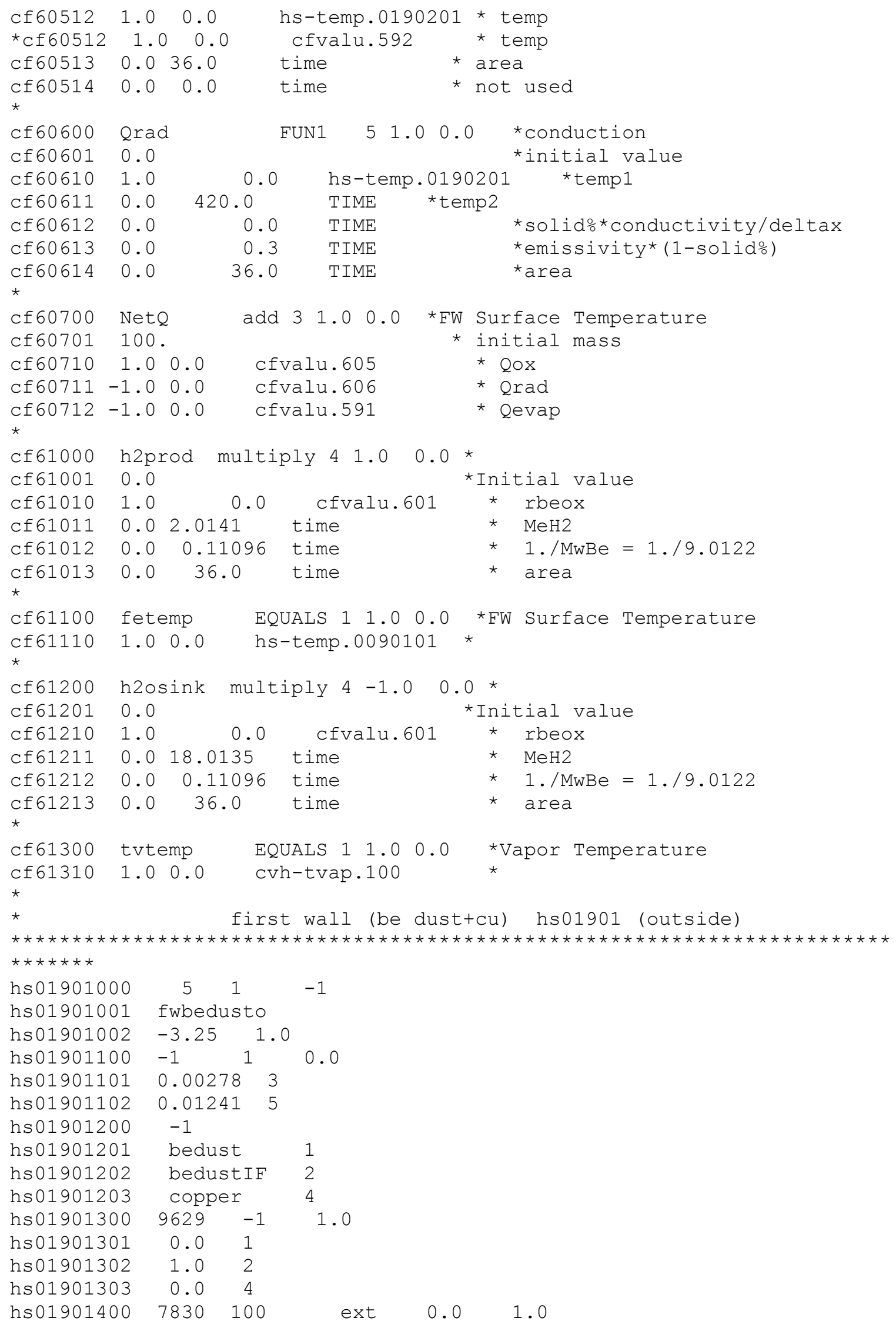




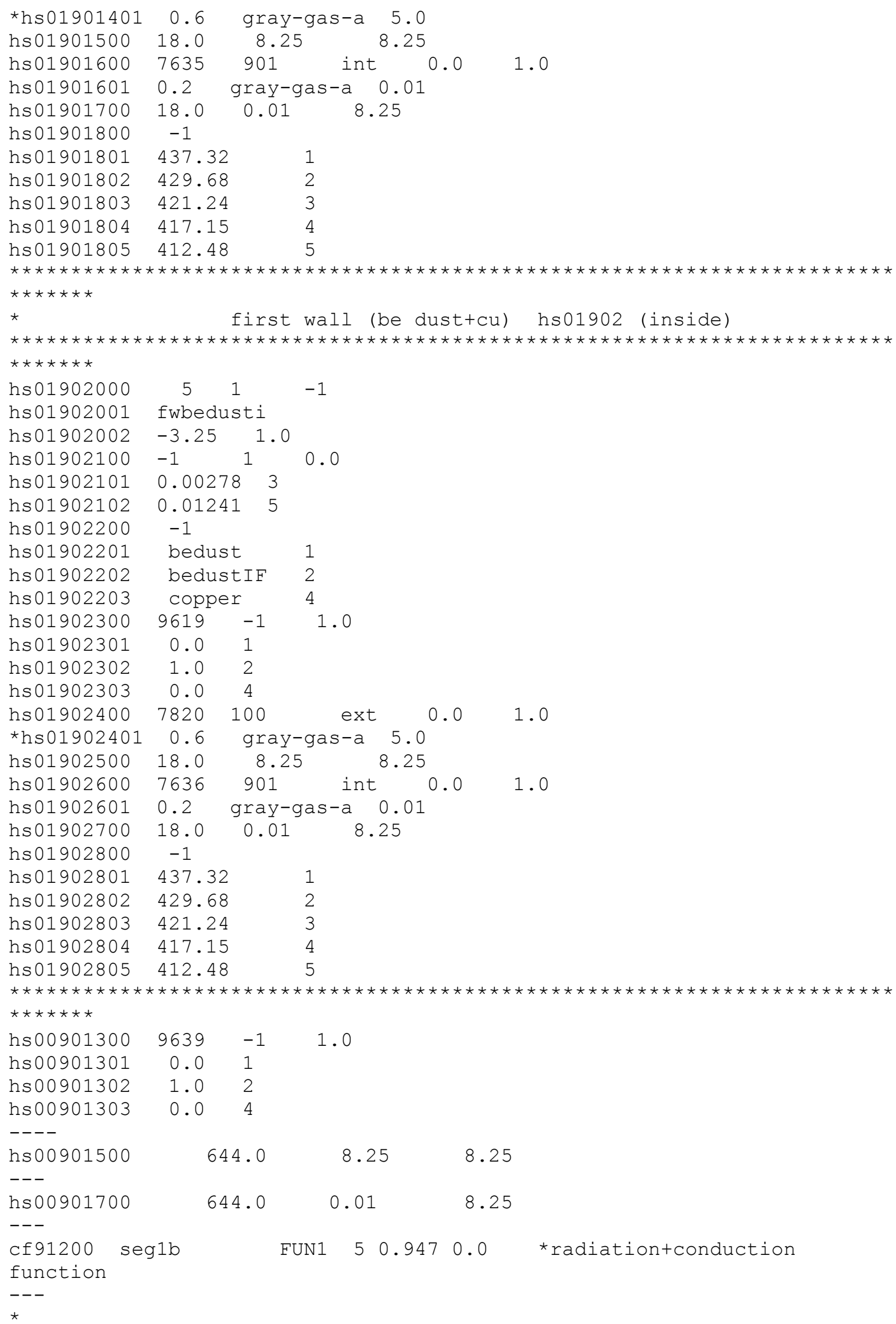




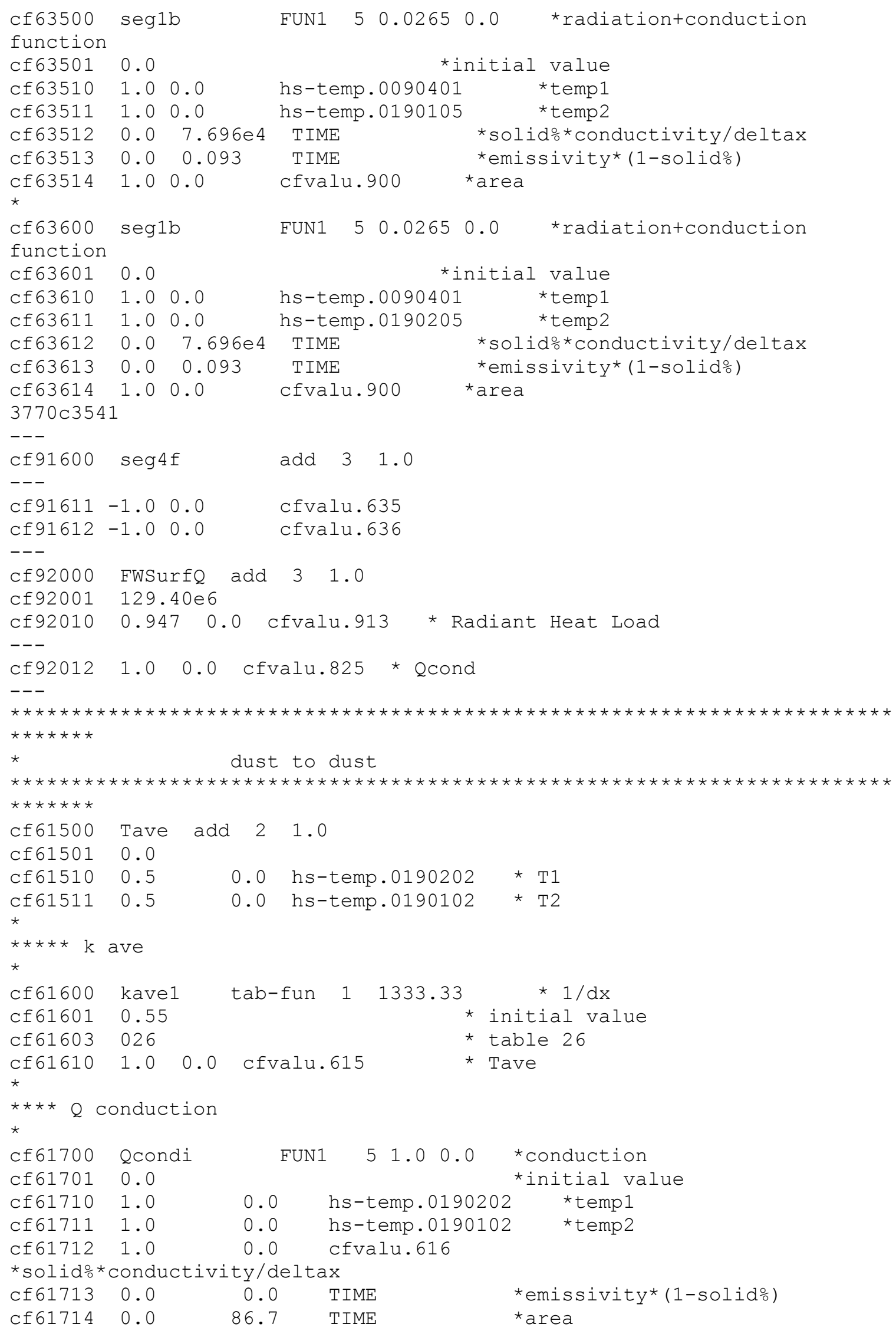




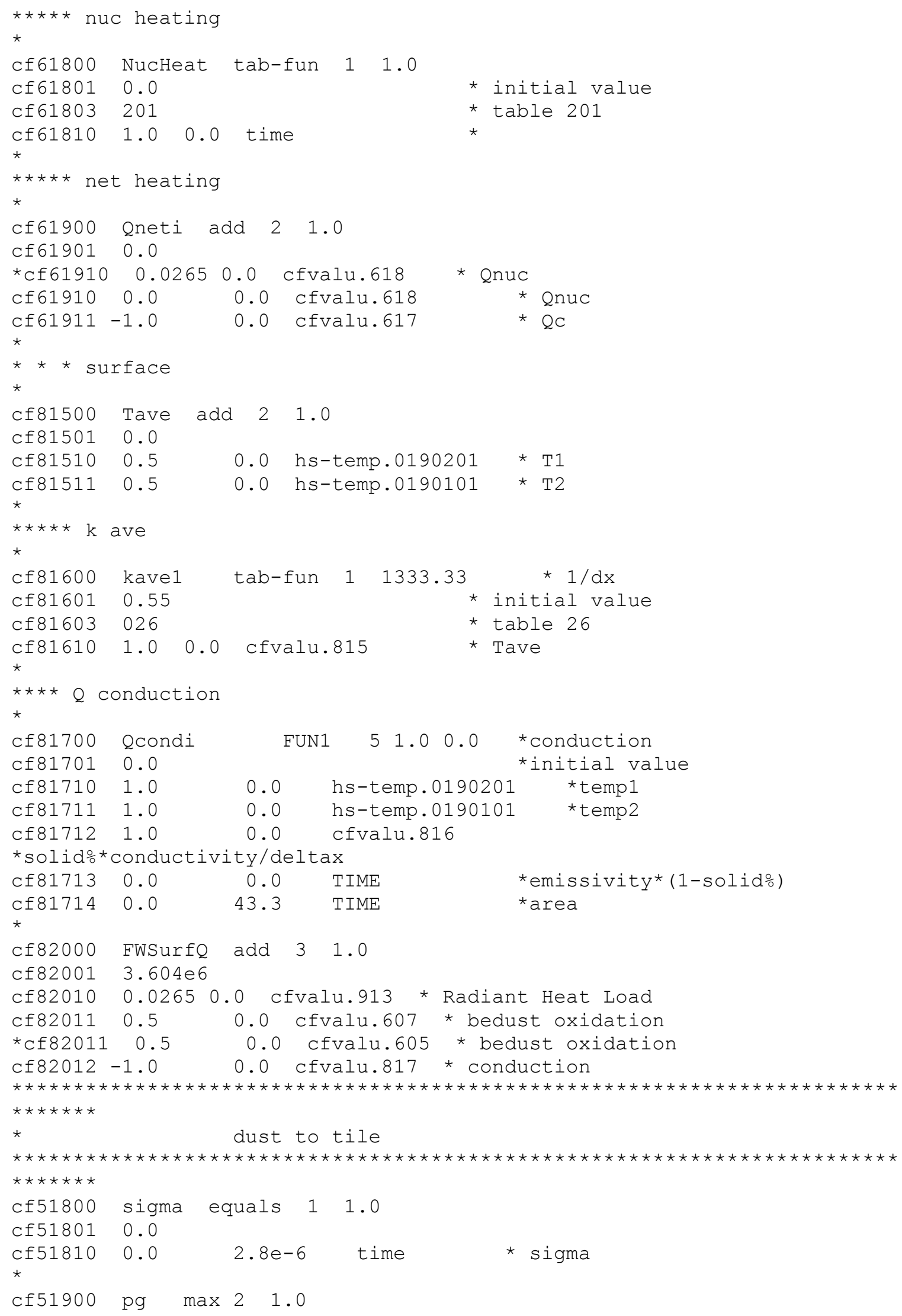




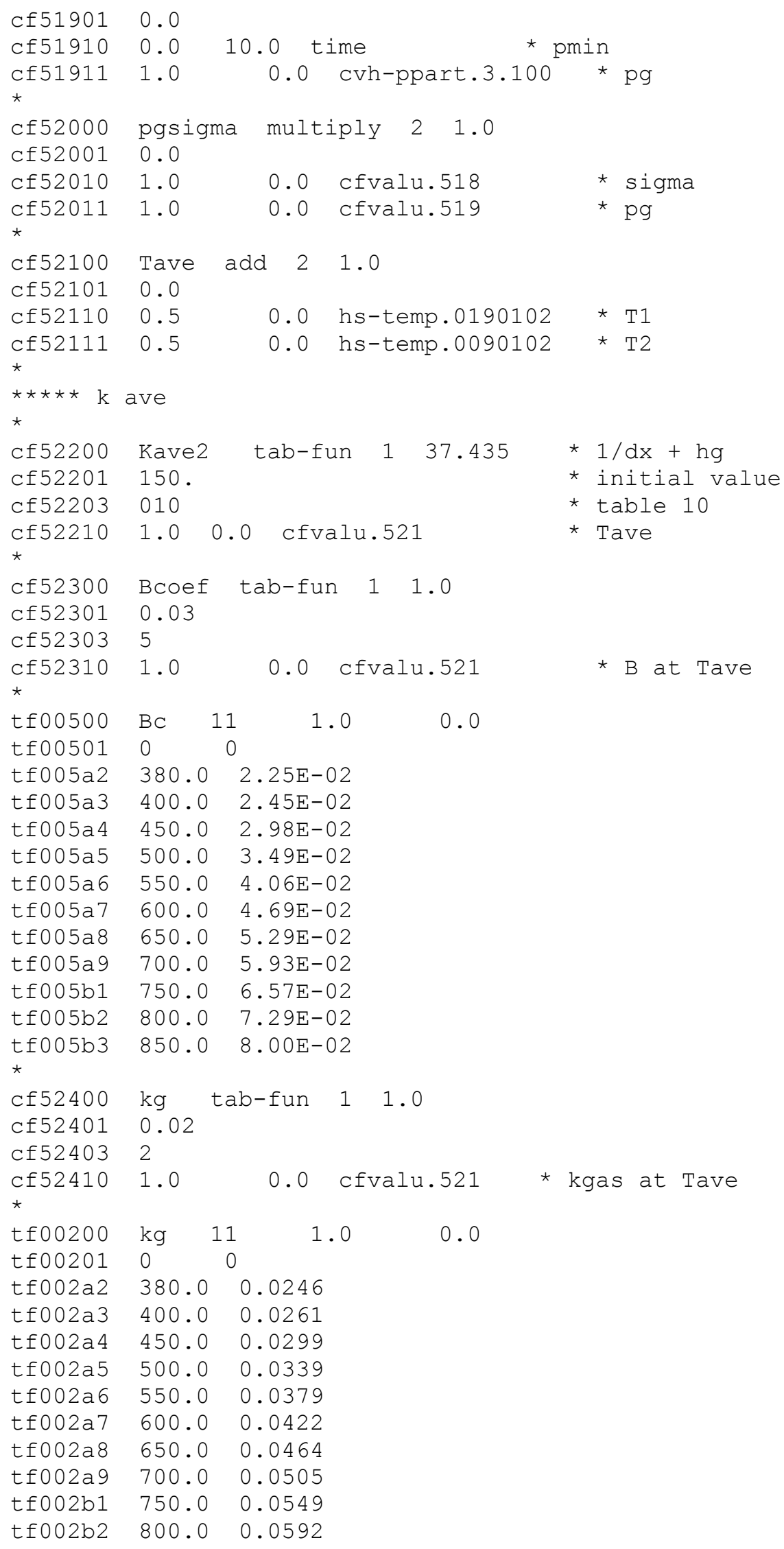




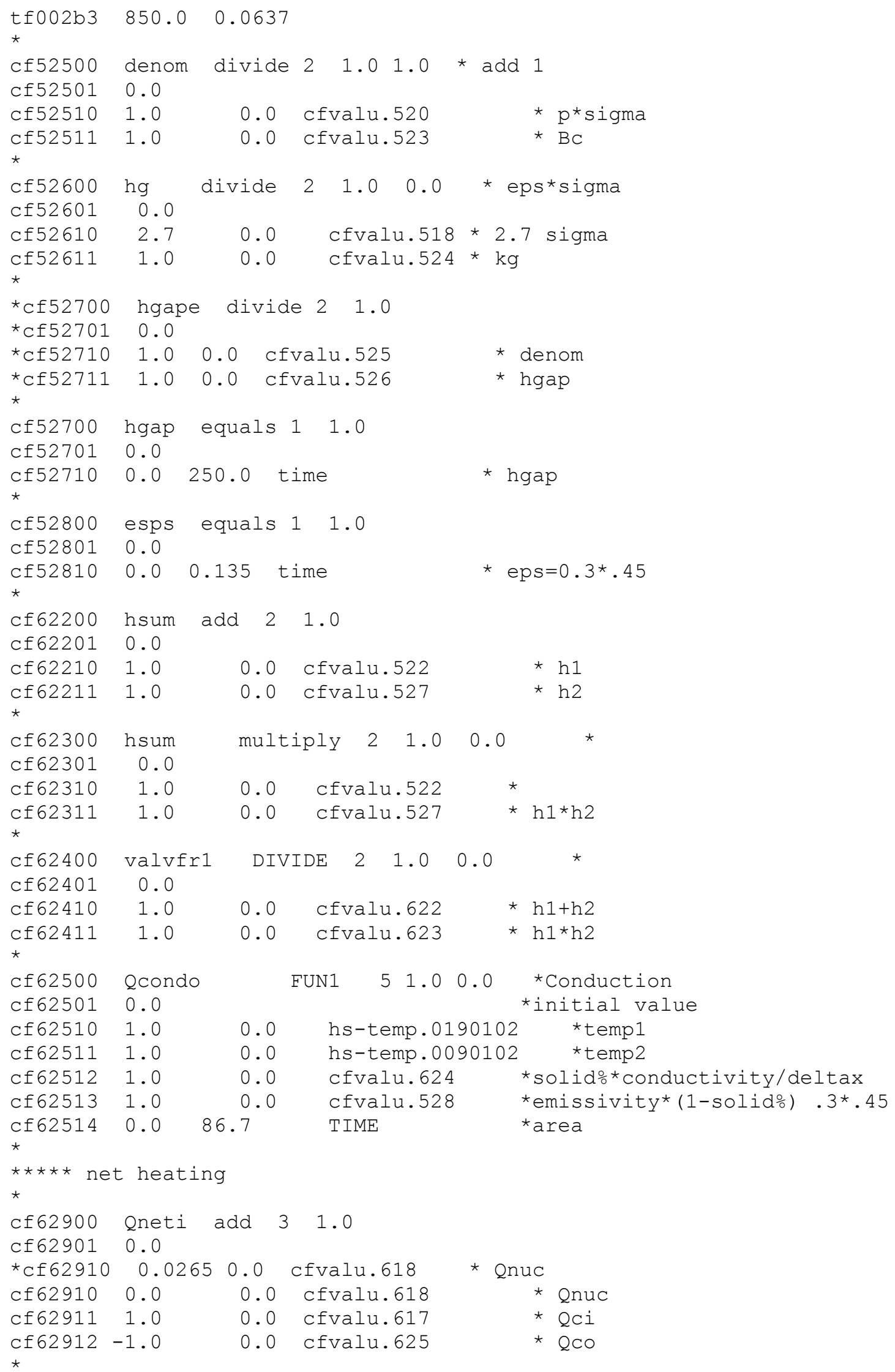




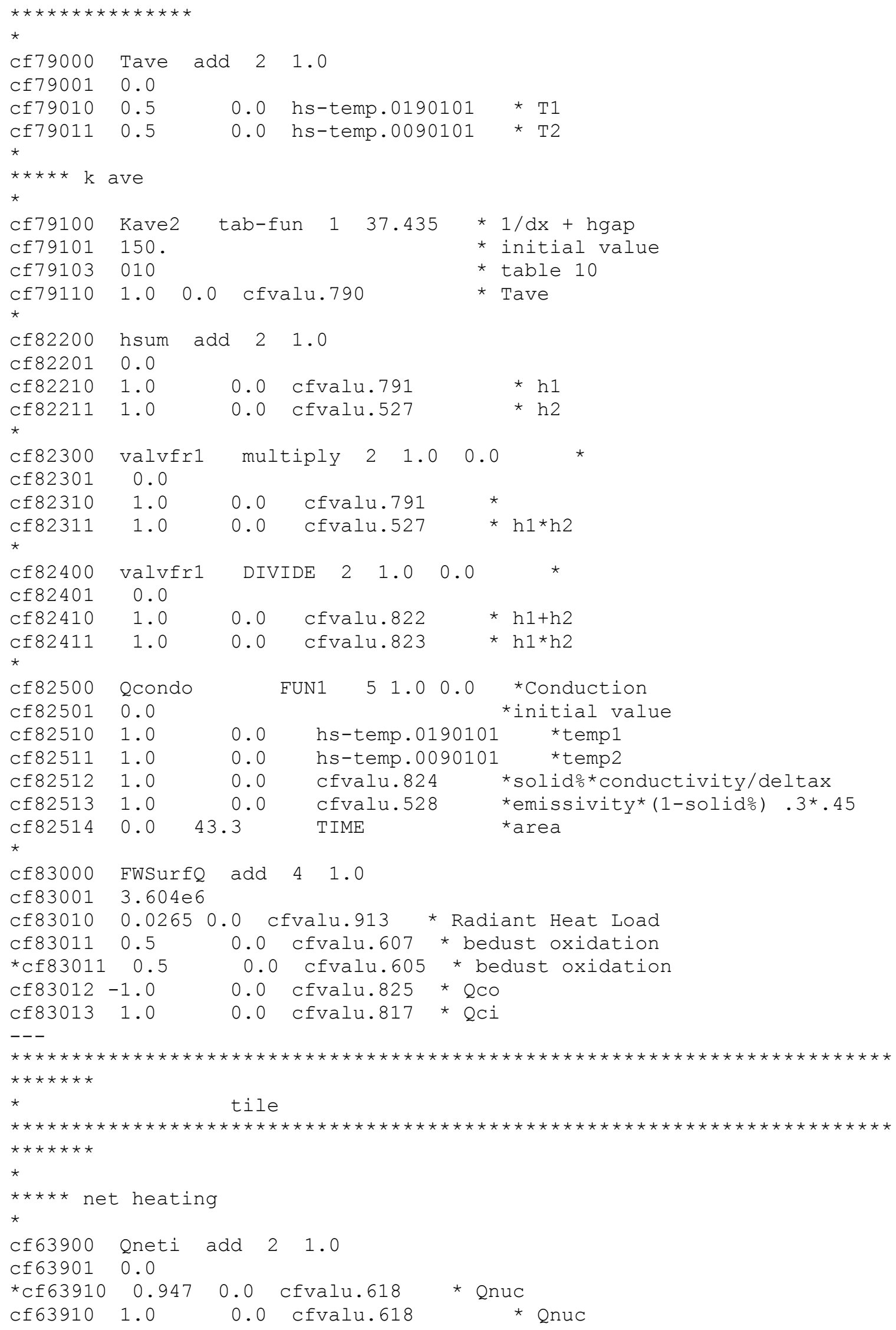




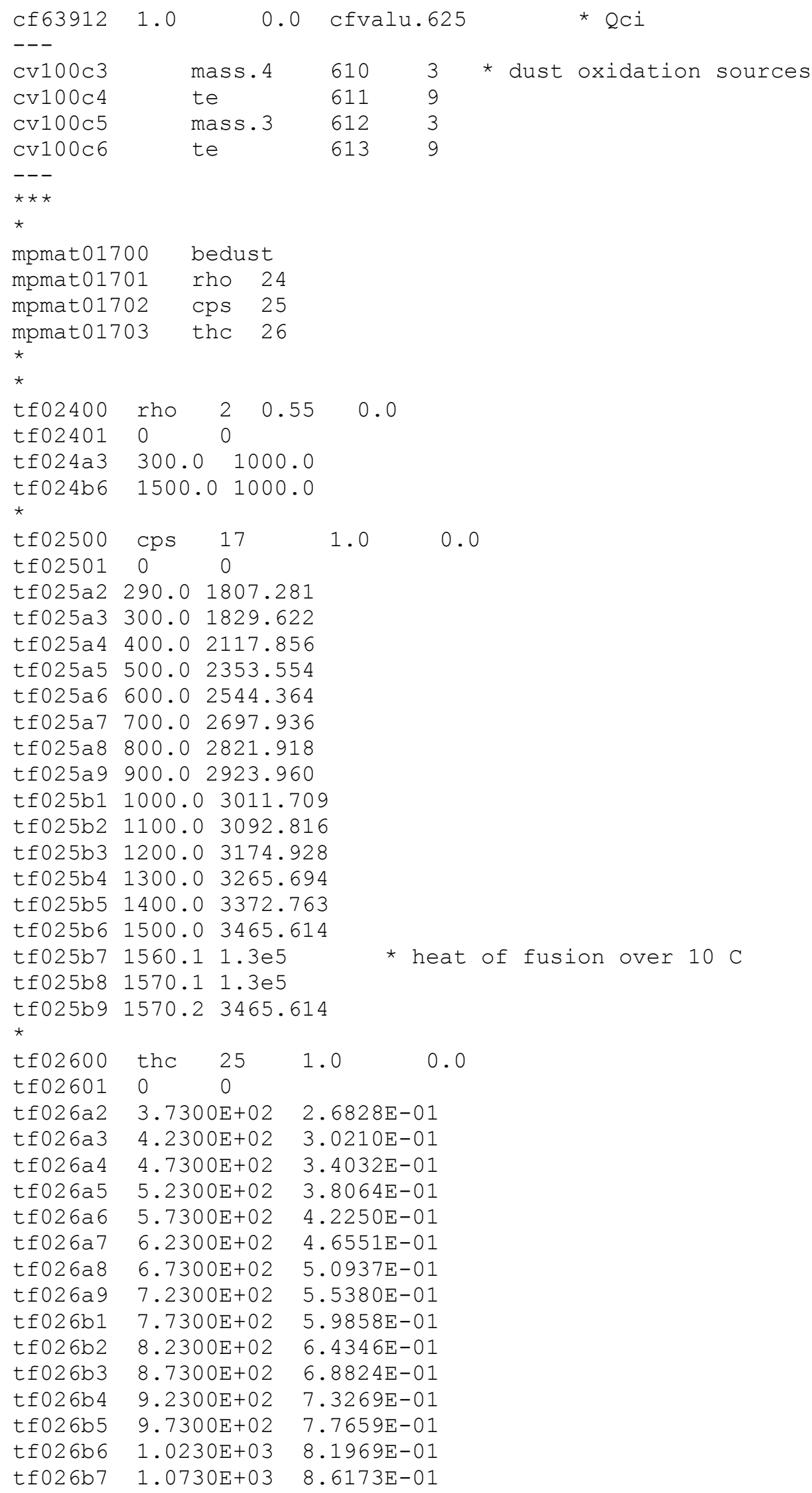




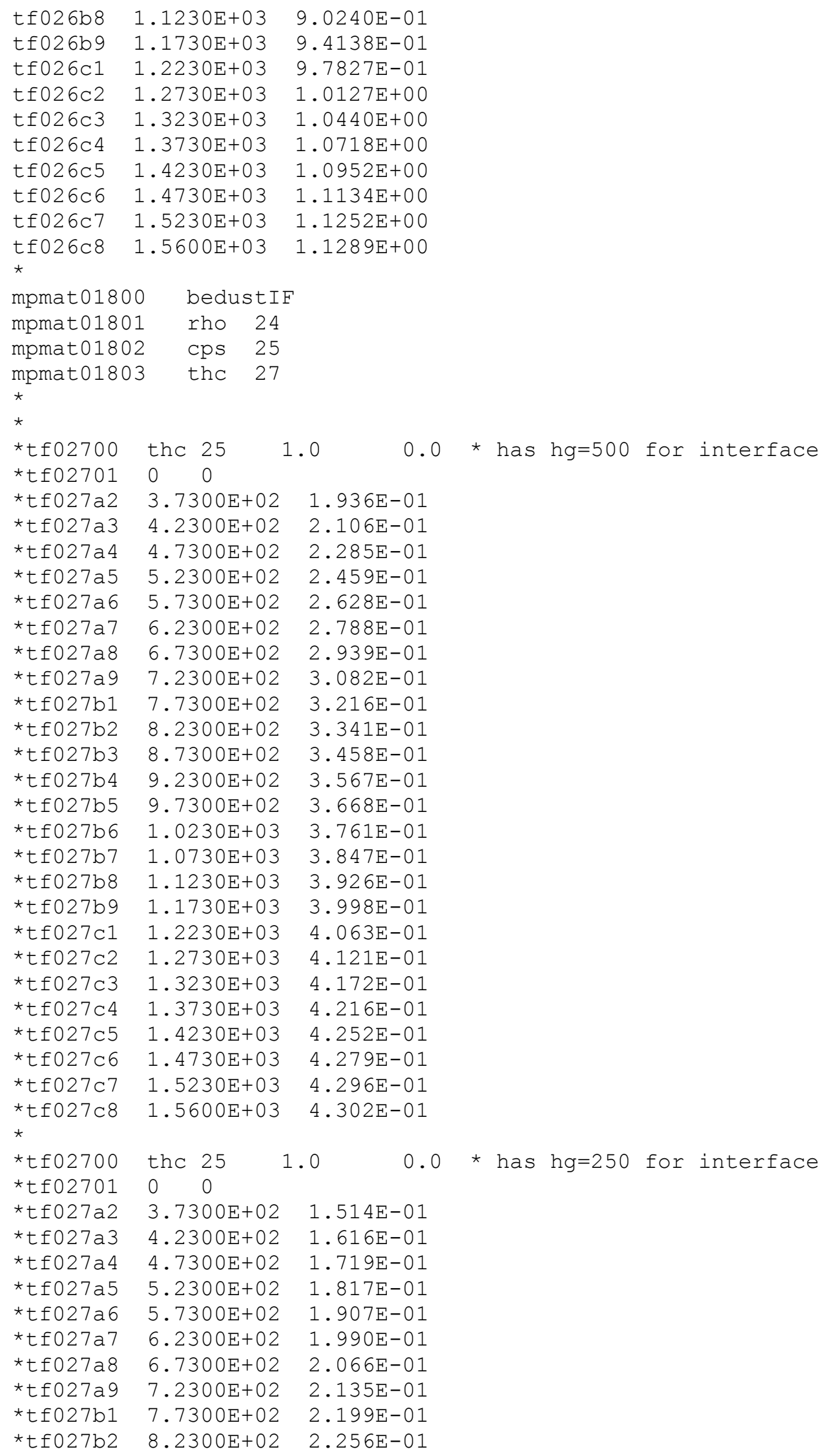




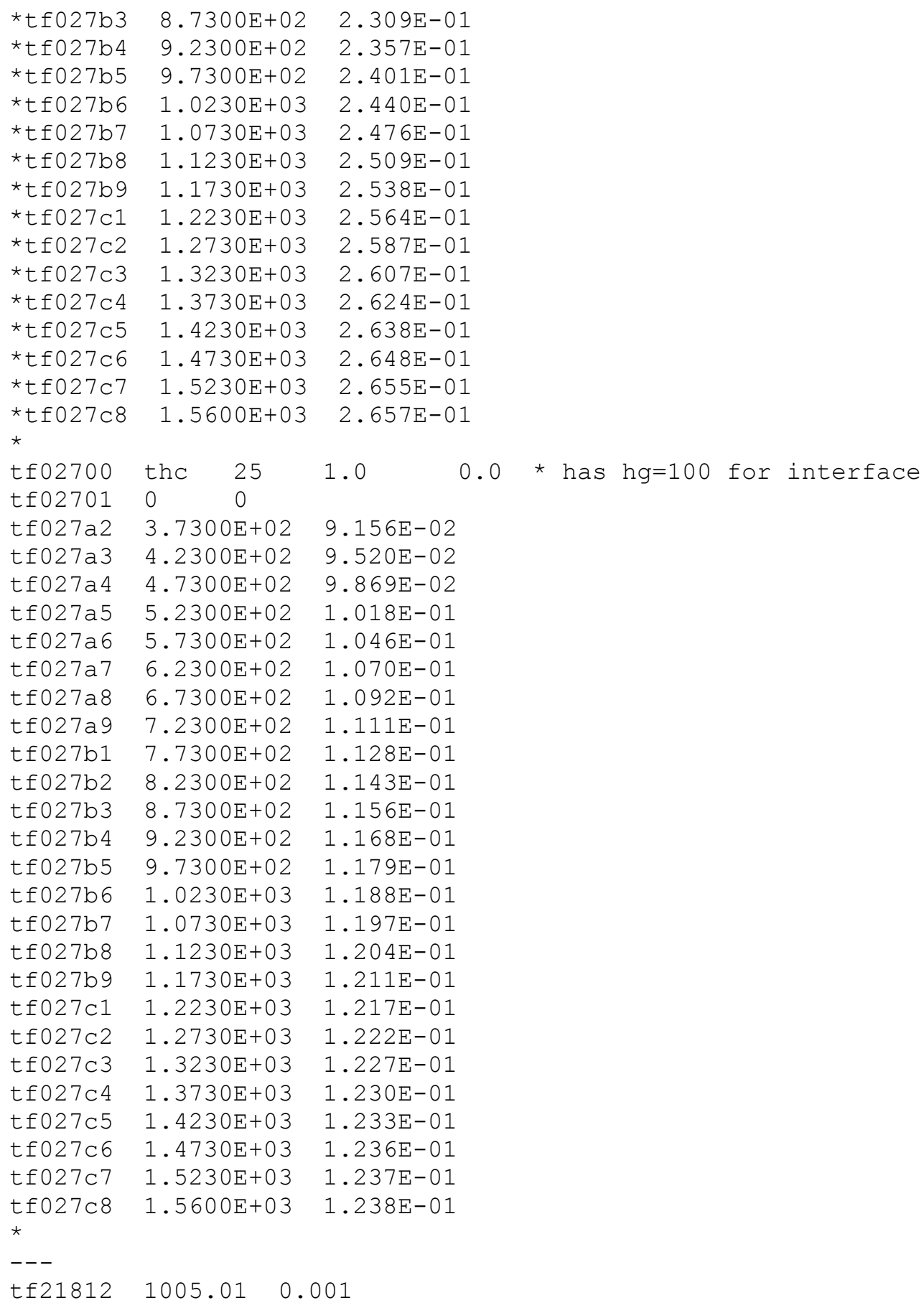

